\title{
IN SITU BURNING OIL SPILL
}

\begin{tabular}{ll}
\hline WORKSHOP & Orlando, Florida \\
PROCEEDINGS & January 26-28, 1994 \\
& Nora H. Jason, Editor
\end{tabular}

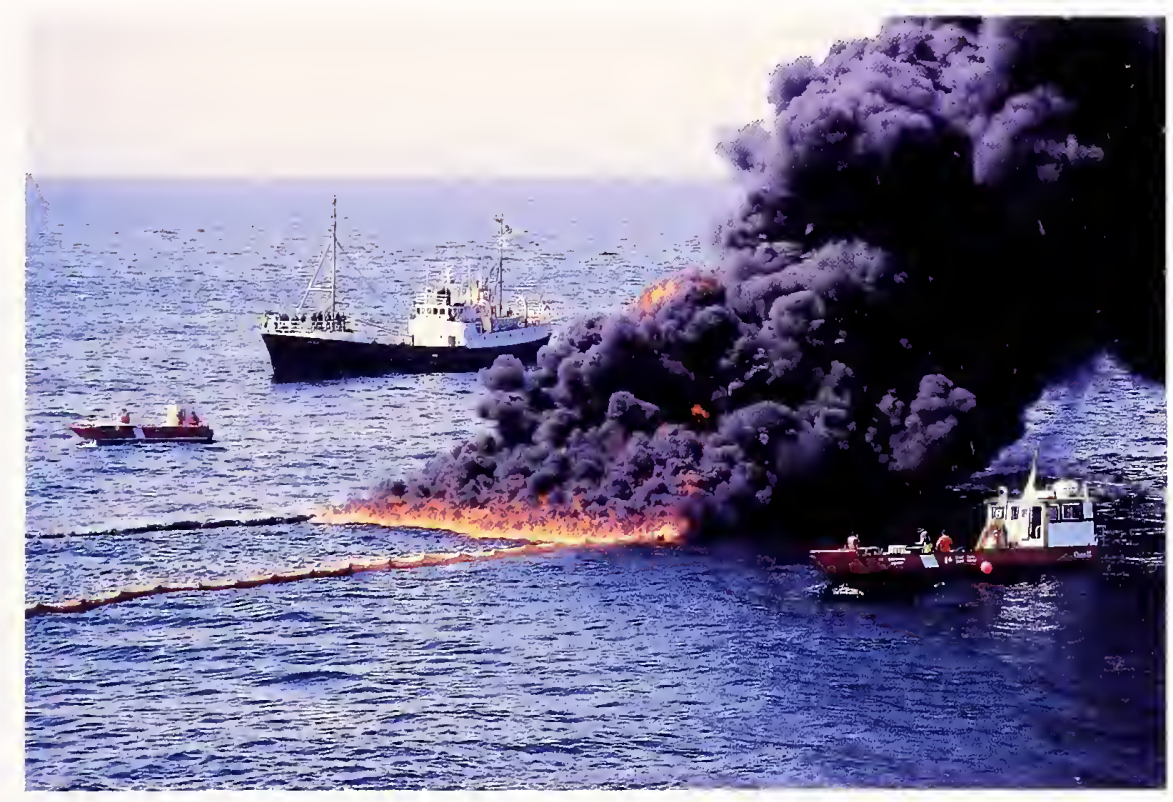

Sponsored by Minerals Management Service, U.S. Department of the Interior

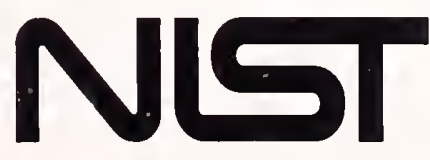

United States Department of Commerce Technology Administration

National Institute of Standards and Technology

$Q C$

100

.457

NO. 867 


\section{NOTICE}

The statements and conclusions of this report are those of the authors and do not necessarily reflect the views of the National Institute of Standards and Technology.

\section{COVER}

Newfoundland Offshore Burn Experiment, August 12, 1993. David D. Evans, Photographer. 


\section{In Situ Burning Oil Spill Workshop Proceedings}

Orlando, Florida, January 26-28, 1994

Nora H. Jason, Editor

Building and Fire Research Laboratory

National Institute of Standards and Technology

Gaithersburg, MD 20899-0001

August 1994

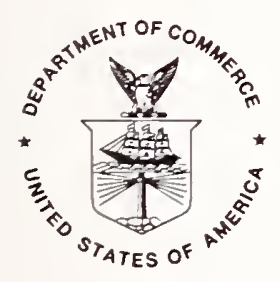

U.S. Department of Commerce

Ronald H. Brown, Secretary

Technology Administration

Mary L. Good, Under Secretary for Technology

National Institute of Standards and Technology

Arati Prabhakar, Director
Sponsored by:

U.S. Depar tment of the Interior Minerals Management Service Herndon, VA 22070 
National Institute of Standards and Technology

Special Publication 867

Natl. Inst. Stand. Technol.

Spec. Publ. 867

101 pages (Aug. 1994)

CODEN: NSPUE2
U.S. Government Printing Office

Washington: 1994
For sale by the Superintendent of Documents U.S. Government Printing Office Washington, DC 20402 


\section{CONTENTS}

Page

AGENDA

$\begin{array}{ll}\text { INTRODUCTION } & 1\end{array}$

PANEL SUMMARIES

Research Needs Associated with In Situ Burning; Report of the

Environmental and Human Health Panel - Jean Snider, Chair 3

Report of the Operational Implications Working Panel - Bruce

McKenzie, Chair

WORKSHOP PAPERS

In Situ Burning Overview - Edward J. Tennyson

In Situ Burning of Oil Spills: Smoke Production and Plume

Behavior - David D. Evans

Emissions from In Situ Oil Fires - Merv F. Fingas

Environmental and Human Health Concerns Related to In Situ

Burning - D. Kennedy, N. Barnea, G. Shigenaka

Operational Implications of In Situ Burning - Peter Tebeau

Newfoundland Offshore Burn Experiment - NOBE - Merv F. Fingas

Iri Situ Burning: Legal and Regulatory Issues - John Cunningham

Texas Marsh Burn, Removing Oil From a Salt Marsh Using In Situ

Burning - M. F. Gonzalez, G. A. Lugo

Brunswick Naval Air Station JP-5 Aviation Fuel Discharge In Situ

Burn of Fuel Remaining in Fresh Water Marsh, April 6-8,

1993 - Steven J. Eufemia

In Situ Burning: Louisiana Oil Spill Response Interests

[Summary only] - J. Heather Warner Finley

ABOUT THE AUTHORS AND PANEL CHAIRS 93

$\begin{array}{ll}\text { ACKNOWLEDGMENTS } & 97\end{array}$

$\begin{array}{ll}\text { LIST OF ATTENDEES } & 99\end{array}$ 


\section{In Situ Burning Oil Spill Workshop \\ Howard Johnsons Resort Hotel \\ Lake Buena Vista, FL \\ January 26-28, 1994}

Agenda

Wednesday, January 26,1994

8:00 AM Registration

Session Chairperson - Elmer P. Danenberger, US Minerals Management Service

9:00 AM Tom Gernhofer, Associate Director, US Minerals Management Service - Welcome

9:15 AM Edward J. Tennyson, US Minerals Management Service - In Situ Burning Overview

9:45 AM David D. Evans, National Institute of Standards and Technology - In Situ

Burning of Oil Spills: Smoke Production and Plume Behavior

10:15 AM Break

10:45 AM Merv F. Fingas, Environment Canada - Effluent Chemistry

11:15 AM Nir Barnea, National Oceanographic and Atmospheric Administration -

Scientific Information Issues and Environmental Concerns

11:45 AM Peter Tebeau, Marine Environmental Consultant - Operational Implications of Burning

12:15 PM Lunch

1:30 PM Merv F. Fingas, Environment Canada - Newfoundland Offshore Burn Experiment

2:00 PM John Cunningham, US Environmental Protection Agency - Legal/Regulatory Issues

2:30 PM Elmer P. (Bud) Danenberger, US Minerals Management Service - Purpose of Panels Bruce McKenzie, Alaska Clean Seas - Chair, Operational Implications

Jean Snider, National Oceanographic and Atmospheric Administration - Chair, Environmental Effects

3:30 PM Break

5:00 PM Panel Chairs Update

Thursday, January 27, 1994

8:30 AM Manny Gonzalez, Texas General Land Office - Texas Marsh Burn

9:00 AM Steven J. Eufemia, Maine Dept. of Environmental Protection - Maine Marsh Burn

9:30 AM Heather Finley, Louisiana Oil Spill Coordinator's Office - In Situ Burning:

Louisiana Oil Spill Response Interests

10:00 AM Break

10:30 AM Panel Sessions Resume

12:30 PM Lunch

1:30 PM Panels Reconvene

3:00 PM Break

5:00 PM Panel Chairs Summarize Priorities 
Friday, January 28, 1994

8:30 AM Priorities Discussion

9:00 AM Annotated Priorities List Collected for Summary Presentation

9:30 AM Break

10:00 AM Panel Chairs Presentation

10:30 AM Consensus List Developed

11:20 AM Elmer (Bud) P. Danenberger, US Minerals Management Service - Closing Remarks

11:30 AM Workshop Closes 


\section{INTRODUCTION}

The U. S. Minerals Management Service (MMS) is designated as the lead agency for in situ burn research in the Oil Pollution Research and Technology Plan prepared under the authority of Title VII of the Oil Pollution Act of 1990 (OPA-90). Significant advances in the technology of oil spill response have been made as a result of the MMS funded research program. This workshop is part of MMS's continuing effort to ensure the relevance of their research program to the needs of the user community. Specific emphasis was given to environmental and operational implications of in situ burn response technology.

The goals of the In Situ Oil Burning workshop were:

1. To present the state of knowledge to representatives of industry, government, and research organizations.

2. To review the present status guidelines for use of in situ burning as an oil spill response method.

3. To prioritize research and information needs to support decisions on the use of in situ burning of oil spills.

To facilitate the discussions, preprints of technical papers were distributed at registration. The Keynote Speaker presented the current state-of-the-art of in situ burning of oil spills. The presentation was followed by the presentation of ongoing research: Smoke Production and Plume Behavior and Effluent Chemistry. Two papers addressed the concerns facing the participants: Environmental and Human Health Concerns Related to In-Situ Burning and Operational Implications of Burning and In Situ Burning: Legal and Regulatory Issues. Three recent oil spill burn experiences were presented: Newfoundland Offshore Burn Experiment, and oil spill burns in marshes and wetlands from Texas and Maine, respectively. The presentation by the Louisiana Oil Spill Coordinator's Office represented the view of a state agency on the issue of in situ burning.

Participants were divided into two breakout panels: Environmental and Human Health; Operational Implications. The panels examined the information presented, determined a consensus, and developed a list of priority needs. The results of the workshop will be delivered to MMS as input to their planning of future research efforts.

This proceedings is the official transmittal of workshop information and recommendations to the sponsor, Minerals Management Service, Department of the Interior. It reflects the combined input of the workshop participants. The Panel recommendations and the individual papers follow this Introduction. 



\title{
RESEARCH NEEDS ASSOCIATED WITH IN SITU BURNING; Report of the Environmental and Human Health Panel
}

\author{
Jean Snider, National Oceanic and Atmospheric Administration \\ Panel Chair
}

\section{BACKGROUND}

The groups divided themselves into two sections according to interests: 1) Operational and 2) Environment and Human Health. Participants in the Environment and Human Health Panel included representatives from several states, industry, and human health agencies. The discussion focused on the human health aspects of in-situ burning (ISB), since that seemed to be the topic of primary concern. Less time was spent on the environmental consequences of in-situ burning, since the group felt that with the publication of a MSRC/Environment Canada/NOAA report on the toxicity of the burn residue, the major unanswered environmental question will have been addressed. In addition, there were some issues which, although not solvable by research, were critical to the successful implementation of ISB as a response tool. Three issues were identified as falling into this category: public education regarding ISB -- the tradeoffs involved in choosing response countermeasures, and the relation of the risks associated with ISB - to better-known risks; a thorough evaluation of the legal constraints and risks associated with ISB under state and federal law; and education of the decision-makers who are held responsible for the consequences of an oil spill. This latter issue is particularly difficult since the turnover of personnel is rapid in comparison to the frequency of instances where ISB would be considered.

Two activities evolved from the discussion that, if implemented, would facilitate research and would perhaps, facilitate decisions to use ISB. The first was the recommendation of a network of researchers who could be rapidly contacted, should a decision be made to burn. This is most likely to occur inland or in a coastal area where marsh burning or burning associated with agriculture is more common. Although it was stressed that the consequences of burning under these conditions are not totally transferable to ISB of oil spills, it was felt that some data may be collected which would be useful. The second suggestion was that a directory of experts on different aspects of ISB be disseminated to state and local decisionmakers to provide answers to questions associated with ISB. (Note: Such a directory could not be construed to be an endorsement of the opinions offered, since the ultimate responsibility remains with the decision-maker to judge the applicability of the information to his/her needs.)

The panel's discussion would have been facilitated by the release of several reports. These papers were assumed, in several instances, to answer environmental or human health concerns and thus would diminish or alleviate the need for further research. Integration of the findings of these reports and dissemination to the user community, both decision makers 
and the public, was judged to be the critical factor hindering implementation of ISB as an oil spill response tool. Research needs relating to the human health and environmental consequences from ISB were judged to be few. Those areas remaining emphasized validating previous findings and increasing the range of conditions where ISB could be safely used. Some of the remaining concern might be addressed through planned test burns at the US Coast Guard facility in Mobile, Alabama.

The panel discussion was divided into three parts: human health concerns, monitoring requirements and environmental issues. Worker health and safety was addressed by the Operational Panel. Within each topic, the question was defined, the research that was needed to address that question was explained, and the type of appropriate implementation was listed. These needs were then ranked, by general consensus, according to importance. The following summary follows that format, with explanatory text added as necessary.

\section{HUMAN HEALTH EFFECTS}

\section{General}

The potential for human health effects appears to be the greatest impediment to approval for ISB. While the plume components are known, data are still lacking on downwind concentration, especially of particulates. A smoke plume model developed for that purpose needs to be validated in actual burnings. In addition, there is no concentration level of fine particulates (i.e., $<10 \mu \mathrm{g}$ or $\mathrm{PM}^{10}$ ) which is an accepted standard for the exposure time period expected during a burn. The only national level that exists for $\mathrm{PM}^{10}$, the plume component of most concern, is EPA's National Ambient Air Quality Standard which has been established for a 24-hour exposure.

The uncertainty related to the potential health effects to adjacent populations is shown by the variation in state guidance for offshore burning: Louisiana requires 3 miles offshore and Alaska requires 6 miles offshore.

The group did not feel that the lack of an appropriate standard was the major factor hindering decision-making. Rather it was the lack of sufficient data or credible model estimates of the concentrations of the plume components upon which to make decisions. In addition, it appeared that data from related types of fires (e.g., the Kuwaiti oil well fires, forest fires, farm field burning, marsh burning) or opportunities to collect measurements at some of these events had not been fully utilized.

\section{RESEARCH NEEDS IDENTIFIED}

Need: Improve predictions of potential human health effects from ISB

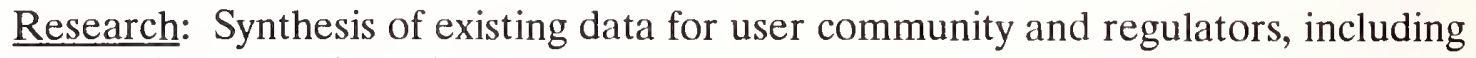
mechanisms for dissemination 
Method for implementation: Workshop to produce usable data and information (e.g., generic plume footprint, comparison to oil emissions); discussions would be based upon soon to be released data, other reports relating to oil burning, evaluation of related burns (e.g. agricultural land) and trade offs with other counter measures.

Priority: Very High

Comment: Integration of the multiple research efforts ongoing (see Table 1 on page 17).

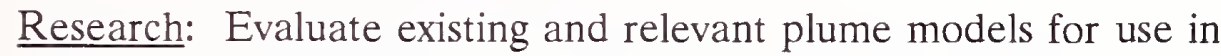
planning and real time estimation

Method for implementation: Workshop (with state air quality, health experts, developers and other regulators)

Priority: High

Comment: This workshop would examine existing models, their validation with field data and their relationship to the needs of air quality and health experts.

Need: Reduction of smoke emission from ISB

Research: Investigate other methods of smoke suppression (e.g., ferrocene, other chemicals, etc.)

Method for implementation: Ongoing research by SINTEF and Imperial Oil Priority: Medium

\section{MONITORING}

General

Several Regional Response Teams have given the Federal On-Scene Coordinator authorization to use ISB under specific circumstances or in limited geographic areas. These authorizations and supporting implementation plans include the requirement for monitoring of the downwind concentrations of constituents in the smoke plume; however, most of the plans, to date, do not include specifics of the monitoring strategy (e.g., frequency, spatial distances from burn site, etc.), parameters to be monitored, and actions to be taken based upon the monitoring results. Because of this lack of specificity, as well as the common requirement of monitoring during a burn, the panel spent some time discussing the reasons for monitoring and the sufficiency of information to provide guidance for effective monitoring.

Five objectives were identified by the panel which may be the purpose for a monitoring program:

1. To satisfy regulatory requirements. 
Many states have defined air quality standards which cannot be exceeded during burning, regardless of the material being burned. These standards have been applied to ISB, or some adjustment has been made to these standards to account for their being no specific standards for the burning of oil.

\section{To gain public confidence.}

Because models estimating the extent and concentration of the particulates and other constituents of a burn are inaccurate and not fully field-validated, conducting a monitoring program during an ISB is required to reassure the public that model predictions are acceptable. Furthermore, since ISB, especially offshore burning, is not yet an established practice, such monitoring is needed to validate the use of this procedure as a safe countermeasure.

3. To terminate a burn.

Conducting a monitoring program during an ISB may result in a decision to extinguish the burn, due to a change in the parameters being monitored (e.g., wind conditions, ability to control the burn, etc.).

4. To expand the knowledge base.

In certain circumstances, the opportunity may arise to allow monitoring to validate ISB models to increase knowledge of the ISB process or procedures. The results of such monitoring may result in more efficient, safer or broader use of ISB in the future.

5. To meet legal requirements.

Implementing a monitoring program may be desirable to ensure that data are subsequently available to demonstrate the conditions to which the public, response workers, the biota, etc. were exposed.

Based upon the possible reasons for a monitoring program, the following research needs were identified:

Need: To develop relevant and effective monitoring methods

Research: Verify existing smoke plume models with real time measurements, including compound-specific measurements Method of Implementation: Collect ground level (i.e., 4-6 feet) concentrations of airborne pollutants at varying distances from burn source at spills of opportunity or experimental spills, such as Mobile.

Priority: High

Comments: $\mathrm{PM}^{10}$ concentrations are the measurement of most concern.

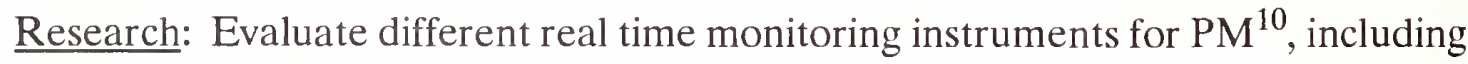
laboratory methods. 
Method of implementation: Smoke house, Mobile, spill of opportunity. Priority: Very High

Comment: Comparison of existing methods and instruments for field use in monitoring ISB, such as that available through the USCG Strike Teams, the EPA Environmental Response Teams, and other field instrumentation. Existing field instrumentation has sensitivity to $5 \mu \mathrm{g} / \mathrm{m}^{3}$. Real-time measurements need to be compared to existing acceptable methods to verify accuracy.

Research: Resolve question of particulates and VOCs behavior, i.e., the interrelationship of gas and particulate movement from the near to far field. Method of implementation: Mobile test facility. Priority: Medium Comment: This research is needed to determine if the particulates and gases are adsorbed to the $\mathrm{PM}^{10}$ fraction and need to be modeled separately.

Research: Test operational monitoring protocols.

Method of implementation: Mobile test facility.

Priority: High

Comment: This should include not only the testing of the protocols for operational feasibility and effectiveness under field conditions, but also the integration in the field effort of supplementary data collection, such as meteorological data.

INLAND RESEARCH NEEDS (wetlands, rivers, etc.)

\section{General}

Most of the information presented during the opening sessions were from marine spills in open waters. Because of this emphasis, some time was spent by the panel in discussing the use of in-situ burning in inland environments. Burning of vegetation following inland spills, as well as the burning of vegetation for other purposes, such as the clearing of agricultural lands, is relatively common; however, the consequences of these activities has not been well documented. Information on the smoke plume components from these activities or on the environmental effects from burning is lacking, precluding any potential benefit that could be applied to marine burns. As a consequence, the panel suggested several "research" areas that were in part systemic: establishment of a network to provide researchers the opportunity to monitor or otherwise study inland burns so that the measurements at inland burns could benefit those who are making decisions for marine spills. Another recommendation which did not require the collection of new data was the identified need to compile and evaluate existing information on inland burns. Other recommendations emanated from the general lack of attention spent on inland spills by the spill community.

Need: To determine the effects of inland burning that are unique from offshore burns 
Research: Determine recovery rates of different habitats following burning. Methods of implementation: Develop network for notification of inland burn opportunities for conducting monitoring and long term studies.

Priority: High

Comments: Implementation of part of this recommendation included in the synthesis of existing information on the burning of marshes; field work following burns would supplement information synthesis.

Research: Determine the human health risks specific to inland burning.

Methods of implementation: Monitor related inland burns (e.g., agricultural burns, etc.).

Priority: Low

Comments: This research would include an evaluation of the effects of vegetation on the plume composition, including the VOCs.

Research: Determine the comparative human health risks between burning and no burning.

Method of implementation: Evaluation of existing literature.

Priority: Low

Comment: This information was considered necessary to document the risk to humans from the oil spill itself, since decision making during spills is always a tradeoff.

Research: Develop better environmentally protective marsh burning guidelines (including coastal environments).

Method of implementation: Past burns, burn network testing different techniques. Priority: High

Comments: Some marshes that had been burned appeared to recover more rapidly than others. However, documentation of these effects, or results from intentional spills are lacking. These data, if developed, would provide the basis for guidelines for marsh burning that could effect more rapid recovery.

ENVIRONMENTAL RESEARCH NEEDS (coastal and marine)

General

The work group felt that most of the environmental concerns associated with ISB in the coastal and marine environments had been adequately addressed during the Newfoundland Experiment and other ongoing synthesis efforts. Except for the few remaining issues identified, there appears to be no unacceptable environmental risks associated with burning, especially when evaluated against the alternative of shoreline impacts. 
Need: Characterization of the fate of the burn residue. Does the residue float or sink?

Research: Determine which, if any, types of burned oil residues sink (e.g., to protect live bottoms, coral reefs).

Method of Implementation: lab burns

Priority: Medium

Comment: Toxicity of residue does not appear to be issue; rather smothering potential of sinking residue in environmentally sensitive area.

Need: What is the toxicity of the burn residue?

Research: Determine the toxicity of the residue from a range of oils, including the potentially, most toxic oils.

Method of implementation: Mobile facility, laboratory experiment.

Priority: Medium

Comment: This research would only be necessary if work being done by MSRC, NOAA, and Environment Canada did not address the range of oils required.

\section{NON-RESEARCH AND DEVELOPMENT ISSUES}

\section{General}

Several issues were identified in the general discussion and were reiterated during the work group meetings that cannot be considered research, but can obstruct the proper use of ISB. These issues need to be addressed to facilitate acceptance of ISB and to prevent or minimize unnecessary difficulties following a burn. These needs were not ranked.

Need: Determine the legal constraints and liabilities involved in burning, both on government and private lands.

"Research" Synthesize and evaluate the legal constraints and liabilities associated with ISB. Methods of implementation: Legal study

Need: Develop materials to educate the public and media about burning--its risks, tradeoffs with other countermeasures, and oil, alone.

"Research" Synthesize existing knowledge about oil spills, the trade-off decisions that must be made, and the risks and benefits of different countermeasures. Method of Implementation: Interagency work group of experts to develop information. Distribution could be through agencies' public affairs offices, prior to 
a spill, as well as through a joint information center established during a spill.

\section{PENDING REPORTS}

Bruist, I. A., Ross, S. L., Trudel, B. K., Taylor, E., Campbell, T. G., Westphal, P. A., Myers, M. R., Ronzio, G. S., and Allen, A. A. The Science, Technology, and Effects of Controlled Burning of Oil Spills at Sea. Marine Spill Response Corp., Washington, DC. MSRC Technical Report Series 93-017. To be published in 1994.

Daykin, M., Setgy, G., Aurand, D., Shigenaka, G., Wang, Z., and Tang, A. Aquatic Toxicity Resulting from In Situ Burning of Oil on Water. In: Arctic and Marine Oil Spill Program (AMOP) Technical Seminar, 17th, Proceedings, Volume 2. June 8-10, 1994, Vancouver, British Columbia. Ottawa, Ontario, Canada, Environment Canada, pp. 1165-1193, 1994. 


\title{
REPORT OF THE OPERATIONAL IMPLICATIONS WORKING PANEL
}

\author{
Bruce McKenzie, Alaska Clean Seas \\ Panel Chair
}

\section{BACKGROUND}

Participants in the Operational Implications Panel included representatives from response organizations, the US Coast Guard, industry, research organizations and regulatory agencies. The discussion focused on the operational elements of in-situ burning: what tools or information is needed to successfully conduct a burn. To avoid getting bogged down on the controversial issue of permitting requirements, it was agreed by the Panel that for the purpose of the workshop, permission to conduct a burn had been received.

The Operational Implications Panel session was structured into two parts. The first part involved identifying data gaps that preclude or restrict burning as a response tool and identification of areas where there is potential to improve performance of the technique or extend/expand its usage. These data gaps and potential improvement areas were then prioritized into a high, medium or low need. It is important to note that the suggested needs were not prioritized within each of these categories.

The second part of the Panel session involved a brain storming session to identify potential R\&D needs related to the identified data gaps/areas for improvement. The complete list of brain storming ideas is provided in Table 1. For the purposes of this project, the needs were then placed under the most appropriate identified information gap/improvement need as a possible means of resolving or addressing the data gap.

Three noteworthy general observations came out of the Panel discussion. Firstly, due to the limited number of burns that have been conducted in a real response situation, there are still some fundamental questions that remain unanswered concerning the survivability of equipment, the ignitability of certain oils and the validity of suggested operational techniques. Secondly, that the operational expertise and experience to conduct burns is presently vested in a relatively few number of individuals. Finally, much of the knowledge related to burning is focused on burning at sea. Relatively little work has been done on assessing the viability of in-situ combustion in nonmarine environments. 


\section{OPERATIONAL INFORMATION GAPS/IMPROVEMENT AREAS}

\section{High Priority}

1) Criteria, protocols and performance data for fire resistant booms and ignitors presently available on the market.

- Based on the results of the Newfoundland burn, a potentially significant problem with durability of fabric based fire resistant booms was identified. Further development, testing and evaluation is required to understand the survivability limitations (when exposed to both thermal and mechanical stress) of existing fire-booms on the market and methods of improving the fire resistant boom design.

- The methods of igniting oil on water should be documented and their advantages and limitations quantified. Additionally, the factors which may limit and govern ignitability of oils ( properties of oil and environmental conditions ) should be identified and quantified.

\section{Brainstorming suggestions:}

- Use reactive metals for igniting oil

- Standardized testing for ignitors and booms

- Meso-scale verification of ignitor capability

- Standardized testing for booms

- Improvements to fire boom

- Create a light weight, compactible fire boom

2) Can heavy oils (Number 5, Bunker C) and emulsified oils be made more burnable? What are the ignition requirements? Can the techniques used be improved to facilitate combustion of these types of products?

- There is a need to push the window of opportunity in which burning can successfully be used (both from an oil type and a \% emulsification point of view)

\section{Brainstorming suggestions:}

- Better ways of breaking emulsions. How can we add additional heat to the emulsion? 
- New or better ways to burn emulsions with high water content

3) When can uncontained oil be burned? For example, will emulsified oil stop or retard the spreading process to allow uncontained combustion? In a large burn will the movement of air into a fire ( fire storm) provide sufficient force to keep the oil from spreading and thus extinguish itself.

- There have been a number of situations where an oil release from a tanker or a blowout has accidentally caught on fire and burned uncontained. The processes involved in a large scale fire such as this need to be better understood. Additionally, there is a possibility of using surface collecting agents as a non-mechanical means of containment so they might possibly be used in a real spill situation.

\section{Brainstorming suggestions:}

- Use of emulsion as a means of containment

- Uncontained burning - foam and/or other alternatives to contained burning

4) Feasibility of burning in environments other than water. Of specific interest is burning on land, in marshes and on beaches. While a number of elements of burning in these environments were identified ( efficiencies, substrate penetration on beaches and ignition techniques) the primary concern was fire control techniques.

- Most of the focus of in-situ burning in recent years has been related to burning of oil at sea. Recent successful burns in marshes (Maine \& Texas) have shown that in-situ burning is a viable response tool for other environments as well.

\section{Brainstorming suggestions:}

- Investigate fire extinguishing techniques

- Test burning on or against a beach

5) Ability to control/extinguish an in-situ burn at sea.

Of primary concern when conducting a burn is the ability to control or extinguish the fire. The common theory for an in-situ burn conducted within a fire resistant boom is that by speeding up the tow, entrainment will occur, thus reducing oil thickness to below levels where combustion is sustainable. This theory has never been tested in the field. 


\section{Brainstorming suggestions:}

- Investigate fire extinguishing techniques

- Field tests of fire control with booms

6) Chemical agents that can be applied to enhance various elements of the burn: smoke suppression, breaking of emulsions and promotion of combustion.

Recent work in Norway has suggested that it may be possible to add a mixture of chemical additives that suppress smoke emissions while simultaneously breaking emulsion and promoting combustion. The possibility of meeting the operational objective of effectively burning emulsions while also addressing the environmental concern related to air emissions merits pursuit.

Brainstorming suggestions:

- Chemical treatment for emulsion burning

- Chemical additives that could be added prior to spillage

- Use of ferrocene

- A catalyst to enhance burning

- Adding oxidizers, such as those available for solid rocket fuel

Medium Priority

7) When do physical environmental conditions such as: wind speed, gusts, wind direction shifts, wave height/geometry and currents preclude burning?

More information is needed on the limits of wave height, form and period as it effects the ignition and burning of oil on water. Particularly when dealing with emulsified and/or heavy oils.

Brainstorming suggestions:

Low Priority 
8) Personal protection for workers conducting burning. This includes protocols, personal protective equipment requirements and techniques, monitoring on scene, follow-up medical monitoring and exposure characterization. The key element of this was identified as exposure characterization, to ensure that the personal protective equipment requirements were not overly onerous.

- While the health and safety of workers conducting a burn is of the highest priority, it was felt by the panel that much of the information required to meet this data gap was already available from other disciplines (i.e., fire fighting).

\section{Brainstorming suggestions:}

9) Fate, behavior and mechanical techniques for recovery of residue.

- There is still some concern related to the toxicity of the residue from a burn. Based on observations from some actual offshore burns there is reason to believe that the residue may sink or escape under a barrier (such as a boom) if currents are sufficiently strong. No effective mechanical means of recovering the residue from a burn has yet been devised.

\section{Brainstorming suggestions:}

- Bioremediate residue at sea

- Let the residue go (don't pick it up) 
During the Panel session, a number of suggestions came up concerning the direction that future In-situ Burning Research \& Development should take. The key points were captured and are provided below.

1) Cooperative and coordinated $R \& D$ efforts need to continue and if possible expanded to incorporate work being done outside of North America.

2) Look for potential solutions/answers to some of the identified needed research areas in other related industries that have been dealing with similar type issues for a number of years (i.e., fire fighting industry; for emulsions, the cosmetics and food industry)

3) In the present economic climate, recognize $R \& D$ funding constraints and scale projects accordingly. Attention needs to be given to more focused, smaller projects in recognition of limited funding.

4) Look for alternatives to at sea burn tests, which tend to be expensive, logistically difficult to coordinate and have long lead times.

5) the need for a testing facility where oil can be burned and dynamic testing conducted. The concern revolved around the difficulty to obtain permits to spill oil and produce black smoke for research related work.

Towards the end of the workshop session, the panel members were asked if, from an operational point of view, you could fund one project for 1994 what would it be. The response was as follows.

1) To develop a light weight, permanent fire resistant boom that can withstand the rigors of an offshore burn.

2) To be able to burn high water content emulsions. 


\section{Table 1}

\section{Operational R\&D Brainstorming Ideas}

\section{Ignition}

- Use reactive metals for igniting oil

- Standardized testing for ignitors and booms

- Meso-scale verification of ignitor capability

\section{Containment}

- Test burning on or against a beach

- Use of emulsion as a means of containment

- Uncontained burning - foam and/or other alternatives to contained burning

- Improve encounter rate without entrainment

- Standardized testing for booms

- Improvements to Fire boom

- Create a light weight, compactible fire boom

\section{Emulsions}

- Better ways of breaking emulsions. How can we add additional heat to the emulsion?

- New or better ways to burn emulsions with high water content

\section{Combustion Promotion}

- Make the boom a better wick

- Make the surface of the boom reflectant to radiate heat back

- Can anything be done beneath the slick to enhance the process

- Can we promote the vigorous burn phase (catalysts, bubblers, etc.)?

- Increase the draft into the fire

- Combustion enhancer that contains nutrients and enhances droplet formation

- Increase heat radiation for the flame back to the oil (currently $\approx 1 \%$ )

- Air injection to enhance burning process

- Inject oxygen into the oil to promote burning 


\section{Table 1 (cont)}

\section{Residue}

- Bioremediate residue at sea

- Let the residue go (don't pick it up)

Soot

- Biodegradation of soot on water

- Fate and behavior study of soot on water

- Find a substance that will make all soot particles $>10 \mu$

\section{Operational}

- Novel techniques that may be applied with existing equipment

- What are the effects of debris on burning

- Robotic responders to avoid health/safety issues

- Night lighting

- Logistical and operational constraints

- Aerial deployment of equipment

- Investigate fire extinguishing techniques

- Means of remotely determining oil thickness

- Portable real time vessel speed indicator $(<1 \mathrm{kt}$.)

\section{Chemicals}

- Chemical treatment for emulsion burning

- Chemical additives that could be added prior to spillage to prevent or slow weathering and emulsification

- use of ferrocene

- A catalyst to enhance burning

- Adding oxidizers, such as those available for solid rocket fuel 


\section{TERMS OF REFERENCE FOR THE WORKSHOP}

Prior to moving into the breakout sessions, all participants in the workshop took part in defining the geographic area of in situ burning during the workshop. The consensus of the group was that discussions would include burning in both marine and inland situations and in all latitudes.

\section{CRITERIA FOR PROJECT RECOMMENDATION}

- Addresses a data gap restricting use as a tool for response

- Cost / Benefit

- Project duration (timeliness)

- Probability of success

- Improves performance of technique

- Extends / expands usage (e.g.: to land, marshes)

- Relevance to operational conditions (simplicity in implementing)

- Safety

- Meets a permit requirement need

- Helps with public acceptance 


\section{NON-RESEARCH AND DEVELOPMENT ISSUES}

A number of issues arose during the conference that were identified as important, but were not specifically related to $R \& D$ needs. It was felt important to capture these issues, but not to dwell on them during the limited time available in the workshop. These issues were captured and are provided below.

- Legal / regulatory constraints

- Need for Education of

- Regulators

- Public

- Operations personnel

- Burning of residual wastes (sorbents / booms)

\section{SUMMARY CONCLUSIONS}

1) Based on the information provided at the workshop through the presenters and also the discussions held in the breakout sessions, there are no significant road blocks to having in-situ burning accepted as a viable response technique.

2) As additional information is gained from $R \& D$ efforts and the regulators become more comfortable with the knowledge base, the procedures and approvals process will continue to be refined. 


\title{
IN SITU BURNING OVERVIEW
}

\author{
Edward J. Tennyson \\ Technology Assessment and Research Branch \\ U. S. Minerals Management Service \\ Herndon, Virginia 22070-4817 USA
}

\section{SUMMARY}

In situ burning of spilled oil, as a primary response technique, has been extensively investigated over the past 11 years. Evaluations of air emissions and effectiveness in removing oil from the ocean surface have been completed for a wide variety of oils in the laboratory and at mesoscale. Results from a field verification offshore of Newfoundland, Canada are becoming available.

A brief overview of the historical research perspective is contained in this paper. An overview of the purposes of the workshop also is given.

\section{INTRODUCTION}

Significant advances in oil spill response capabilities have been made in recent years as a result of the Minerals Management Service (MMS) funded cooperative research program. Areas of major progress include improved remote sensing, chemical treating agents including dispersants, understanding of weathering phenomena in realistic slick thicknesses, and in situ burn (Tennyson, 1993).

This workshop is part of MMS's continuing efforts to ensure maximum applicability and benefits of its cooperative research to the user community. The invited participants represent our best attempts to include all segments of that community.

\section{PURPOSE OF THE WORKSHOP}

The workshop is organized into two major segments. First, we have assembled a speakers' roster of recognized experts in various aspects of in situ burning of spilled oil. These speakers will present the current state of knowledge and their ideas for future research to improve our understanding of this promising oil spill response strategy. Response managers who have recently used this tool for onshore spills will also describe their experiences. We have attempted to involve regulatory and scientific agencies as well as the public in the dialogue during this conference.

The second major part, and the most beneficial part of the workshop for us, will be the results of deliberations during the two breakout panels. There are two panels: 1 . Environmental and Health and Safety, and; 2. Operational implications. We recognize that many potential issues overlap this distinction. 
We ask you to place priorities on each panel's recommendations. On the last day, we will attempt to reach consensus on the priorities of information needs across panel lines.

Our goal is to reach consensus on the present status of information for decision making to allow the use of in-situ burning as appropriate. We want to cut across disciplines and political lines to examine existing information and to identify specific needs that have not been met. You, as decision makers and advisors, will probably have the opportunity to use in situ burning. The time to take stock of your information base and to conduct research to answer your questions is now, certainly not after an event has occurred.

You will have opportunities to cross fertilize between panel deliberations at the scheduled plenary sessions. We encourage you to take advantage of the breaks and unscheduled times to discuss issues of particular importance. All of the speakers will make every effort to be available to answer questions and support panel efforts.

Results of this workshop will be used by MMS to refine future research efforts to address the most important issues developed at this workshop.

\section{HISTORICAL PERSPECTIVE - AN OVERVIEW}

The MMS began a cooperative research program on in situ burning of spilled oil in 1983 to quantify the limitations of this innovative response strategy. Initial efforts were predicated upon the extensive Department of Energy (DOE, 1979) literature search and upon early demonstrations in ice covered areas. Results of this program, supported by Environment Canada (EC), U.S. Environmental Protection Agency (EPA) and U.S. Coast Guard (USCG), immediately indicated that in situ burn could be utilized in a wide range of environmental conditions. Specific physical variables evaluated were slick thickness, degree of oil weathering (sparging), sea state, wind velocities, air and water temperatures, oil type, degrees of emulsification and degree of ice coverage. A wide range of oils tested all burned with 50 to 90 percent removal ratios as long as significant emulsification had not occurred. Slick thicknesses of $3 \mathrm{~mm}$ or thicker were required to sustain ignition. Extinguishment occurred when the slick reached approximately $1 \mathrm{~mm}$ thick. Heavily weathered (sparged) oils burned more completely than fresh by approximately 7 percent. Wind velocities from 0 to 51 knots were experienced at Ohmsett during these tests. At wind speed over $30 \mathrm{knots}$ the flame would not propagate up wind, however slicks ignited on the windward side would continue to burn irrespective of the wind speed. Air temperatures ranged from $-11^{\circ} \mathrm{C}$ to $23^{\circ} \mathrm{C}$ and water temperatures varied from $-1^{\circ} \mathrm{C}$ to $17^{\circ} \mathrm{C}$ without effect on burn efficiencies. Ice coverage also had minimal effect. Coverage ranged from 99 percent to less than 10 percent during testing (Smith and Diaz, 1985). Insufficient funding existed to quantify the concentration and behavior of the airborne pollutants resulting from the released oil and from combustion at Ohmsett. 
The next phase of the research involved an extensive laboratory effort to quantitatively analyze the pollutants created by in situ burning, including chemical composition of the parent oil, burn residue, and water and airborne constituents. These studies were conducted at the National Institute of Standards and Technology (NIST) with major emphasis on particulate and gaseous components created by the burning process. Analyses were also conducted at the EC laboratories in Ottawa, Canada. These research efforts, with a wide variety of crude oils over several years, yielded data that indicated that aldehydes ketones, dioxans, furans, and polycyclic aromatic compounds (PAHs) were not formed in the burning process. The airborne pollutants reflected similar concentrations of these compounds as in the parent oil. The overall concentrations of PAHs were reduced in the smoke versus the parent oil with a conversion of lighter molecular weight PAHs to heavier compounds.

Predominant burn products released were: Carbon Dioxide - 75 percent, water vapor 12 percent, soot - 10 percent, carbon monoxide -3 percent and other products listed above -0.2 percent. The burn residue was composed of the higher molecular weight compounds present in the parent oil. The lighter molecular weight compounds in unburned oil are the major sources of acute toxicity of spilled hydrocarbons. The burn residue tended to be consistently weathered throughout and did not contain relatively fresh oil (lighter compounds) in the center of weathered oil coverings, as typically found in naturally weathered tar balls (Evans et al, 1986-1993) (Fingas et al, 1991-1993).

Concern for the behavior of the airborne products of in situ burning resulted in an extensive effort to develop a model to predict the concentrations of pollutants in the smoke plume, including depositional patterns on the earth's surface. This sophisticated model is under development at NIST. It has been run for various predictive applications in Alaska and other areas. Verification is underway utilizing data from mesoscale experiments at the USCG Fire and Safety Detachment, Mobile, Alabama, and the open ocean field verification exercise offshore Newfoundland, Canada, August 12, 1993 (Evans et al, 1989-1983).

The third phase of this research involved evaluation of the effects of fire size upon the extensive results obtained in the laboratory. In 199114 mesoscale experiments were conducted to measure the burning characteristics of crude oil on salt water. The fire sizes ranged from 5 meters to 15 meters square with burn volume ranging from 343 to 3,720 gallons. The amount of oil removed from the water surface in these experiments ranged from 90 to 99 plus percent with one burn yielding 75 percent for unknown reasons. Extensive sampling of the burn plume was conducted with emphasis on burn rate, radiation, and the concentration and behavior of particulate and gaseous burn products. Burns lasted from 5 to 25 minutes with the most usual duration of 16 minutes. The burning rates indicated removal of $0.55 \mathrm{~mm} / \mathrm{sec}$ plus or minus $0.01 \mathrm{~mm} / \mathrm{sec}$ for pan fires up to 7 meters. These rates of removal are significantly higher than those of conventional oil spill response strategies (Evans and Tennyson, 1991). Smoke particulate generation from fires larger than 2 meters in diameter was approximately 13 percent, 
although various estimates range from 3 to 15 percent (Evans et al, 1992 and Fingas et al, 1993). Data from the mesoscale tests confirmed laboratory results. The effects of fire size from laboratory to 15 meters square has been quantified.

Burning at Mobile continued with 6 mesoscale burns and 2 evaporation experiments being conducted in 1992 (Fingas et al, 1993 and Evans et al 1993).

Comparison experiments of air quality impacts of spilled oil under the burn and no-burn scenarios were conducted. This data is in preliminary form.

On August 12, 1993, EC and the Canadian Coast Guard, with support from MMS, USCG, Marine Spill Response Cooperation (MSRC) and over 20 other funding entities, conducted a very successful field verification of in situ burning of spilled oil offshore St. John's, Newfoundland, Canada. Several major objectives including quantifying removal effectiveness, air and water borne pollutants generated by the burn, background levels of volatile compounds prior to burning and evaluation of selected spill response equipment were accomplished. Information on this landmark activity will be presented during this workshop.

Volumes of weathered Alberta Sweet Mixed Blend released in this activity were $48.3 \mathrm{~m}^{3}$ $\left(12,760\right.$ gal.) and $28.9 \mathrm{~m}^{3}$ (7,635 gal.). Despite mechanical problems with the fire resistant boom during the second burn, approximately 99 plus percent of the oil was removed in each burn. Extensive air and water quality samples were taken and analysis is underway. Mr. Merv Fingas (EC) will be presenting this information.

\section{GENERAL OBSERVATIONS AND FINDINGS}

The following are based upon 10 plus years of involvement in situ burn research and 24 years of oil spill response activity:

o In situ burning of spilled oil has the potential of removing 100 to 1000 times as much oil, prerecovery effort, as any other current response methods.

o Airborne pollutant levels rapidly reach background levels.

o We know more about the efficiencies, effects and operational procedures for in situ burn than we do for dispersants.

o Research suggest no increase in water pollution (water soluble fractions) during burning compared with non burning response scenarios. 
o Health hazards associated with near field exposure to airborne pollutants may be reduced by burning compared to other response strategies.

o Responders and near populations exposed to visible smoke should be protected with combination $\mathrm{PM}_{10}$ and organic vapor filtered respirators.

o $\quad$ Fire containment boom technology needs improvement and verification.

o Testing protocols for fire resistant booms are needed.

o For the wide range of oils investigated, the burn residue approximates heavily weathered oil with low toxicity.

o No residue, in our experiments, were observed to sink.

o Additional research is needed on near full scale burning of emulsions in waves.

o Particulate pollutant concentrations in the mid field (300 to $2000 \mathrm{~m}$ downwind) needs to be evaluated more fully.

o We need your input to most efficiently proceed with our research.

\section{ACKNOWLEDGEMENT}

The author gratefully acknowledges the contributions from a number of co-sponsors for the research described in this paper. Among the cosponsors with MMS were EC; American Petroleum Institute; Imperial Oil Ltd., Canada; USCG; Alaska Clean Seas; EPA; MSRC and others. 


\section{REFERENCES}

DOE Combustion: An Oil Spill Mitigation Tool. Report No. DOE/EVANS-1380-1. August 1979.

Evans D., Combustion of Oil Spills on Water, in: Technology Assessment and Research Program for Offshore Minerals Operations, 1986 Report, OCS Study MMS 86-0083, Minerals Management Service, Herndon, Virginia, 1986.

Evans, D., Mulholland, G., Gross, D., Baum, H., Saito, K., Environmental Effects of Oil Spill Combustion, in: Proceeding of the Tenth Arctic and Marine Oil Spill Program Technical Seminar, Edmonton, Alberta, Canada, June 9-11, 1987.

Evans, D. Mulholland, G., Gross, D., Baum, H., Saito, K, Burning, Smoke Production, and Smoke Dispersion from Oil Spill Combustion, in: Proceedings of the Eleventh Arctic and Marine Oil Spill Technical Seminar, Vancouver, British Columbia, Canada, June 7-9, 1988.

Evans, D., Mulholland, G., Grass, D., Baum, H., Saito, K., Generation and Dispersion of Smoke Oil Spill Combustion, in: Proceedings 1989 Oil Conference - Prevention, Behavior, Control, Cleanup, San Antonio, Texas, 1989, February 13-16, 1989.

Evans, D. D., Baum, H., Mulholland, G., Bryner, N., Forney, G., Smoke Plums from Crude Oil Burns, in: Proceedings of the Twelfth Arctic and Marine Oil Spill Program Technical Seminar, Environment Canada, Ottawa, Ontario, Canada, pp. 1-22, 1989.

Evans, D. D., Tennyson, E. J., In Situ Burning - A Promising Response Strategy, in: Proceedings of the Seventh Symposium on Coastal and Ocean Management, Long Beach, California, July 8-12, 1991.

Evans, D. D., Walton, W. D., Baum, H. R., Notarianni, K. A., Lawson, J. R., Tang, H. C., Keydal, K. R., Rehm, R. G., Madrzykowski, D., Zile, R. H., Koseki, H., Tennyson, E. J., In Situ Burning of Oil Spills: Mesoscale Experiments, in: Proceedings of the Fifteenth Arctic and Marine Oil Spill Technical Seminar, pp. 593-657, Edmonton, Alberta, Canada, June 10-12, 1992.

Evans, D. D., Walton, W. D., Baum, H. R., Notarianni, Tennyson, E. J., Tebeau, P. A., Mesoscale Experiments Help to Evaluate In Situ Burning of Oil Spills, in: Proceedings of the Thirteenth Biennial Conference on the Prevention, Behavior, Control, and Cleamup of Oil Spills, Tampa, Florida, March 29 - April 1, 1993. 
Fingas, M. F., Li, K., Ackerman, F., Campagna, P., Turpin, R. D., Getty, S. J., Soleki, M. F., Tresplacios, M. J., Pare, J., Bissonnette, M. C., Tennyson, E. J., Emissions From Mesoscale In situ Oil Fires: The Mobile 1991 and 1992 Tests, in: Proceedings of the Sixteenth Arctic and Marine Oil Spill Technical Seminar, pp. 749-832, Calgary, Alberta, Canada, June 7-9, 1993.

Smith, N. K., Diaz, A., In-Place Burning of Crude Oils In Broken Ice, in: Proceedings of the Eighth Arctic and Marine Oil Spill Program Technical Seminar, Edmonton, Alberta, Canada, June 18-20, 1985.

Tennyson, E. J., Results from Oil Spill Response Research--An Update, in: Proceedings of the 1993 Oil Spill Conference, pp. 541-544, March 29-April 1, 1993.

Walton, W. D., Evans, D. D., McGratten, K. B., Baum, Twilley, W. H., Madrzykowski, D., Putorti, A. D., Rehm, R. G., Koseki, H., Tennyson, E. J., In-Situ Burning of Oil Spills: Mesoscale Experiments and Analysis, in: Proceedings of the Sixteenth Arctic and Marine Oil Spill Technical Seminar, pp. 679-734, Calgary, Alberta, Canada, June 7-9, 1993. 



\title{
IN SITU BURNING OF OIL SPILLS: SMOKE PRODUCTION AND PLUME BEHAVIOR
}

\author{
David D. Evans \\ Large Fire Research Group \\ Building and Fire Research Laboratory \\ National Institute of Standards and Technology \\ Gaithersburg, Maryland 20899
}

\section{SUMMARY}

In 1985, the National Institute of Standards and Technology (NIST) began a study of in situ burning of crude oil to provide information to support decisions about the use of this technology for oil spill response. Measured smoke production from burning of crude oils in the laboratory, in mesoscale experiments, and in an offshore experiment are presented. Calculations of smoke plume dispersion for an oil spill burn in the vicinity of Cook Inlet, Alaska show that beyond $5 \mathrm{~km}$ downwind of the burn, smoke particulate concentrations near the ground averaged over 1 hour do not exceed $150 \mu \mathrm{g} / \mathrm{m}^{3}$.

\section{INTRODUCTION}

In situ burning of spilled oil has distinct advantages over other countermeasures. It offers the potential to convert rapidly large quantities of oil into its primary combustion products, carbon dioxide and water, with a small percentage of smoke particulate and other unburned and residue byproducts. Burning of spilled oil from the water surface reduces the chances of shoreline contamination and damage to biota by removing the oil from the water surface before it spreads. In situ burning requires minimal equipment and less labor than other techniques. It can be applied in areas where many other methods cannot due to lack of response infrastructure and/or lack of alternatives. Oil spills amongst ice and on ice are examples of situations where practical alternatives to burning are very limited. Because the oil is mainly converted to airborne products of combustion by burning, the need for physical collection, storage, and transport of recovered fluids is reduced to the few percent of the original spill volume that remains as residue after burning.

Burning oil spills produces a visible smoke plume containing smoke particulate and other products of combustion which may persist over many kilometers downwind from the burn. This fact gives rise to public health concerns, related to the chemical content of the smoke plume and the downwind deposition of particulate, which need to be answered. The program of research in oil spill burning began at NIST in 1985 addresses this need for information through measurements and calculations. 


\section{BACKGROUND}

As a result of 1983 experiments in which 50 to 95 percent of all the oils tested were removed from the water surface by burning in the Oil and Hazardous Materials Simulated Environmental Test Tank (OHMSETT) facility in Leonardo, New Jersey [1], studies were initiated at the NIST under funding from the Minerals Management Service (MMS). The NIST research program was designed to study how burning large oil spills would affect air quality by quantifying the products of combustion and developing methods to predict the downwind airborne smoke particulate concentrations. Measurements were performed at three scales. Initially, laboratory experiments of $0.4 \mathrm{~m}$ to $1.2 \mathrm{~m}$ diameter pool fires were conducted to measure burning rates and smoke product in a controlled environment [2]. Subsequent mesoscale burn experiments up to $15 \mathrm{~m}$ square were conducted outdoors to examine scaling of laboratory results to a size approaching that expected to be used in oil spill mitigation. New instrumentation techniques were developed to perform measurements of smoke production in a free smoke plume [3]. These measurement methods were employed in the large scale experiments conducted recently in at sea burns off the coast of Newfoundland, Canada [4].

Concurrent with the development of measurements techniques for smoke plumes, a Large Eddy Simulation (LES) model for the calculation of smoke plume trajectory and predicting the "footprint" of soot particle deposition downwind of a burn was developed. LES is a steady-state three-dimensional calculation of smoke plume trajectory and smoke particulate deposition based on a mixed finite difference and Lagrangian particle tracking method [3].

\section{SMOKE YIELD}

The smoke production from a fire may be expressed in terms of a smoke yield $Y_{S}$ which is defined as the mass of smoke particulate $m_{P}$ produced from burning a fuel mass $m_{F}$, as:

$$
Y_{S}=\frac{m_{P}}{m_{F}}
$$

The mass of carbon in the fuel that is consumed by burning is equal to the mass of carbon in the smoke plume.

$$
m_{C, \text { Sinoke }}=m_{C, \text { Fuel }}
$$

Three assumptions are made in the analysis. The first is that the smoke particulate is predominately carbon. Previous laboratory measurements [5] have shown that the organic carbon fraction of smoke from crude oil pool fires is not greater than 10 percent before 
there is any boiling in the supporting water sublayer. The remainder of the smoke contains greater than 90 percent elemental carbon. Thus the total carbon content which includes the elemental carbon and the carbon contained in the organic fraction is well over 90 percent of the content of the smoke. Based on this evidence, for the purpose of the smoke yield analysis, the smoke particulate is considered to be pure carbon. The second assumption is that samples are collected over a suitable time period to average out natural fluctuations in the fire and plume. In the mesoscale tests and laboratory tests, samples are drawn over a period of 600 seconds to over 1000 seconds. This is deemed sufficient to represent the average burning conditions for the fires. The third assumption is that no preferential separation of smoke particulate and combustion gases occur in the smoke plume up to the point where the sample is taken. In all field measurements, and unconfined laboratory burns, the smoke yield measurement is made close to the source where the smoke and gaseous combustion products move in a well formed smoke plume. Combining eqs (1) and (2) and taking into account the three assumptions above yields:

$$
Y_{S}=\frac{m_{P}}{m_{C, \text { Smoke }}} \frac{m_{C, \text { Fuel }}}{m_{F}}
$$

To evaluate the above ratio, a known volume of smoke is drawn though a filter and the gaseous portion collected in a sample bag. The mass of carbon in the smoke $\left(\mathrm{m}_{\mathrm{C}, \text { Smoke }}\right)$ is equal to the mass of carbon in the smoke particulate, assumed equal to the mass of particulate $\left(\mathrm{m}_{\mathrm{p}}\right)$ collected on the filter, plus the mass of carbon in the $\mathrm{CO}_{2}$ and $\mathrm{CO}$ in the gaseous portion of the smoke sample. The second fraction on the right-hand-side of eq (3), the mass fraction of carbon in the fuel, is determined from an elemental analysis of the fuel. For example, the ratio;

$m_{C, F u e l} / m_{F}$ for Louisiana crude oil, is 0.858 , which is typical for crude oils.

Controlled laboratory experiments provided the opportunity to evaluate if the smoke yield measurements are constant over the entire cross section of the smoke plume. Following the assumption that both the gases and the particulate travel together near the fire mixing with the entrained air as the smoke moves away from the source, the smoke yield should be equal when measured at the center of the plume and at its edge. In mesoscale tests, due to variations in the wind, natural fluctuations in the fire, and difficulties in positioning smoke measurement instruments which are suspended below a tethered blimp, the smoke samples are drawn from a variety of positions within the plume over the long sampling time. Therefore it is important to assure the accuracy of these measurements, and that position is not a sensitive factor in the smoke yield measurement. 
Table 1. Smoke yield from laboratory burn

\begin{tabular}{|cc||}
\hline Location & $\begin{array}{c}\text { Smoke Yield } \\
(\boldsymbol{\%})\end{array}$ \\
Plume centerline & 10.90 \\
1 m radial from plume centerline & 10.90 \\
1 m radial from plume centerline & 10.68 \\
2 m radial from plume centerline & 11.07 \\
2 m radial from plume centerline & 10.76 \\
\hline
\end{tabular}

In the laboratory burn of a $1.2 \mathrm{~m}$ diameter Louisiana crude oil pool fire [6], smoke yield measurements were made at three positions: plume centerline, $1 \mathrm{~m}$ radius and $2 \mathrm{~m}$ radius (near the edge of the visible plume) at a height of $15 \mathrm{~m}$ above the burning fuel surface. Table 1 shows the results of the measurements. The smoke yield is seen to be nearly constant across the plume and the measurement method is seen to be repeatable at each measurement station. The average smoke yield for the $1.2 \mathrm{~m}$ diameter Louisiana crude oil fire is 10.9 percent.

Smoke yields from the larger mesoscale burns (6.88 $\mathrm{m}$ and $17.2 \mathrm{~m}$ effective diameter) are given in table 2. It appears that smoke yield in the $1.2 \mathrm{~m}$ diameter laboratory fires (10.9\%) is a good indicator of smoke yield from the $17.2 \mathrm{~m}$ diameter fires $(10.5 \%$ average of five tests [6]). This result based on measurement of a single crude oil type should be regarded as preliminary. Also, the single $6.88 \mathrm{~m}$ fire measured produced a larger smoke yield than the $17.2 \mathrm{~m}$ burn which has four times the burning surface area [6]. This result is interesting as it suggests that either there is peak in the smoke production rate, or that there is a characteristic of the $6.88 \mathrm{~m}$ diameter fires that has not been taken into account. Both 1.2 $\mathrm{m}$ and $17.2 \mathrm{~m}$ fires produced significantly less smoke per unit mass of fuel consumed than the $6.88 \mathrm{~m}$ burn. In field tests of in situ oil spill burning off the coast of Newfoundland [4], a smoke yield of nominally 15 percent was measured for weathered Alberta Sweet Mixed Blend crude oil. 
Table 2. Smoke yield from mesoscale and field burns

\begin{tabular}{||ccc||}
\hline Crude Oil & $\begin{array}{c}\text { Effective Burn } \\
\text { Diameter (m) }\end{array}$ & Smoke Yield (\%) \\
$\begin{array}{l}\text { Louisiana [6] } \\
\text { Louisiana [6] }\end{array}$ & 6.88 & $14.0-15.2$ \\
$\begin{array}{l}\text { Alberta Sweet } \\
\text { Mixed Blend }\end{array}$ & 17.2 & $9.4-12.3$ \\
\hline * VoBE field test [4]. Oil burned in the apex of a $150 \mathrm{~m}$ \\
long boom towed in a U-configuration, August 12,1993
\end{tabular}

Table 3. Smoke Yield from Crude Oils Fires (1.2 m diameter)

\begin{tabular}{|cc|}
\hline Crude Oil & Smoke Yield (\%) \\
Louisiana [6] & 10.9 \\
Cook Inlet [7] & 9.2 \\
$\begin{array}{c}\text { Alaska North } \\
\text { Slope [7] }\end{array}$ & 11.6 \\
\hline
\end{tabular}

Table 3 shows the results of laboratory burns of three crude oils in $1.2 \mathrm{~m}$ diameter pans. The smoke yield for each was slightly different but nominally 10 percent.

\section{SMOKE PLUME BEHAVIOR}

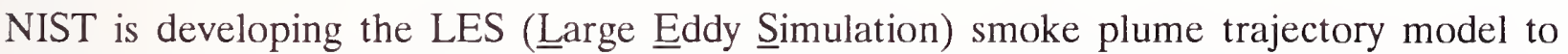
address the need for accurate predictions of downwind smoke dispersion from large buoyant sources such as oil spill fires to support the decision process about the application of in situ burning in response to oil spills. This model differs from most of the atmospheric dispersion models in use today because it is a deterministic rather than an empirical model; that is, the approach taken is to solve the governing equations of motion directly rather than relying on empirical formulae which approximate the extent of the dispersion. These empirical models typically assume the pollutant of interest to be Gaussian distributed in the plane perpendicular to the direction of the prevailing wind. The parameters defining the distribution are estimated from experiments. Unfortunately, the problem of in situ burning of crude oil is inappropriate for these types of models for two reasons: (1) The nature of the "source" is different than what is normally assumed, a smokestack, and (2) the size of the source is well beyond those considered in industrial applications and thus outside of the experimental parameter range. 
Because the LES model approaches the dispersion problem from first principles, it is more flexible, and ultimately easier to apply because it reduces the number of empirical parameters demanded of the user. The long range goal of the LES modeling study is to provide high resolution predictions that can account for the actual terrain and atmospheric conditions in the vicinity of the spill. LES version 2.0 was used to predict smoke plume trajectory from oil spill burns in Alaska [7]. This version of the model is limited to predictions of downwind smoke concentration for uniform winds and flat terrain. Details of the model derivation are given in reference [7].

Application of the model is demonstrated by calculation of a hypothetical in situ burn of North Slope crude oil in the vicinity of Cook Inlet, Alaska. It is assumed that spilled crude oil is being burned in the confines of a fire resistant boom. Figure 1 presents the results from an example calculation for a steady burning fire for 1 hour with a burning area of 465 $\mathrm{m}^{2}\left(5000 \mathrm{ft}^{2}\right)$. In that figure, (A) is a typical atmospheric temperature profile for the Cook Inlet region in the winter. The effect of the temperature inversion on the plume rise is evident in (B) which shows the crosswind extent of hour-averaged plume particulate concentrations of 150 and $300 \mu \mathrm{g} / \mathrm{m}^{3}$ at a cross section $5 \mathrm{~km}$ downwind of the burn site. (C) is a similar plot showing the downwind extent of these concentration levels in the plume. (D) displays the concentrations at the ground level, where the darker shaded areas indicate values higher than $150 \mu \mathrm{g} / \mathrm{m}^{3}$. The term "ground level" refers to the first 10 to $20 \mathrm{~m}$ of the atmosphere, reflecting the resolution of the finite difference approximation of the conservation equations. In this example calculation, the concentrations of smoke particulate exceeding $150 \mu \mathrm{g} / \mathrm{m}^{3}$ are confined to a small area less than $2 \mathrm{~km}$ long immediately downwind of the fire. Finally, (E) is included to quantify the previous contour plot. It shows the decrease in the ground concentration along the plume centerline. A comprehensive evaluation of many burn scenarios for the state of Alaska [7] showed that for a $465 \mathrm{~m}^{2}$ burn, $150 \mu \mathrm{g} / \mathrm{m}^{3} 1$ hour average smoke particulate concentrations were not found at distances greater than $5 \mathrm{~km}$ downwind of the burn and did not extend beyond a width of $1 \mathrm{~km}$. The $300 \mu \mathrm{g} / \mathrm{m}^{3} 1$ hour average ground level smoke concentrations were limited to less than $2 \mathrm{~km}$ downwind.

Finally, if doubling of the burning area to $930 \mathrm{~m}^{2}\left(10,000 \mathrm{ft}^{2}\right)$ is considered both the heat and mass release rates are assumed to be double, but the particulate concentrations near the ground are not double. The reason for this is that the plume will rise higher when the fire is larger in area. The higher elevation of the plume causes greater dispersion, and thus the particulate matter is spread over a larger area.

\section{CONCLUSION}

Smoke production from crude oil fires was found to vary with the area of the burn and the type of crude oil. It appears that 10 to 15 percent of the mass of crude oil burned in large areas is converted to particulate that is carried in the smoke plume. Calculations performed to predict near ground level concentrations of particulate from oil spill burns have shown 
that 1 hour average concentrations do not exceed $150 \mu \mathrm{g} / \mathrm{m}^{3}$ at downwind distances greater than $5 \mathrm{~km}$ and do not exceed $300 \mu \mathrm{g} / \mathrm{m}^{3}$ beyond $2 \mathrm{~km}$ downwind of burns for a wide variety of weather conditions.

\section{ACKNOWLEDGMENTS}

The author would like to thank Mr. William D. Walton and Dr. Kevin B. McGrattan for their help in preparing clear and concise explanations of smoke yield calculations and LES model capabilities. The program of studies to understand in situ burning of oil spills was begun under funding from the Minerals Management Service, Department of the Interior in 1985. MMS has been a substantial and continuous source of funding for this research and has played an important role in steering the research effort to the best advantage of industry. Cooperative research has been performed with Environment Canada to characterize the combustion products from crude oil burns. The U.S. Coast Guard Fire Safety and Test Detachment in Mobile, Alabama has been an invaluable resource for test data and opportunities to develop instrumentation during mesoscale pan burns. Funding from the USCG Research and Development Center has helped to establish means to measure the chemical composition of smoke plumes from large fires. Cooperative support for mesoscale experiments was received from the American Petroleum Institute, Marine Spill Response Corporation, Marine Industry Group, Exxon Baton Rouge Refinery, and BP America. Large laboratory fire experiments were conducted in cooperation with the Fire Research Institute in Japan. Analysis of smoke plume dispersion for in situ oil spill burns in Alaska using the LES model was performed under support from the Alaska Department of Environmental Conservation (ADEC).

\section{REFERENCES}

[1] Smith, N.K. and Diaz, A., In-place Burning of Prudhoe Bay Oil in Broken Ice. Proceedings 1985 Oil Spill Conference, Prevention, Behavior, Control, Cleanup, American Petroleum Institute, Washington, DC 20005, pp. 405-410, (1985).

[2] Evans, D., Mulholland, G., Gross, D., Baum, H., and Saito, K., Burning, Smoke Production, and Smoke Dispersion from Oil Spill Combustion, Proceedings of the Eleventh Arctic and Marine Oil Spill Program Technical Seminar, June 7-9, 1988, Vancouver, British Columbia, Ministry of Supply and Services Canada, Cat. No. En 49-11/5-1988 E/F, pp. 41-87, (1988).

[3] Evans, D., Walton, W., Baum, H., Notarianni, K., Lawson, J., Tang, H., Keydel, K., Rehm, R., Madrzykowski, D., Zile, R., Koseki, H., and Tennyson E., In-Situ Burning of Oil Spills: Mesoscale Experiments, Proceedings of the Fifteenth Arctic and Marine Oil Spill Program Technical Seminar, June 10-12, 1992, Edmonton, Alberta, Ministry of Supply and Services Canada, Cat. No. En 40-11/5-1992. pp. 593-657, (1992). 
[4] NOBE, Newfoundland Offshore Burn Experiment, Environment Canada, Ottawa, Ontario, June, 1993.

[5] Benner, B. A. Jr., Bryner, N. P., Wise, S. A., Mulholland, G. W., Lao, R. C., Fingas, M. F., Polycyclic Aromatic Hydrocarbon Emissions from the Combustion of Crude Oil on Water, Environmental Sciences \& Technology, Vol. 24, pp. 1418-1427, (1990).

[6] Walton, W.D., Evans, D.D., McGrattan, K.B., Baum, H.R., Twilley, W.H., Madrzykowski, D., Putorti, A.D., Rehm, R.G., Koseki, H., and Tennyson, E.J., In situ Burning of Oil Spills: Mesoscale Experiments and Analysis, Proceedings of the Sixteenth Arctic and Marine Oil Spill Program Technical Seminar, June 7-9, 1993, Calgary, Alberta, Environment Canada, Ottawa, Ontario, (1993).

[7] McGrattan, K.B., Putorti, A.D., Twilley, W.H., Evans. D.D., Smoke Plume Trajectory from In Situ Burning of Crude Oil in Alaska, NISTIR 5273, National Institute of Standards and Technology, Gaithersburg, Maryland 20899, (1993). 


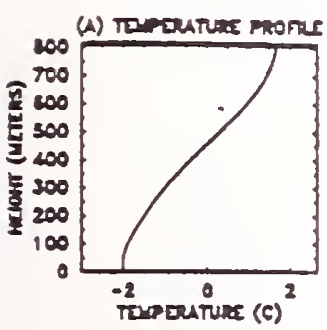

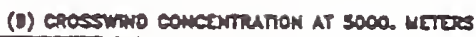

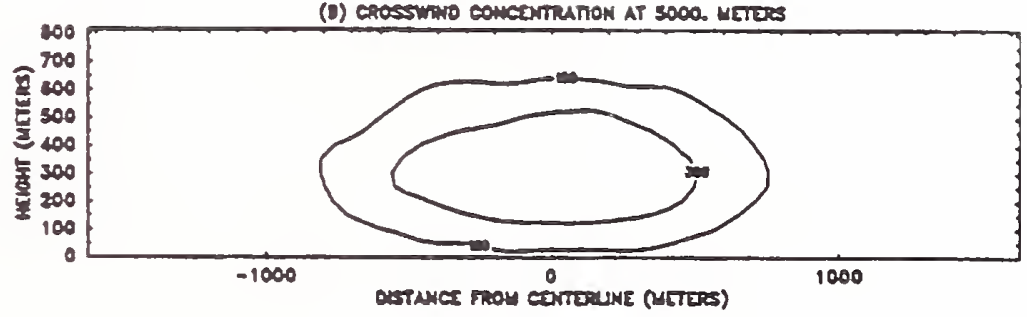

(C) VERTCU CENLELDE CONCENTRATON

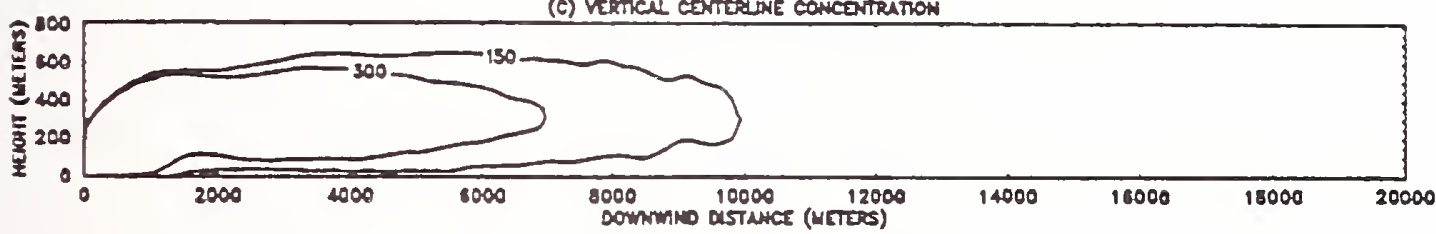

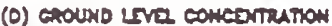

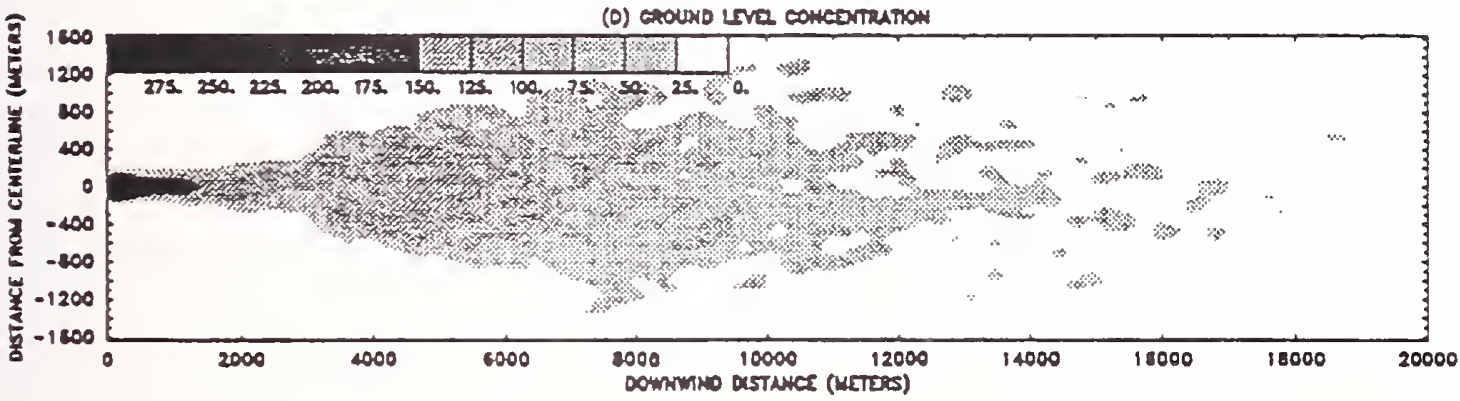

(E) GROUND CENTERLNE CONCENTATION

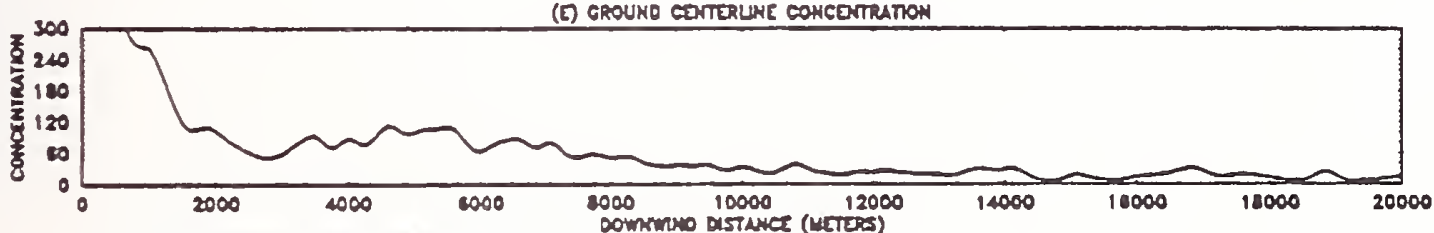
Ul concomthations Domessed in umts or $\mathrm{ma} / \mathrm{m}$

Figure 1. LES smoke plume calculations for in situ burning of a Alaska North Slope crude oil in the vicinity of Cook Inlet in the winter. 



\section{EMISSIONS FROM IN SITU OIL FIRES}

Merv F. Fingas ${ }^{1}$, Ken $\mathrm{Li}^{1}$, Philip R. Campagna ${ }^{2}$, Rodney D. Turpin ${ }^{2}$, Francine Ackerman ${ }^{1}$, Martine C. Bissonnette ${ }^{1}$, Pat Lambert ${ }^{1}$, Samuel J. Getty ${ }^{3}$, Miguel J. Trespalacios ${ }^{3}$, J. Belanger ${ }^{1}$ and Edward J. Tennyson ${ }^{4}$

\section{SUMMARY}

A series of 30 mesoscale burns was conducted in 1991 and 1992 to study various aspects of oil burning. Twenty of these burn tests were sponsored by the U.S. Minerals Management Service (MMS) and were conducted at the U.S. Coast Guard facility in Mobile, Alabama. A further round of tests was conducted in Calgary, Alberta and was co-sponsored by Exxon Biomedical Services, Environment Canada (EC) and Esso Resources. EC and the U.S. Environmental Protection Agency (EPA) conducted extensive sampling and monitoring of these burns to determine the emissions resulting from the burn. Measurements and samples of air, soot (smoke), water and residue were taken and analyzed for specific pollutants. Subsequently, a full-scale burn was conducted offshore Newfoundland in 1993 and very extensive measurements and samples were taken. Although not complete at time of writing, these new results shed even more light on the environmental acceptability of oil in-situ burning.

Polyaromatic hydrocarbons $(\mathrm{PAH})$ were found to be lower in the soot than in the starting oil and were consumed by the fire to a large degree. Metals in the oil were found exclusively in the residue and could not be measured in soot samples using conventional industrial hygiene sampling techniques. Particulates in the air were measured by several means and found to be of concern up to 150 metres downwind at ground level. Particulate matter may not be a concern past this distance. Combustion gases including carbon dioxide, sulphur dioxide and carbon monoxide do not reach levels of concern. These gases are emitted over a broad area around the fire and are not directly associated with the plume trajectory. Volatile organic compounds (VOCs) are extensive from fires, however are less than emitted from a mon-burning test spill. Over 50 compounds can be quantified, several at levels of concern up to 150 metres downwind.

1 Emergencies Science Division, River Road Environmental Technology Centre, Environment Canada, Ottawa, Ontario.

2 Environmental Response Team, Environmental Protection Agency, Edison, New Jersey

3 Roy F. Weston/REAC, Edison, New Jersey

4 Minerals Management Service, Herndon, Virginia 
Water under the burns was analyzed; no compounds of concern (or any compounds generally) could be found at the detection level of the methods. The burn residue was analyzed for the same compounds as the air samples. The residue contains elevated amounts of metals, explaining the fate of these metals. PAHs are at a lower concentration in the residue than in the starting oil, however there is a slight concentration increase in some higher molecular-weight species. The overall mass of PAHs including that of the higher-molecular-weight species, is about 6 orders-of-magnitude lower after the burn. Overall, indications from these burn trials are that emissions from in-situ burning are low in comparison to other sources of emissions and result in concentrations of air contaminants that are acceptable beyond 500 metres downwind.

\section{INTRODUCTION}

In-situ burning has long been a means for dealing with oil spills. Acceptance in some regions has been poor because of concern over the resulting air emission. A series of studies have been started by several groups to address these concerns. In Canada, Environment Canada commissioned several studies to address this issue. ${ }^{1-3}$ In the United States the U.S. Minerals Management Service contracted the National Institute of Standards and Technology (NIST) to study burns. ${ }^{4-6}$ These efforts have been coordinated to ensure the maximum use of resources. Studies have been done at laboratory scale to study emissions. ${ }^{7-9}$ In 1991, MMS began the sponsorship, in cooperation with several agencies, of a series of mesoscale burn tests at Sand Island situated at upper Mobile Bay, Alabama. ${ }^{10}$ Environment Canada and the U.S. Environmental Protection Agency cooperated to set up a series of instruments and samplers to monitor all suspect emissions. In 1992, a similar series of experiments was set up to monitor these burns. In 1993, the full-scale Newfoundland Offshore Burn Experiment was conducted to extend these measurements to a realistic burn situation.

\section{SAMPLING}

Sampling methodologies and target emissions are summarized in Table 1. Detailed methods are described in the literature. 


\begin{tabular}{|c|c|c|c|c|}
\hline Table 1 & Summary of An & ytical Methods & & \\
\hline $\begin{array}{l}\text { Sample } \\
\text { Taken }\end{array}$ & Sampler & $\begin{array}{l}\text { Measurement } \\
\text { Parameter }\end{array}$ & $\begin{array}{l}\text { Secondary } \\
\text { Parameters }\end{array}$ & $\begin{array}{l}\text { Additional } \\
\text { Parameters }\end{array}$ \\
\hline \multirow[t]{4}{*}{ Soot at Ground } & High Volume Sampler & Dioxins and Dibenzofurans & Particulates & PAHs \\
\hline & Sampling Pump & PAHs & Particulates & \\
\hline & medium volum & & & \\
\hline & RAM & Particulates & & \\
\hline \multirow[t]{3}{*}{ Soot in Smoke } & Sampling Pump & PAHs & Particulates & Metals \\
\hline & low volume & & & \\
\hline & blimp, remote-controlle & helicopter, research aircraft & & \\
\hline \multirow[t]{7}{*}{ Gases } & Summa Canister & Volatile Organic Compounds & & \\
\hline & Sampling Pump & Volatile Organic Compounds & & \\
\hline & low volume & & & \\
\hline & CO2 Meter & Carbon Dioxide & & \\
\hline & SO2 Meter & Sulphur Dioxide & & \\
\hline & NO2 Meter & Nitrogen Dioxide & & \\
\hline & CO Meter & Carbon Monoxide & & \\
\hline Oil & & PAHs & Metals & Full Analysis \\
\hline Burn Residue & & PAHS & Metals & Full Analysis \\
\hline Water under Burn & & PAHs & Organics & Toxicity \\
\hline
\end{tabular}

PAHs were sampled using several collection methods. Mid-volume air samplers were used at a nominal flow rate of $7 \mathrm{~L} / \mathrm{min}$. Air/smoke was drawn through a teflon filter, followed by sorbent tube packed with XAD resin. A high-volume sampler collected particulates on a 10.2 $\mathrm{cm}$ (4-in) diameter glass-fibre filter. This was in tandem with a polyurethane foam plug (PUF) which adsorbed the volatile components of the target analytes. Typical sampling rate was $200 \mathrm{~L} / \mathrm{min}$. A typical sampling volume was thus $2 \mathrm{~m}^{3}$ for a sampling duration of $20 \mathrm{~min}$. A high volume sampler collected total suspended particulate matter (TSP) on a tared $20 \mathrm{X}$ $25 \mathrm{~cm}\left(8 \times 10\right.$ in ) filter. Typical flow rate was $1 \mathrm{~m}^{3} / \mathrm{min}$. After gravimetric determination of TSP, 36-cm discs were cut out using a metal punch and extracted for PAHs. Filter, PUF, $\mathrm{PUF} / \mathrm{XAD}$, airborne particulate samples from the samplers were spiked with surrogate $\mathrm{PAH}$ standards and extracted with toluene. The raw extract was concentrated and applied quantitatively to an activated silica column. The second fraction, containing $\mathrm{PAH}$, was 
recovered using benzene. This fraction was concentrated, spiked with d14-terphenyl as an internal standard before GC/MSD analysis.

Aliquots of fresh crude and residue were collected from the burn pan before and after each burn using a sampler. The water in the burn pan was also sampled before and after the burn for PAH and metal analyses. Crude and residue sample was first dissolved in cyclohexane to precipitate asphaltenes. An aliquot was spiked and subjected to silica column cleanup. The saturates were first eluted with hexane; the aromatic (PAH) fraction was eluted using benzene. This fraction was concentrated down and the column cleanup was repeated to remove the residual oil. An internal standard of d14-terphenyl was added prior to injection into a GC/MS for analysis. Water samples were spiked and extracted 3 times by dichloromethane (DM). The extracts were dried, combined and concentrated before instrumental analysis.

Volatile Organic Compounds (VOCs) were initially taken using Gilian or SKC personal samplers were employed at the same locations as the PAH samplers. Sampling media was a two-stage charcoal tube at a nominal flow rate of $2 \mathrm{~L} / \mathrm{m}$. Typical sample size was $50 \mathrm{~L}$. Whole air/smoke samples were also taken using $6 \mathrm{~L}$ pre-evacuated (to $0.05 \mathrm{~mm} \mathrm{Hg}$ ) stainless steel canisters (Summa canister). A fixed orifice with a stainless steel frit was used to restrict the flow to about $200 \mathrm{~mL} / \mathrm{min}$. For a few selected runs, samples were also collected at an upwind location to evaluate the non-combustion related emission of VOC. Summa VOC analysis was performed by GC/MS after desorption on a cryogenic trap The C2 hydrocarbons were determined separately on a packed-column GC. VOC's on sorption tubes were extracted using $\mathrm{CS}_{2}$ and then injected onto a GC/MS. For the Newfoundland trials, the Summa canisters were also analyzed for $\mathrm{CO}_{2}$ using a third analytical technique.

Heavy metals in soot were collected using personal samplers on a membrane cellulose ester filter. Metals were analyzed by acid digestion followed by measurement on an ICP-AE spectrometer. In later tests, soot samples were taken with high-volume samplers to improve sensitivity.

Polychlorinated dibenzo-p-dioxin/furans were measured on soot and in the oil. High volume samplers were employed to collect samples at upwind and downwind locations. Sampling media were $10.2 \mathrm{~cm}$ (4 in) glass-fibre filters followed by a polyurethane foam plug (PUF). The samples were spiked with a mixture of carbon-13 surrogates covering tetra- to octachloro DX/DF and extracted by soxhlet using toluene. The raw extract was cleaned up using a silica column which removed the easily-oxidisable organics. This was followed by an activated alumina column that separated the dioxins/furans from interfering PCBs, pesticides etc. The extracts were then injected on a high-resolution GC/MS.

Sampling of carbonyls such as aldehydes and ketones was accomplishing using a speciallydesigned tube with subsequent extraction and analysis by liquid chromatography. Sampling of the smoke plume was also accomplished using a remote-controlled model helicopter equipped with a sampling pump. Samples from a tethered blimp were also analyzed. 
Sampling at the full-scale Newfoundland burn was similar in design to that described for the mesoscale tests above except that more sophisticated and extensive techniques were generally applied both for sampling and the subsequent analysis.

\section{FINDINGS}

The quantitative analytical data clearly show that the emissions from in-situ oil fires are not a serious concern. All compounds and parameters measured are below health concern levels beyond about 150 metres from the fire. The fate and behaviour of oil components in fires, are still not fully understood and could be the subject of future experiments.

Several generalizations can be made about the fate, behaviour and quantity of the basic emissions from burning:

Gases - combustion gases are very diffuse and do not have spatial relationship to the plume. A good model is to view gas dispersal as following a doughnut-like pattern around the burn. This pattern is deformed by increasing wind velocities. Generally gas concentrations downwind are very low. Gas concentrations, especially in low winds can be as high around the fire as downwind.

Particulate Matter/Soot - Particulate matter at ground level is only a matter of concern very close to the fire and under the plume. The concentration of particulates in the smoke plume may not be a concern past about 500 metres. The level of respirable particulates, those which have a size less than $10 \mu$, is poorly understood. These may be carried away in the vestiges of the smoke plume. Measurements at ground level do not detect respirable particles.

Water Emissions - No compounds have yet been detected in the water of the test tanks. The aquatic toxicity of the water under a burn is either not measurable or not extant.

Organic Compounds - No exotic or highly-toxic compounds are generated as a result of the combustion process. Organic macro-molecules are in lesser concentration in the smoke and downwind than they are in the oil itself. Volatile organic compounds are released in large concentration by fires, but in lesser concentrations than the evaporating slick if not burning.

Residue - The residue is generally lighter than water. Density appears to relate to efficiency. If a burn is highly efficient ( $>99.9 \%$ ), then the residue may be neutrally buoyant. The residue resembles high-weathered oil, measurements showed this to be about 40 to $50 \%$ weathered (\%weight loss). The residue contains a lower amount of PAHs than the starting oil, although proportionately high amounts of multi-ringed PAHs are present. Metals are concentrated in the residue.

The following are conclusions relating to specific compounds or specific groups: 


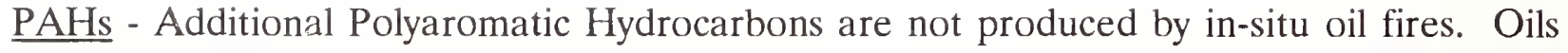
contain significant quantities of PAHs. These are largely destroyed in combustion. The $\mathrm{PAH}$ concentrations in the smoke, both in the plume and the particulate precipitation at ground level are much less than the starting oil. This also includes the concentration of multi-ringed PAHs that are often created in other combustion processes such as lowtemperature incinerators and diesel engines. This finding is very different from that noted in earlier lab experiments. It is suspected that re-precipitation of large soot particles occurs in large-scale tests which does not occur in laboratory tests. These large soot particles are conducive to the accumulation of large multi-ringed PAHs. The burn residue does, however, show a slight increase in the concentration of multi-ringed PAHs. However, when considering the mass balance of the burn, most of the five and six-ringed PAHs is destroyed by the fire.

A comparison of the mass of PAHs in the starting oil, residues and soot at downwind points is shown in Figure 1. This figure is based on the use of average PAH values from the 1992 Mobile tests. Soot percent is taken as $0.7 \%$ which is the average of several series of lab scale tests by several workers. These figures clearly show that the PAH's are largely consumed by the fire. Furthermore, there is net loss of even the larger PAHs in the smoke. Only in the residue is there an increase in the amount of 5 and 6 ring PAHs by a factor of two. This figure shows that the mass of PAHs is actually reduced by about 6 orders-ofmagnitude using combustion. This is true for all PAHs including the larger or multi-ringed compounds.

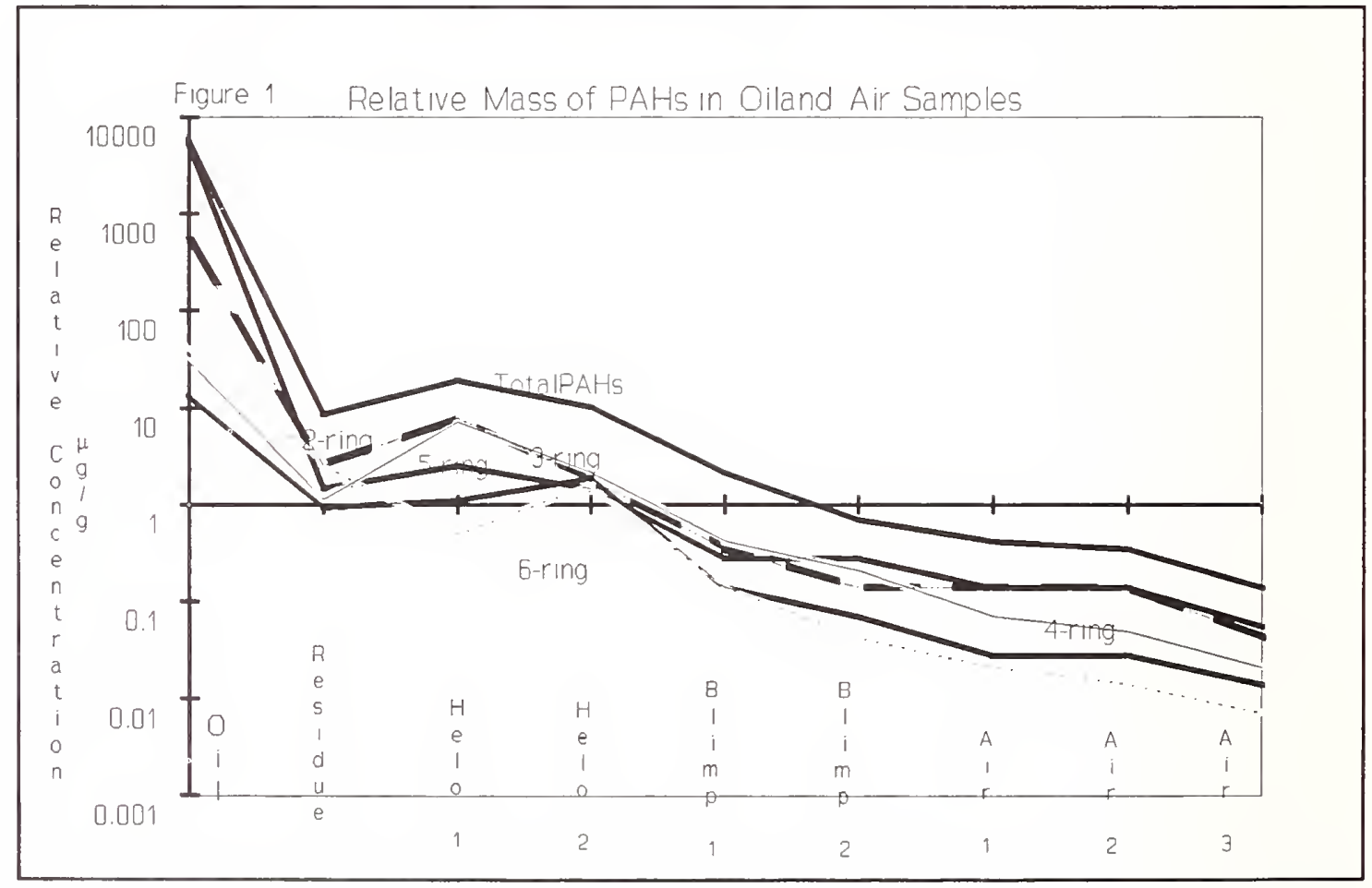

Dioxins and Dibenzofurans - Analysis for dioxins and dibenzofurans on particulate matter 
both upwind and downwind of the fires show that these compounds are not produced during in-situ fires. Levels of all samples taken are at background levels.

Metals - Crude oil contains several metals in the ppm range. These metals could not be detected on soot particles using the analytical techniques described here. The burn residue has an elevated metal content - leading to the conclusion that the metals largely remain in the residue. More sensitive analytical techniques were used in recent burn tests, however results are still not available.

Carbon Dioxide - The Carbon Dioxide concentration is well below concern levels - even near the fire. The distribution of the gas is very widespread, especially with low wind conditions. Carbon dioxide is the only good indicator of the presence or absence of a fire. It rises quickly near the fire (all around if winds are low) and then falls after the fire is out.

Carbon Monoxide - Very little Carbon Monoxide is produced by large-scale fires. These concentrations are well below concern levels and are generally at the lower detection levels of most instruments.

Sulphur Dioxide - The concentration of Sulphur Dioxide is far below what is expected from the sulphur content of the oil. This is probably due to the wide dispersal of the gas during the combustion process. Again the levels are just at or below the detection level of most instruments.

Nitrous Oxides - Tests for Nitric Oxides were performed; however, no levels above the background were detected.

Volatile Organic Compounds - The levels of volatile organic compounds are well above concern levels within 200 metres of these size of fires. The levels of these compounds are even greater from an evaporating slick that is not burning.

Carbonyls - Formaldehyde and Acetaldehyde are produced in low concentrations. Their concentrations fall far below concern levels a short distance from the fire.

\section{REFERENCES}

1. Twardus, E.M., A Study To Evaluate The Combustibility and Other Physical and Chemical Properties of Aged Oils and Emulsions, Environment Canada Manuscript Report EE-5, Ottawa, Ontario, 1980.

2. Georghiou, P.E. and Sheppard, P.E., A Study of Mutagenicity of Residue Resulting From the Burning of Crude Oil, Environment Canada Manuscript Report EE-29, Ottawa, Ontario, 1982. 
3. Fingas, M.F. and Laroche, N., An Introduction To In-Situ Burning of Oil, Spill Technology Newsletter, Vol. 13, No. 2, pp. 1-12,1990.

4. Evans, D.D., Combustion of Oil Spills on Water, in: Technology Assessment and Research Program for Offshore Minerals Operations, OCS Study MMS 88-0057, Reston, Virginia, pp. 169-179, 1988.

5. Evans, D.D., Mulholland, G.W., Gross, D., Baum, H., and Saito, K., Environmental Effects of Oil Spill Combustion, in: Proceedings of the Tenth Annual Arctic Marine Oilspill Program Technical Seminar, Environment Canada, Ottawa, Ontario, pp. 91-130, 1987.

6. Evans, D.D., In-Situ Burning of Oil Spills, in: Alaska Arctic Offshore Oil Spill Response Technology Workshop Proceedings, Washington, D.C., pp. 47-55, 1988.

7. Evans, D.D., Mulholland, G.W., Lawson, J.R., Tennyson, E.J., Tebeau, P.A., Fingas, M.F., and J.R. Gould, Burning of Oil Spills, in: Proceedings of the 1991 Oil Spill Conference, American Petroleum Institute, Washington, DC., 1991.

8. Benner, B.A., Jr., Bryner, N.P., Wise, S.A., Mulholland, G.W., Evans, D.E., Fingas, M.F., and Li, K., Emissions of Polycyclic Aromatic Hydrocarbons From the Combustion of Crude Oil On Water, Spill Technology Newsletter, Vol 16(1), Environment Canada, Ottawa, Ontario, 1991.

9. Evans, D.D., Walton, W., Baum, H., Mulholland, G., Lawson, J., Koseki, H., and Ghoniem, A., Smoke Emission From Burning Crude Oil, in: Proceedings of the Fourteenth Annual Arctic Marine Oilspill Program Technical Seminar, Environment Canada, Ottawa, Ontario, pp 421-499, 1991.

10. Evans, D.D., Walton, W.D., Baum, H.R., Notarianni, K.A., Lawson, J.R., Tang, H.C., Keydel, K.R., Rehm, R.G., Madrzykowski, D., Zile, R.H., Koseki, H., and Tennyson, E.J., In-situ Burning of Oil Spills: Mesoscale Experiments, in: Proceedings of the Fifteenth Annual Arctic Marine Oilspill Program Technical Seminar, pp. 593-623, 1992.

11. Fingas, M.F., Li, K., Ackerman, F., Campagna, P.R., Turpin, R.D., Getty, S.J., Soleki, M.F., Trespalacios, M.J., Paré, J., Bissonnette, M.C., and Tennyson, E.J., Emissions From Mesoscale In-Situ Oil Fires: The Mobile 1991 and 1992 Test, in: Proceedings of The Sixteenth Arctic and Marine Oil Spill Program Technical Seminar, Environment Canada, Ottawa, Ontario, pp. 749-821, 1993. 


\title{
ENVIRONMENTAL AND HUMAN HEALTH CONCERNS RELATED TO IN SITU BURNING
}

\author{
D. Kennedy, N. Barnea, G. Shigenaka \\ National Oceanic and Atmospheric Administration \\ Seattle, WA 98115 USA
}

\section{SUMMARY}

The mechanics, chemistry, and operational feasibility of in-situ burning as a spill response technique have been studied over the last fifteen years, primarily in the laboratory and in mesoscale environments, although there have been some field tests, the most recent being the Newfoundland Offshore Burn Experiment (NOBE) in August 1993. Interest in in-situ burning as a spill response technique has continued to increase. This paper summarizes the current state of knowledge about the possible effects of in-situ burning on human health and the environment, and suggests areas for future research.

\section{INTRODUCTION}

The apparent environmental effects associated with in-situ burning may be less than those resulting from alternative response methods. For example, burning can rapidly remove a large volume of oil from the surface of the water, reducing the magnitude of subsequent environmental impacts of stranded oil. It has become clear that human health concerns represent one of the main impediments to using in-situ burning. Health considerations should thus be a high priority during contingency planning, experimental burn experiments, and during actual spill incidents. We need more human health-oriented studies that could be performed during mesoscale or full-scale test burns. Many experts (e.g., Booher, Ferek, Butler, Laursen, Hobbs, Allen) believe that the risk is relatively small, particularly when compared to health and safety risks associated with mechanical remediation. This assessment, coupled with the likelihood that the lighter fraction of a spill will evaporate unless burned and thus impose its own set of health concerns, suggests that the risk is worth considering.

\section{HUMAN HEALTH CONCERNS}

The possible health hazards of in-situ burning for response personnel conducting the burning will be different from those for the general public at a substantial distance away.

1. Response personnel working in close proximity to the burn may be exposed to levels of gases and particulates that may require the use of personal protective equipment. Training for burn personnel should include proper use of personal 
protective equipment which may be used to minimize inhalation of, and skin contact with combustion by-products. Exposure limits such as the Occupational Safety and Health Administration's Permissible Exposure Limits are applicable to this group of typically healthy adults.

2. The general public would be expected to include sensitive individuals (e.g., the very young or old, pregnant women, people with pulmonary or cardiovascular diseases, people with allergic sensitivities). This population's tolerance to exposures may be significantly lower than a healthy worker population. When the burning is conducted far enough from population centers and under normal weather conditions public exposure to combustion by-products is expected to be minimal. The National Ambient Air Quality Standards should be the main level of concern for the public at large.

For purposes of risk communication, it sometimes can be useful to compare the risk expected from in-situ burning to other more familiar risks. Based on the analysis of the Kuwait oil pool fires, a hypothetical in-situ burning of oil was compared to other combustion sources[1]. In this exercise, an oil combustion rate of 10,000 barrels/day ${ }^{1}$ was assumed. The amount of particulate material smaller than 3.5 micrometers $(\mu \mathrm{m})$ from such an in-situ burn would be comparable to that released from a 4.5 -acre slash burn; the amount of $\mathrm{CO}_{2}$ comparable to a two acre of slash burn; the amount of $\mathrm{CO}$ to a 0.2 acre of slash burn; the amount of $\mathrm{SO}_{2}$ would be similar to the emission of an average coal-fired power plant; and PAH emissions would be equivalent to the amount emitted from 12,000 wood stoves. While this is a considerable emission to the environment, it should be noted that the oil burned in the Kuwaiti oil fires was likely destined to be used as fuel. Most of this emission would have occurred regardless (although presumably in a more efficient manner and distributed over a larger area).

In general, humans are well adapted to living in dusty environments. Humans' ability to keep their respiratory systems clean and functioning properly has enabled them to survive times when the air was laden with airborne particulates from volcanic eruptions, massive forest fires, and dust carried by the wind. Over time, humans have developed an efficient mechanism to clear the respiratory system and prevent particulates from reaching the sensitive alveoli in the lungs.

However, recent studies have suggested that a higher level of respirable particulates are associated with higher daily mortaility[2]. These studies suggested that exposure to elevated leels of respirable paticulates in the air resulted in increased mortality and morbidity of individuals suffering from pulmonary, cardiovascular, or severe allergic diseases. These

For purposes of comparison: an estimated 6,000,000 barrels/day were burned at the height of the Kuwaiti oil fires, with the total burned estimated to be 1 billion barrels; and the Exxon Valdez spilled a total of 250,000 barrels of oil. 
studies resulted in increased public interest and awareness of this problem.

\section{SAFETY CONCERNS}

Burning large amounts of combustible liquids on the surface of the water presents some unique safety concerns for workers and response personnel. These include fire hazard, which requires that extreme care be taken that the fire be controlled at all times so that it will not harm the personnel or equipment managing the process. The ignition hazard requires particularly careful coordination of aircraft operations to ignite oil with gel or other aerial ignition methods. Weather and water conditions should also be kept in mind, and proper safety distances be kept at all times. In-situ burning at sea will involve several vessels, working in relatively close proximity to each other, perhaps at night, or in other poorvisibility conditions. Such conditions are hazardous by nature, and require great degree of practice, competence and coordination). Other hazards include personnel being exposed to extreme heat from the compounded effects of hot weather and fire, or extreme cold in places like Alaska. Working under time constraints may impair judgment or increase the tendency to attempt costly shortcuts. It is important that good and thorough training and strict safety guidelines be part of any in-situ burning operation.

\section{POTENTIAL ECOLOGICAL EFFECTS}

Potential ecological impacts of in-situ burning have not been extensively discussed or studied. As a result, the answer to this question is largely speculative and is based on documented physical effects observed in the laboratory and at limited test burns. Recently, the environmental effects of the Kuwait oil well fires have been proposed as a surrogate for assessing ecological and human health impacts of in-situ burning. However, investigations by NOAA chemists, among others, determined that the situation in Kuwait was qualitatively different from controlled burning of an oil spill at sea. In particular, the emissions from the Kuwaiti oil well fires included a large constituent of unburned crude oil. This unburned oil formed a substrate that profoundly influenced the chemical composition of the emissions and the nature of the physical interactions among airborne constituents[3]. In addition, the areal impact in Kuwait, where hundreds of wells were deliberately set ablaze, was much more extensive than would be expected for a controlled in-situ burn arising from a single spill incident. The surface area affected by in-situ burning is likely to be small relative to the total surface area and depth of a given body of water. This does not necessarily preclude adverse ecological impacts, particularly if rare or sensitive species are present. Organisms possibly affected by in-situ burning include those that use the uppermost layers of the water column, those that might come into contact with residual material, and possibly some bottom-dwelling plants and animals.

\section{Direct Temperature Effects}

Burning oil on the surface of the water could adversely affect those organisms at or near the 
interface between oil and water, although the area affected would presumably be relatively small.

The surface of the water represents the "surface microlayer," a unique ecological niche. The microlayer, variously defined but often considered to be the upper millimeter or less of the water surface, is a habitat for many sensitive life stages of marine organisms, including eggs and larval stages of fish and crustaceans, and reproductive stages of other plants and animals.

During an experimental combustion of crude oils on water, the water immediately below the oil was brought to a vigorous boil during the peak of the burn period[4]. However, observations during large-scale burns using towed containment boom did not indicate such an impact on surface waters[5]. It was suggested that, in these cases, the length of time the burning layer resides over a given water surface may be too brief to induce boiling because ambient temperature seawater is continually supplied below the oil layer as the boom is towed.

Static tests of burning (e.g., in tanks) would likely represent worst-case situations with respect to in-situ burn heating effects at the surface of the water. In an operational application, there would be a continuous exchange of water below the slick as the boomed burn material is towed over the surface. At the Mobile, Alabama mesoscale burn tests in 1992, researchers found that temperature did not increase in the static water layer at depths greater than $4 \mathrm{~cm}$ below the oil[6].

The ecological importance of the surface microlayer and the potential impacts to it from burning activities have been discussed in the different, but related, context of ocean incineration. The Office of Technology Assessment noted in an evaluation of the technique[7], "...given the intermittent nature of ocean incineration, the relatively small size of the affected area, and the high renewal rate of the surface microlayer resulting from new growth and replenishment from adjacent areas, the long-term net loss of biomass would probably be small or non-existent."

Despite the obvious differences between shipboard incineration of hazardous wastes and surface burning of spilled oil, the above rationale applies to in-situ burning. Accordingly, potential impacts to the ecologically important surface microlayer are, to some extent, offset by the presumably short-lived nature of the burn and its associated residual material.

\section{Toxicological Considerations: The 1993 In-Situ Burn Aquatic Toxicity Study}

This study looked at the potential toxicity effects on aquatic organisms exposed to materials in the water column that resulted from oil combustion[8]. Through bioassay testing of laboratory-generated burn samples in May and June 1993 and through full-scale, fieldgenerated burn samples taken in August 1993, the study compared the lethal and sublethal aquatic toxicity of water beneath unburned and burned crude oil collected in both laboratory 
and field conditions. The study also evaluated the aquatic toxicity of the burn residues remaining after the combustion of oil in laboratory and field experiments.

Small-sale burns were conducted in the laboratory to generate samples. Each burn unit consisted of an interior burn crucible surrounded by a water bath, supporting a burn of a 1centimeter thick oil layer within the 100 centimeter-square surface area of the crucible, and generating an one-liter water sample for testing. Inter-burn variability was determined by comparing water chemistry on replicated burns. Immediately after collection, each water sample was evaluated using five different toxicity tests, performed in triplicate. These included the echinoderm fertilization test, embryo test, and cytogenetic tests; the oyster larvae test, and the inland silverside acute toxicity test. This test battery addressed different types of effects on different species and life stages. It was recognized that water samples collected at the field burn trial in August would not be tested immediately due to transit time from the collection point to the test facility. Thus, an additional component of the lab study evaluated the effects of a 48-hour holding time on the toxicity and chemistry of the samples. Hydrocarbon chemistry was conducted on all samples at the time they were generated and at the beginning and end of toxicity testing.

When the actual field burn took place in Newfoundland in August 1993, a series of water and burn residue samples were collected for comparable biological testing. Problems were encountered with the water sampling apparatus during the field burns, but a usable set of samples were collected and shipped to a laboratory facility in Vancouver, B.C. for toxicity testing. Although the results are still being interpreted and a report is being prepared, preliminary data from both the lab trials and the Newfound field burn indicate that both burned and unburned oil on water result in slight increases in aquatic toxicity. However, there did not appear to be a significant toxicity difference between burning oil and not burning oil: no additional toxic effect was conferred by burning. Chemistry results from the lab and field tests both showed that very little oil-measured both as total petroleum hydrocarbons and as polynuclear aromatic hydrocarbons-could be found in the water samples themselves.

The preliminary results indicate that water column toxicity is not expected to be a major concern with the use of in-situ burning. If another field experiment is undertaken in the future, confirmation of the field results would be desirable due to the reduced water sample size that occurred in Newfoundland.

\section{POTENTIAL ENVIRONMENTAL TRADEOFFS}

As is the case with all response methods, the environmental tradeoffs associated with in-situ burning must be considered on a case-by-case basis and weighed with operational tradeoffs. In-situ burning can offer important advantages over other response methods in specific cases, and may not be advisable in others, depending on the overall mix of circumstances. 
- Burning may offer the only realistic means of removal that will reduce shoreline impacts in areas where containment and storage facilities may be overwhelmed by the sheer size of a spill, or in remote or inaccessible areas where other countermeasures are not practicable.

- If properly planned and implemented, in-situ burning may prevent or significantly reduce the extent of shoreline impacts, including exposure of sensitive natural, recreational, and commercial resources.

- Burning rapidly removes oil from the environment, particularly when compared to shoreline cleanup activities that may take months or even years.

- In-situ burning puts many less people directly at risk. Manual shoreline cleanup is one of the most hazardous jobs at a spill. Burning oil with a small, well-trained crew will hopefully minimize worker injury.

\section{Cons}

- The method, when employed in its simplest form, generates large quantities of highly visible smoke that may adversely affect human and other exposed populations downwind.

- Burn residues may sink, making it harder to recover the product and to prevent the potential exposure of benthic organisms.

- Plant and animal deaths and other adverse biological impacts may result from the localized temperature elevations at the sea surface.

- While these could be expected to occur over a relatively small area, in specific bodies of water at specific times of the year, affected populations may be large enough or important enough to represent reasons for not considering burning as a cleanup technique.

- The longer-term effects of burn residues on exposed populations of marine organisms have not been investigated. It is not known whether these materials would be significantly toxic in the long run.

- The burn must be carefully controlled in order to maintain worker safety.

\section{CONCLUSIONS AND REMAINING QUESTIONS}

This paper has briefly reviewed the environmental and human health concerns associated with burning oil in place. Yet, fundamental questions related to the physics, chemistry, and 
biology of burning remain unaddressed by research efforts. While researchers have explored many aspects in the laboratory or in medium-scale burns, these may not accurately reflect conditions expected to occur during a full-scale test or operational burn. Many questions on in-situ burning cannot be satisfactorily answered in reduced-scale settings because basic conditions are altered by changes in physical interactions attributable to scale. Some aspects, therefore, must necessarily be explored in the field, i.e., either during a spill of opportunity or during a dedicated test burn. However, past experiences with evaluations of other response techniques (e.g., dispersants) have clearly shown that attempting to conduct research during an actual incident is difficult and often ill-advised. Resources for conducting a proper experiment are rarely in place or available, and operational considerations of response and cleanup take precedence over research activities.

A procedurally oriented question arises: What information is necessary for setting pre-use approval guidelines? The time-critical nature of the decision to employ burning during a response suggests that having pre-approval conditions in place is highly desirable, if not mandatory. What information does the Regional Response Team or the On-Scene Coordinator need to decide whether in-situ burning should be used as a response tool? Based on available information about the method (e.g., observations on operational limitations and production of visible residues), RRTs and other decision-makers should be able to anticipate critical information needs that would determine whether the method is used, or even considered, in specific regions of the country. Identifying knowledge gaps can provide direction for research activity, both in the laboratory and in the field.

It is likely that current monitoring methods and protocols are not entirely adequate to answer many of the remaining questions on in-situ burning. Although recent mesoscale burns at Mobile, Alabama have provided important data on larger-scale oil combustion events, these still do not fully reflect operational burn conditions (the test burns have been conducted in a stationary 50 -foot by 50 -foot tank at a Coast Guard facility in Mobile Bay). Some attention should be directed to developing and refining appropriate methods for collecting information on environmental effects, including measuring plume exposure and evaluating toxicity resulting from burn activities. Operationally, monitoring protocols for both effectiveness and effects, should be developed and incorporated into contingency plans prior to an actual incident.

A number of other information needs exist, particularly from the perspective of ecological effects. Although physical processes related to in-situ burning have been described by such researchers as Fingas and Evans and their colleagues, additional information on fate and effects relevant to environmental toxicology would be valuable. For example, recent observations that residues from the burning of some products are prone to sinking indicates that further research is needed on the physical processes associated with burning. Although a number of studies have identified by-products of in-situ burning, the ecological significance of their introduction into the environment has not be adequately. Specifically, we need toxicity studies on burn residues (soot, dissolved fractions, and solid material) to help us evaluate environmental implications. In addition, because it is likely that the surface 
microlayer would be the zone of highest potential impact to marine organisms, chemical analyses of the microlayer before and after a burn incident would help to define potential exposure levels to marine life. 


\section{REFERENCES}

1. Allen, A. Presentation at Region IV Regional Response Team In-situ Burning Workshop, Orlando, Florida, November 16, 1992.

2. Pope, C.A., D.W. Deckery, X. Xu, F. E. Speizer, J.D. Spengler, and B.G. Ferris. Mortality Risks of Air Pollution: A Prospective Cohort Study. Department of Environmental Health, Harvard School of Public Health, Harvard Medical School, Boston, and Channing Laboratory, Brigham and Women's Hospital, Brigham Young University, Provo, Utah. (1993).

3. Henry, C., Louisiana State University Institute of Environmental Studies, Baton Rouge, personal communication, June 7, 1993.

4. Evans, D., W. Walton, H. Baum, R. Lawson, R. Rehm, R. Harris, A. Ghoniem, and J. Holland. Measurement of large scale oil spill burns. In: Proceedings of the Thirteenth Arctic and Marine Oil Spill Program Technical Seminar, June 6-8, 1990, Edmonton, Alberta, pp. 1-38. (1990)

5. Evans, D., National Institute for Standards and Technology, Gaithersburg, Maryland, personal communication, January 4, 1993.

6. Office of Technology Assessment. Ocean Incineration: Its Role in Managing Hazardous Waste. U.S. Government Printing Office, Washington, D.C. (1986)

7. Newfoundland Offshore Burn Experiment. NOBE FACTS Newsletter, Volume 3, May 1993. Environment Canada, Ottawa, Ontario. (1993).

8. Evans, D.D., W.D. Walton, H.R. Baum, K.A. Notarianni, J.R. Lawson, H.C. Tang, K.R. Keydel, R.G. Rehm, D. Madrzykowski, R.H. Zile, H. Koseki, and E.J. Tennyson. In-situ burning of oil spills: Mesoscale experiments. In: Proceedings of the Fifteenth Arctic and Marine Oil Spill Program Technical Seminar, June 1012, 1992, Edmonton, Alberta, pp. 593-657. (1992) 



\title{
THE OPERATIONAL IMPLICATIONS OF IN SITU BURNING
}

\author{
Peter A. Tebeau \\ Marine Environmental Consultant \\ 158 Wyassup Road \\ North Stonington, CT 06359
}

\section{SUMMARY}

In-situ burning has been considered as an oil spill response technique ever since the TORREY CANYON spill in 1967. In many cases, in-situ burning became an effective de facto response technique for removing spilled oil from the water through accidental explosion and ignition at the source (BURMA AGATE spill, MEGA BORG spill and others). Over the past two decades, much effort has been devoted to perfecting the equipment and methodology employed with this spill technique, and researching the potential environmental impacts associated with its use. At present, it is generally recognized as the most promising countermeasure for dealing with large spills offshore, where the volume of oil and logistics of operating offshore, decrease the effectiveness of other options (dispersants and mechanical recovery). Much of the recent discussion and literature on insitu burning deals with the environmental impacts of the technique. This discussion will focus on the operational issues involved in choosing and implementing in-situ burning as a technique; specifically the feasibility of the technology under various conditions, the requirements for deploying and supporting the technology in the field, the health and safety issues involved on-scene and in the vicinity of the operation, and the cost effectiveness of in-situ burning compared to other options. Operational advantages and disadvantages are summarized.

\section{SELECTION AND IMPLEMENTATION OF IN SITU BURNING}

In-situ burning is a relatively straightforward spill response technique with respect to technology and execution. A concise overview of the technique and environmental implications is given by Fingas and Larouche [1]. A thorough discussion of the operational procedures and issues is provided by Allen and Ferek [2]. Summaries of recent research and development efforts in in-situ burning are provided by Walton et al. [3], Bech, Sveum and Buist [4], and Fingas et. al. [5]. The list of references for these five papers provides an excellent sampling of the extensive literature that exists on the topic.

As with any oil spill response technique, effective cleanup requires the selection of an appropriate technique at the strategic level, followed by effective management of its implementation on the tactical level. Strategic selection involves weighing the technical and logistical feasibility of the technique applied to the present and anticipated spill conditions, against the net environmental benefit that may be accrued. Once chosen, the technique should be implemented and managed weighing the level of effort expended against the environmental damage prevented or mitigated. Thus at both strategic and tactical levels, operational and environmental considerations must be balanced.

Operational considerations include determining if the technique is feasible, deployable and supportable, safe, and cost effective Figure (1) depicts the overall decision process, and the supporting data requirements, for making these determinations in a specific spill scenario. The technique is feasible if the technology and its implementation are suited to the spill conditions (oil type, slick thickness, weather, sea state). Allen [6] provides a comprehensive treatment of the 
feasibility of various oil spill response options for offshore spill. The technique is deployable and supportable if necessary equipment and personnel can arrive on-scene in time to implement the technique successfully, and maintain operations over time so that a reasonable quantity of oil is recovered or removed film the surface of the ocean. The technique is safe if its implementation does not pose an immediate risk to response personnel; nearby vessels, facilities, or populations; or sensitive environmental resources. Finally, the technique is cost effective if the costs are reasonable compared to other options, and if the cost is justifiable based on the net environmental benefit realized.

\section{TECHNICAL FEASIBILITY}

The technical feasibility of in-situ burning depends largely on the particular spill scenario including the general nature of the spill, the location of the spill, the condition of the oil both initially and over time, and weather and sea conditions on-scene. The overall nature of the spill relates to whether the source is moving or stationary, whether the spill is instantaneous or steady-state, and whether the volume or flow rate is large or small. Ideally, in-situ burn operations are best suited to a stationary source, where the oil is spilling at a steady flow rate that can be handled by the equipment available.

The location of the spill can be offshore in open water, inshore in protected water, on solid ice, in broken ice, or on the shoreline. Each location can affect feasibility in different ways. For instance, offshore locations lessen health and safety concerns, but require containment of the slick and generally involve more severe wind and wave conditions. Inshore wind and wave conditions may be more favorable, but burning may be prohibited because of nearby populations. Ice can provide for natural containment of the oil; however, ice can also hamper access to the spill and complicate logistics.

The oil characteristics and slick thickness are of primary importance in determining burnability. Although most oil types are burnable initially, more effort may be required to ignite thicker, less volatile oils. Slick thickness is critical with a 2 to $3 \mathrm{~mm}$ thickness required to support combustion. The oil is most effectively burned when the oil is relatively flesh (1 to 2 days old [2]). As weathering proceeds (evaporation and emulsification), the oil may become more difficult to ignite. Emulsification is particularly important as some oils emulsify quickly. Tests and field experience indicate that slicks with a water-in-oil content of $20-30 \%$ are still readily ignitable. As water-in-oil content approaches $50 \%$, the spill becomes difficult to ignite, and may be impossible to ignite at $50-70 \%$ [1,2].

Closely related to the slick characteristics are the wind and wave conditions. Wind and waves can emulsify or disperse the oil and preclude burning as an option. In the offshore environment, winds in excess of 15-20 knots and seas in excess of 2-3 feet may prevent effective containment of the oil to achieve the 2-3 mm thickness, or extinguish the fire after ignition occurs. Strong currents in the area may complicate containment of the spill depending on the speed and orientation of the current with respect to the sources.

All of the above factors dictate a relatively narrow "window of opportunity" for initiating and carrying out in-situ burn operations. The operational window for in-situ burning relative to other response options is discussed in detail by Allen [6]. In order to catch this window of opportunity, pre-planning is essential with decision processes defined and checklists prepared in advance. This pre-planning is currently underway in Alaska and the Gulf of Mexico (RRT Region VI), where guidelines and 


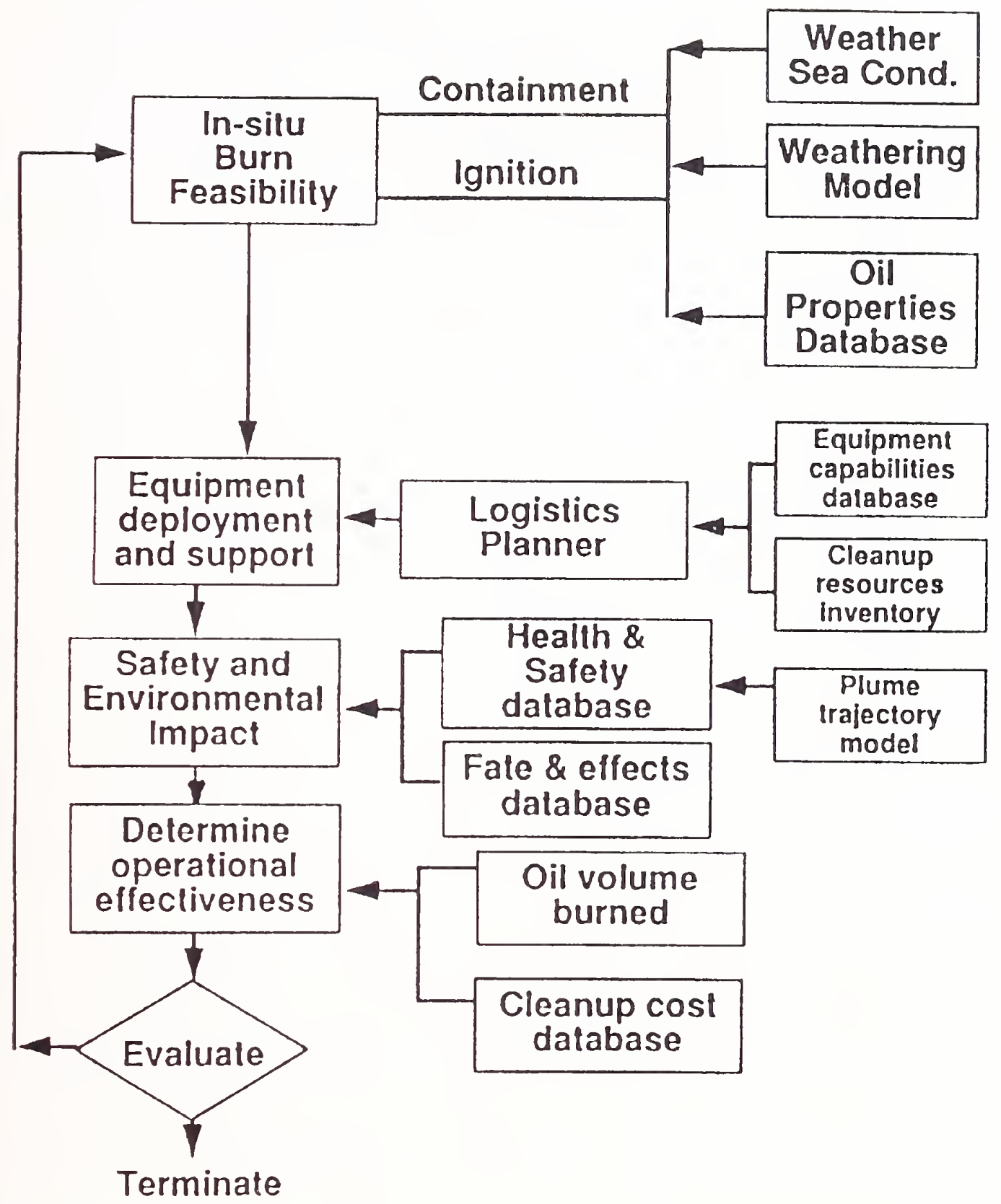

Figure 1. Decision Diagram for the Selection and Operational Management of In-Situ Burning

checklists have been completed. In addition to pre-planning, pre-approval by area can greatly expedite the in-situ burn decision and implementation process. Wherever possible, "Burn Feasibility Areas" should be pre-designated as part of contingency planning by Regional Response Teams. 


\section{DEPLOYMENT AND LOGISTIC SUPPORT FOR IN-SITU BURNING}

Given that in-situ burning is generically applicable to a particular spill scenario, it will often be the deployment and support requirements for that scenario that determine overall effectiveness of the operation. Spills that occur some distance offshore or in remote areas may prevent transport and support of equipment and personnel, unless equipment is pre-staged and logistics are well-planned in advance. Again, this is particularly critical for in-situ burning due to the limited window of opportunity.

For many in-situ burn operations, operational response will proceed in two stages: an initial response to assess the practicality of in-situ burning and begin a limited cleanup operation, followed by an extended response over time to continue the in-situ burn operation, and coordinate it with other cleanup techniques.

For the initial response in an open water environment, the equipment and personnel requirements are moderate. One or more containment and burning units are dispatched to the scene, each consisting of a section of fire resistant boom (300-500 ft. minimum), towed in a U-configuration by two towing-vessels (typically 30-40 ft., twin prop, capable of maintaining 1/2 knot tow speed). An ignition capability is provided by surface igniters, drifted back into the contained slick from the tow vessels or deployed into the slick from a helicopter; or by a Heli-torch suspended from a helicopter which can ignite a larger area, quickly and efficiently, by dispensing gelled fuel into the slick. A spotter aircraft is employed to direct the units through and away from the slick, and conduct overall reconnaissance from the air. If a helo is used for the ignition process, it can effectively serve as the spotter. Of course trained personnel are essential, with the appropriate personal protection and monitoring equipment on hand.

Allen and Ferek [2] have estimated that one such unit, operating continuously, can eliminate 15,000 barrels per day. Such an operation would be possible with a stationary constant source of similar spill rate. Three such units, operating one at a time in a collection-relocation-and-burn mode, could eliminate 8,000 barrels in a 12 hour period. Such would be the case in attacking a large slick. If 24 hour a day operations were feasible, the amount would be doubled.

For larger spills requiring extended responses, additional response platforms, equipment, and personnel would be required. As the number of units increased, and other countermeasures and cleanup activities proceeded; command, control, and communications capabilities would have to be augmented. A command vessel and additional aircraft might be deployed to the scene. In addition, logistics and personnel support vessels would be required to maintain the operation. Additional fireproof boom would be required to replace boom degraded by combustion to where it was no longer serviceable. Backup mechanical recovery equipment and temporary storage capability would be needed to collect and remove burn residue, and to the extent possible, oil that cannot be burned.

\section{HEALTH AND SAFETY DURING IN-SITU BURNING}

The health and safety issues associated with in-situ burning include the safety of vessels, facilities, populations and resources in the surrounding area; safety for the spilling vessel or platform; and safety for personnel on-scene. The safety to the surrounding area will be largely dictated by the location of the spill and proximity to shipping lanes, other oil production platforms, industrial and population centers, sensitive populations (children, elderly, people with respiratory problems), and sensitive natural resources (National Parks, Wildlife Refuges, endangered species). Proximity to these areas must be considered but may not preclude in-situ burning based on the size of the burn, plume 
trajectory, ambient air quality standards, and the risk associated with not burning.

Safety of the spilling platform will be ensured by maintaining a safe distance between the in-situ burn operation and vessel or platform as dictated by the volatility of the product, wind and current speed and direction, and slick continuity. A backup contingency plan and fire fighting equipment may be needed for some situations.

The safety of on-scene personnel can be ensured by maintaining a safe distance from the fire to prevent flame radiation hazard, remaining away from the smoke plume and fallout, and wearing proper clothing and respirators. On-scene ambient conditions should be monitored to detect explosion hazards and monitor airborne emissions from the burn and the oil itself. Follow-up medical monitoring should be considered for extended response operations. Above all, as with any response technique, appropriate health and safety training is essential.

\section{COST EFFECTIVENESS CONSIDERATIONS FOR IN-SITU BURNING}

There are two types of costs to be considered in determining the cost effectiveness of an oil spill response technique. The first is the generic cost which is the "average cost" of implementing a particular response technique. The second is the spill specific cost which is the overall cost of applying the technique at a specific spill. Depending on the spill conditions, the overall cost can be lower, or often much higher than the anticipated generic cost.

Allen and Ferek [2] present a comparison of overall cleanup costs for mechanical recovery, dispersants, and burning. The costs are generic in the sense that they are based on the recovery or elimination of a 8,000 to 10,000 barrel oil volume over 12 hours without reference to oil type or specific spill conditions (slick area, sea conditions, logistics, etc.). Assumptions are made concerning available equipment, recovery efficiency (33\%-67\%), throughput efficiency (50\%-80\%), dispersant efficiency (50\%-70\%), and burn efficiency (95\%). Using these performance characteristics, approximate costs were calculated for all vessels, aircraft, equipment, etc. for each response technique in removing or controlling the 8,000-10,000 barrel volume in the 12 hour period. Included in the estimates were the costs to dispose of mechanically recovered oil/water, current costs to purchase and transport chemical dispersant, and costs of replacing fire containment boom. Based on these calculations, Allen and Ferek report the following generic costs:

Mechanical: $\quad \$ 100$ to $\$ 150$ per barrel of oil recovered \& disposed

Dispersants: $\quad \$ 50$ to $\$ 100$ per barrel of oil dispersed

In-Situ Burning: $\quad \$ 20$ to $\$ 50$ per barrel of oil burned

These costs are constrained by the specific assumptions and will vary with each spill. However, they do highlight the generally accepted cost effectiveness of in-situ burning as compared to the other two techniques. Again the actual costs of carrying out in-situ burn operations on a specific spill may depart significantly from the $\$ 20$ to $\$ 50$ range depending on the remoteness of the site, the spreading of the slick and the effort required to collect burnable volumes, whether natural containment (such as in broken ice) is available, etc. If the technique is used on the shoreline, additional restoration costs may be involved. 


\section{OPERATIONAL ADVANTAGES AND DISADVANTAGES OF BURNING}

The primary operational advantages of in-situ burning can be summarized as follows. The technique is highly effective under favorable conditions allowing the quick removal of significant volumes of oil from the water's surface. It is logistically simple compared to mechanical recovery in that it does not require temporary storage and disposal of the oil after cleanup; and logistically simple compared to dispersants which require large volumes of chemical, and multiple aircraft and vessels for treating a comparable volume of oil. The technique is generically more cost effective than other techniques in recovering/eliminating the same volume of oil. Based on these advantages, in-situ is generally considered the most promising countermeasure for major and catastrophic spills at sea.

There are several significant constraints to be considered as well. Most importantly, the window of opportunity for in-situ burning is limited requiring rapid determination of spill conditions, and immediate deployment and implementation if in-situ burning is chosen as a response option. Fire resistant booms are expensive compared to conventional containment boom. Although fire resistant booms are currently available on the market, they have only been subjected to limited experimental and operational use, and hence the actual replacement rate under various spill conditions is not fully known. Perhaps the greatest uncertainty with in-situ burning stems from its limited use to date under actual spill conditions. However, as research and training in in-situ burn operations continues, and as Regional Response Teams incorporate in-situ burning into their pre-planning and pre-approval process, the technique is becoming generally accepted as a primary response option.

\section{REFERENCES}

1. Fingas, M. and N. Larouche, "An Introduction to In-Situ Burning of Oil Spills", Environment Canada, Spill Technology Newsletter, Vol. 15(4), (December 1990).

2. Allen, A.A. and R.J. Ferek, 1993, "Advantages and Disadvantages of Burning Spilled Oil", Proceedings of the 1993 International Oil Spill Conference, Tampa, Florida, March 29 - April 1, (1993).

3. Walton, W.D., D.D. Evans, K.B. McGrattan, H.R. Baum, W.H. Twilley, D. Madrzykowski, A.D. Putorti, R.G. Rehm, H. Koseki and E.J. Tennyson, "In-Situ Burning of Oil Spills: Mesoscale Experiments and Analysis", Proceedings of the 16th Annual AMOP Technical Seminar, Calgary, Alberta, June 7-9, (1993).

4. Bech C., P. Sveum and I. Buist, "The Effects of Wind, Ice and Waves on the In-Situ Burning of Emulsions and Aged Oils", Proceedings of the 16th Annual AMOP Technical Seminar, Calgary, Alberta, June 7-9, (1993).

5. Fingas, M.F., K. Li, F. Ackerman, J.R.J. Pare, M.C. Bissonnette, P.R. Campagna, R.D. Turpin, M.F. Soleki, S.J. Getty, M.J. Trespalacios, and E.J.Tennyson, "Emissions from Mesosale In-Situ Oil Fires: The Mobile 1991 and 1992 Tests", Proceedings of the 16th Annual AMOP Technical Seminar, Calgary, Alberta, June 7-9, (1993).

6. Allen, A.A., 1988, "Comparison of Response Options for Offshore Oil Spills", Proceedings of the 11th Annual AMOP Technical Seminar, Vancouver, British Columbia, June 7-9, (1988). 


\section{THE NEWFOUNDLAND OFFSHORE BURN EXPERIMENT - NOBE}

Merv F. Fingas ${ }^{1}, \mathrm{Ken} \mathrm{Li}^{1}$, Francine Ackerman ${ }^{1}$, Martine C. Bissonnette ${ }^{1}$, Patrick Lambert ${ }^{1}$, Robert Nelson ${ }^{1}$, Greg Halley ${ }^{1}$, Philip R. Campagna ${ }^{2}$, Nanci Laroche ${ }^{1}$, Paula Jokuty ${ }^{1}$, Rodney D. Turpin ${ }^{2}$, Miguel J. Trespalacios ${ }^{3}$, J. Belanger ${ }^{1}$, Nick Vanderkooy ${ }^{4}$, Edward J. Tennyson ${ }^{5}$, Don Aurand ${ }^{6}$ and Robert Hiltrabrand ${ }^{7}$

\section{SUMMARY}

A group of over 25 agencies from Canada and the United States conducted a major offshore burn near Newfoundland, Canada. Two lots of oil, about 50 tons each, were released into a fire-proof boom. Each burn lasted over an hour and was monitored for emissions and physical parameters. Over 200 sensors or samplers were employed to yield data on over 2000 parameters or substances. The experiment was the largest of its type ever conducted. The operation was extensive, over 20 vessels, 7 aircraft and 230 people were involved in the atsea operation.

The quantitative analytical data show that the emissions from this in-situ oil fire were less than expected. All compounds and parameters measured are below health concern levels beyond about 150 metres from the fire, very little was detected beyond 500 metres. The fate and behaviour of oil components in fires, are still not fully understood and could be the subject of future experiments. Pollutants were found to be at lower values in the Newfoundland Offshore burn than they were in previous pan tests. The reasons for this are not fully understood, but the offshore test appears to have resulted in more efficient combustion.

Polyaromatic hydrocarbons (PAH) were found to be lower in the soot than in the starting oil and were consumed by the fire to a large degree. Particulates in the air were measured by several means and found to be of concern only up to 150 metres downwind at sea level. Particulate matter may not be a concern past this distance except perhaps in the plume remnants. Combustion gases including carbon dioxide, sulphur dioxide and carbon monoxide did not reach levels of concern. These gases are emitted over a broad area around the fire and are not directly associated with the plume trajectory. Volatile organic compounds (VOCs) were abundant, however were less than emitted from the non-burning spill. Over 50 compounds were quantified, several at levels of concern up to 150 metres downwind.

1 Emergencies Science Division, River Road Environmental Technology Centre, Environment Canada, Ottawa, Ontario.

2 Environmental Response Team, Environmental Protection Agency, Edison, New Jersey

3 Roy F. Weston/REAC, Edison, New Jersey

4 Canmar/Amoco Canada, Calgary, Alberta

5 Minerals Management Service, Herndon, Virginia

6 Marine Spill Response Corporation, Washington, D.C.

7 United States Coast Guard, Groton, Connecticut 
Water under the burns was analyzed; no compounds of concern could be found at the detection level of the methods employed. Toxicity tests performed on this water did not show any adverse effect. The burn residue was analyzed for the same compounds as the air samples. PAHs were found at lower concentrations in the residue than in the starting oil. The overall mass of PAHs including that of the higher-molecular-weight species, was about 6 orders-of-magnitude lower after the burn. Overall, indications from these burn trials are that emissions from in-situ burning are low in comparison to other sources of emissions and result in acceptable concentrations of air contaminants.

\section{OPERATIONS}

The oil was released into a fire-resistant boom and burned in this location. Air emissions were monitored downwind using two remote-controlled boats, a research vessel and from an airplane. The plume itself was sampled by two remote-controlled helicopters and a blimp. Water samples were collected from the remote-controlled sampling boats, and air and water temperatures measured from the same vessels. The fire-resistant boom was equipped with thermocouples to monitor temperatures directly impacting it and those in the water directly underneath the fire. A submersible was deployed under the burning slick to monitor temperatures and take video footage. A small boat monitored and measured surface material that escaped and took samples of the burn residue after the burn.

The oil was released from a supply-type ship through a skimmer so that if there were some problem, the flow could be reversed and the oil recovered. A 700-foot section of boom was used. The amount of oil released in each spill was 50 cubic metres or about 10,000 Imperial gallons. This is about the lower limit of a typical boom capacity. Once sufficient oil was in the boom to sustain combustion, it was ignited using a Helitorch.

The fire-resistant boom used was a commercial version along with some experimental sections. The middle sections near the burn were equipped with a number of thermocouples to measure the temperature on the boom. The boom was backed up by another boom, an offshore type, about one kilometre down current. This second boom was loaded with sorbent to ensure that any sheen was recovered. The fire-resistant boom was towed by a major vessel and the opening was maintained by two vessels towing outward at an angle of approximately 45 degrees. Both of the tow vessels were equipped with current meters to ensure that they are able to maintain a forward speed of 0.5 knots.

Command and control operations took place from a major vessel of the Canadian Coast Guard, the ANN HARVEY. One helicopter was used both to ignite the slick and put out flares to guide the procession into the wind. Another helicopter was used to provide still and video footage of documentation. Two charter ships were engaged to bring out observers. They were also used as platforms for some of the documentation and air measurement. Several smaller boats were used for other sampling purposes and for controlling the remote sampling boats and a remote-underwater vessel. 


\section{OPERATIONAL RESULTS}

Burn one started after a second Helitorch run. Reports from the helicopters and both airplanes indicate the smoke plume bifurcated after about $2 \mathrm{~km}$ downwind. A small part remained with the inversion layer at about $0.5 \mathrm{~km}$ and the main portion split with one portion turning southeast and one turning east after rising about $2 \mathrm{~km}$. The pumping during burn 1 had to be stopped several times because the fire often spread back to the discharge point. The average discharge and burn rate for burn 1 was about $550 \mathrm{~L} / \mathrm{min}$. The fire-resistant boom was inspected after the first burn. Some signs of fatigue in the stainless steel core were observed at a point about $10 \mathrm{~cm}$ from the stiffeners. Some of the Nextel fire-resistant fabric was missing from these areas as well. The boom was fit for another burn, however.

The crews re-fit the equipment for the second burn which began in mid-afternoon. The first run of the Helitorch

Table 1 - Burn Summary Burn 1

Oil volume discharged $-48.3 \mathrm{~m}^{3}$

Burn and Pump time - 1.5 hours

Residue in fireproof boom -0.2

$\mathrm{m}^{3}$ (max.)

Residue in backup boom -0.2

$\mathrm{m}^{3}$ (max.)

Efficiency - >99\%

Burn 2

Oil volume discharged $-28.9 \mathrm{~m}^{3}$

Burn and Pump time - 1.3 hours ignited the oil. Some oil was again splashed over, however, unlike the first burn no sheening whatsoever was observed. The oil outside of the boom burned completely leaving only small patches of residue which drifted back into the secondary recovery boom. The wind was 8 to $11 \mathrm{~km} / \mathrm{hr}$ and this resulted in an approximate 45 degree angle for the plume. This burn was characterized by its "classical", regular plume behaviour. The plume did, however, bifurcate about $2 \mathrm{~km}$ downwind, similar to the previous plume.

The pump rate for this burn was adjusted to $560 \mathrm{~L} / \mathrm{min}$ to match the burn rate. Pumping was stopped after $11 / 4$ hours of burn time when some small pieces of the fire-resistant boom were released. The duration had already exceeded planned sampling times and most samplers had already been stopped.

The fire-resistant boom was again inspected for damage and it was found that a prototype section with a middle tension member had lost 3 of its float logs. Inspection of this section at the factory showed that the section had not been properly constructed. The apex of the boom was still holding oil. The boom was in generally good condition, but one would not have used the apex for another burn.

\section{SAMPLING}

Sampling methodologies and target emissions are summarized in Table 2. Detailed methods are described in the literature. 


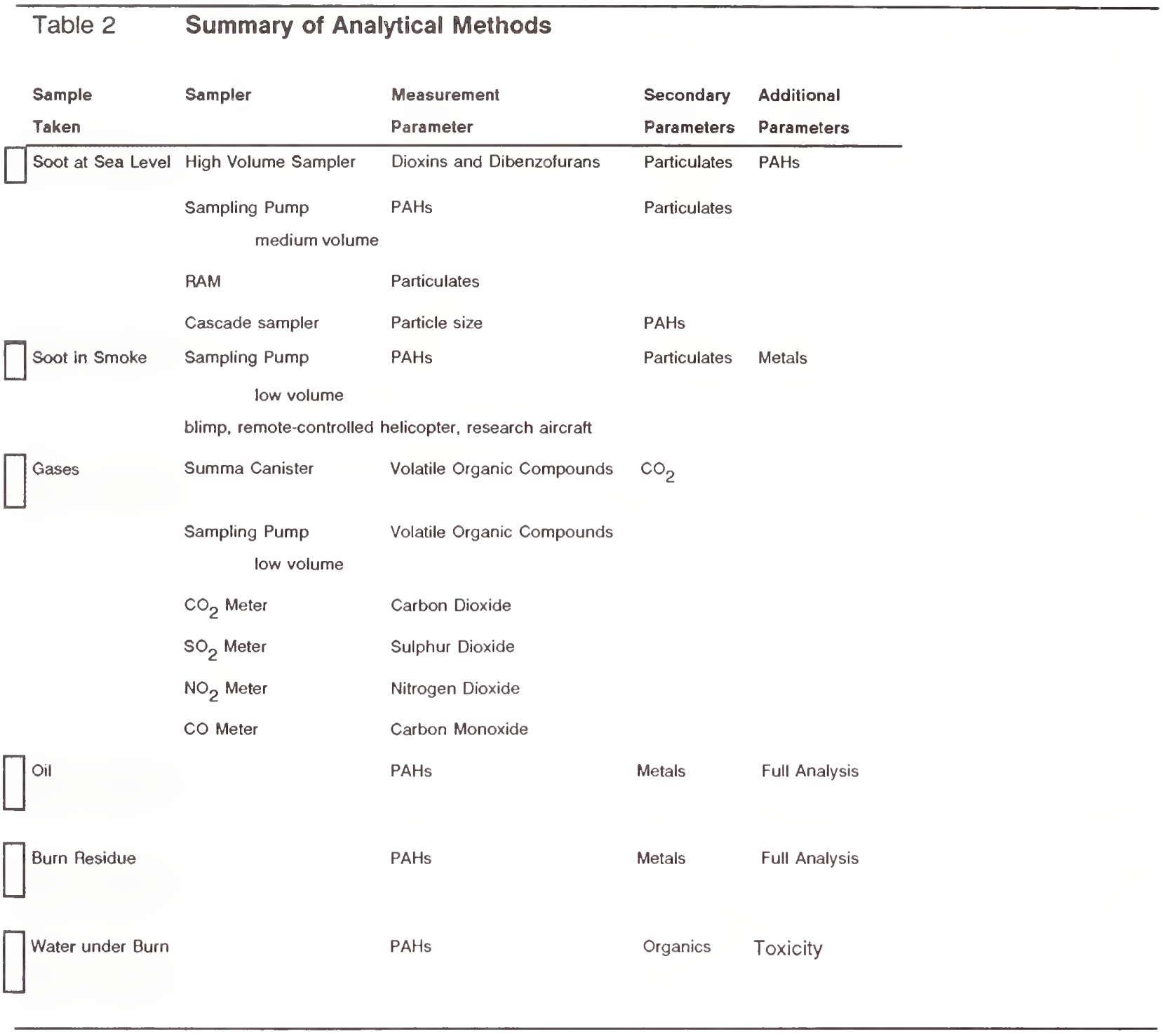

\section{FINDINGS}

\section{Fire Temperature}

Temperatures were recorded at several points on the fire boom. Eight sections were monitored with thermocouples at four locations in the vertical plane. Figure 1 shows a typical output. This shows that the temperature at the top of the fire boom often reached $1000^{\circ} \mathrm{C}$ and the temperatures below were substantially lower. Thermocouple probes known to be in the water show no increase in water temperatures. 


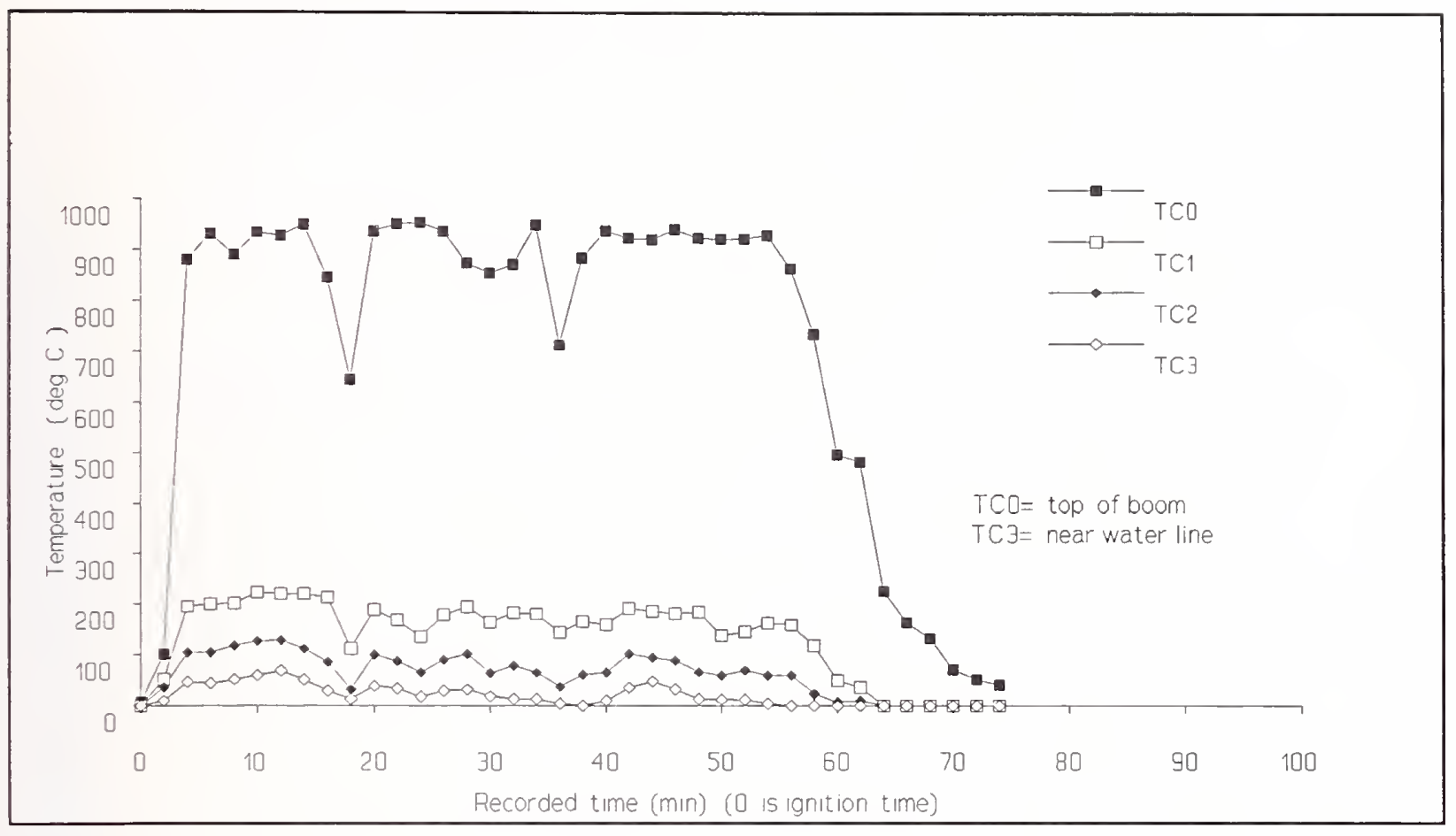

Figure 1 Temperatures Recorded on Fireboom Near Apex

Oil Analysis

The oil was analyzed for physical properties. Table 3 shows the results. The most interesting result is that the residue appears to be an oil with an evaporative loss of about $45 \%$ by weight. 
Table 3 Physical Analysis of NOBE Oil/Residue Samples

\begin{tabular}{||c|c|c||}
\hline & & \\
\hline Weathering Percentage & 0.04 & $40-48 \%$ \\
\hline Density & $0.8437 \mathrm{~g} / \mathrm{mL}\left(15^{\circ} \mathrm{C}\right)$ & $0.9365 \mathrm{~g} / \mathrm{mL}\left(15^{\circ} \mathrm{C}\right)$ \\
\hline Viscosity & $\begin{array}{c}11 \mathrm{cP}\left(15^{\circ} \mathrm{C}\right)\left(\text { shear rate } 500 \mathrm{~s}^{-1}\right) \\
\text { Newtonian visc. }\end{array}$ & $\begin{array}{c}130500 \mathrm{cP}\left(15^{\circ} \mathrm{C}\right) \text { (shear rate } \\
\left.1 \mathrm{~s}^{-1}\right) \\
\text { non-Newtonian visc. }\end{array}$ \\
\hline Pour Point & $-21^{\circ} \mathrm{C}$ & $34^{\circ} \mathrm{C}$ \\
\hline Interfacial Tension & 21.4 dynes $/ \mathrm{cm}\left(15^{\circ} \mathrm{C}\right)($ air $/ \mathrm{oil})$ & Not measurable at $15^{\circ} \mathrm{C}$ \\
\cline { 2 - 4 } & 13.3 dynes $/ \mathrm{cm}\left(15^{\circ} \mathrm{C}\right)(\mathrm{oil} / \mathrm{sea})$ & Not measurable at $15^{\circ} \mathrm{C}$ \\
\hline Emulsion Formation (f $\left.\mathrm{f}_{\mathrm{i}}\right)$ and & $\mathrm{f}_{\mathrm{i}}=0\left(15^{\circ} \mathrm{C}\right) \quad \mathrm{f}_{\mathrm{f}}=0\left(15^{\circ} \mathrm{C}\right)$ & $\mathrm{f}_{\mathrm{i}}=0\left(15^{\circ} \mathrm{C}\right) \quad \mathrm{f}_{\mathrm{f}}=0\left(15^{\circ} \mathrm{C}\right)$ \\
\hline Asphaltene Content & $0.7 \mathrm{wt} \%$ & $2.3 \mathrm{wt} \%$ \\
\hline Wax Content & $10.1 \mathrm{wt} \%$ & $13.8 \mathrm{wt} \%$ \\
\hline Flash Point & $-13^{\circ} \mathrm{C}$ & $>90^{\circ} \mathrm{C}$ \\
\hline Water Content & $0.54 \mathrm{wt} \%$ & $14.01 \mathrm{wt} \%$ \\
\hline Sulphur Content & $0.15 \mathrm{wt} \%$ & $0.40 \%$ \\
\hline
\end{tabular}

Polyaromatic Hydrocarbons (PAHs)

A comparison of the mass of PAHs in the starting oil, residues and soot at downwind points has been done. This comparison shows that the PAH's are largely consumed by the fire. The amounts of PAHs detected at the Newfoundland burn are a fraction of that detected in previous burn trials. This may be indicative of a more efficient burn.

\section{Combustion Gases}

Tests were made for a number of gases, but $\mathrm{CO}, \mathrm{SO}_{2}$ and $\mathrm{NO}_{\mathrm{X}}$ are not above the lower detection level. Carbon Dioxide is clearly measured around the burn and is illustrated in Figure 2. The levels of volatile organic compounds are well above concern levels within 150 metres of the fire. The levels of these compounds are even greater from an evaporating slick that is not burning. Carbonyls such as Formaldehyde and Acetaldehyde are produced in low concentrations. Their concentrations fall far below concern levels a short distance from the fire. 


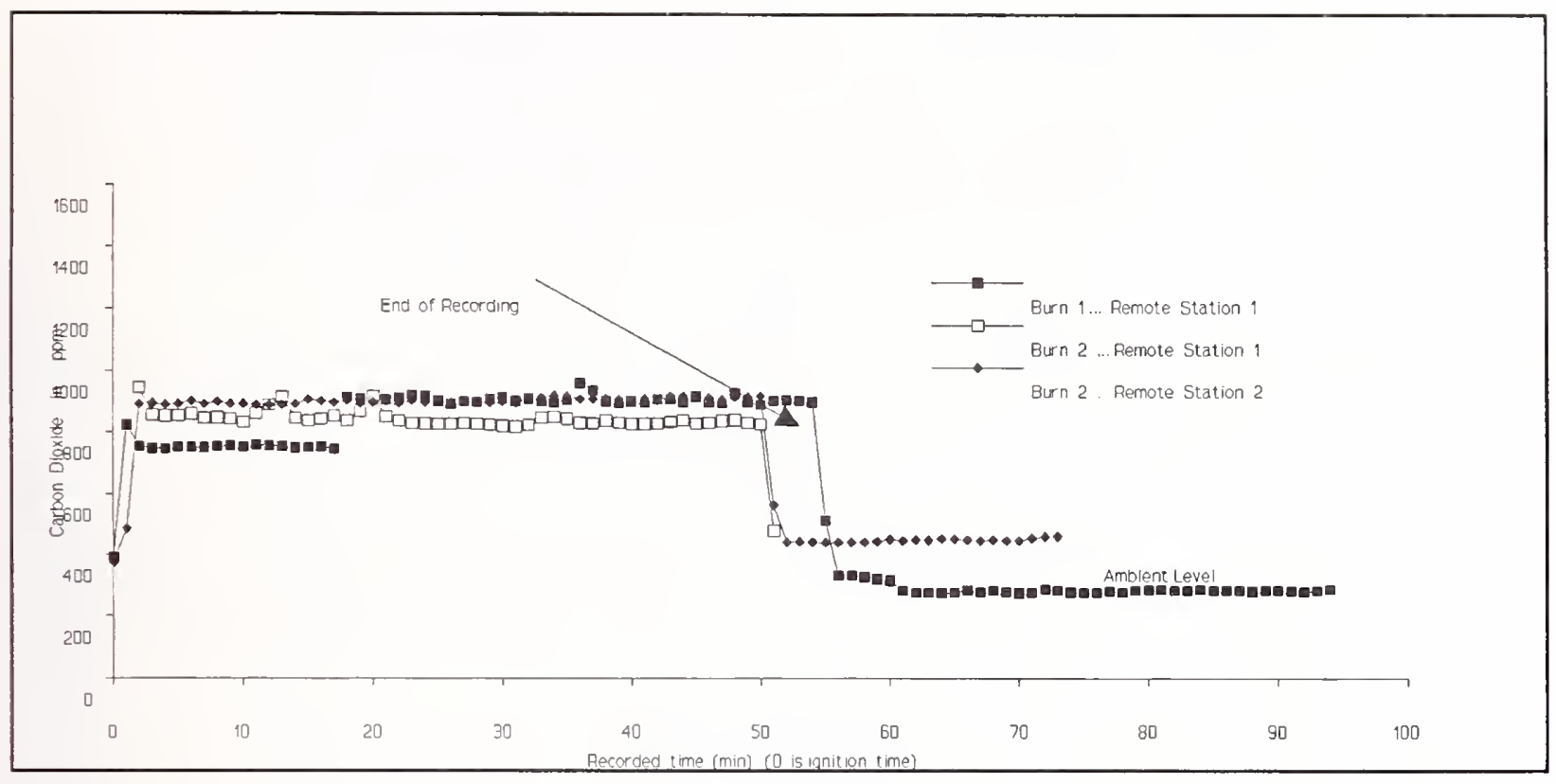

Figure 2 Carbon Dioxide Measurements

Metals

Crude oil contains several metals in the ppm range. The analysis from the Newfoundland tests is not complete, but in previous tank tests, metals could not be detected on soot particles.

Dioxins and Dibenzofurans

Analysis for dioxins and dibenzofurans on particulate matter both upwind and downwind of the fires shows that these compounds are not produced. Levels of all samples taken are at background levels.

\section{OVERALL FINDINGS}

The Newfoundland burn and the previous tank test burns have revealed several facts about the fate, behaviour and quantity of the basic emissions from burning:

Gases - combustion gases are very diffuse and do not have spatial relationship to the plume. A good model is to view gas dispersal as following a doughnut-like pattern around the burn. This pattern is deformed by increasing wind velocities. Generally gas concentrations downwind are very low. Gas concentrations, especially in low winds can be as high around the fire as downwind. 
Particulate Matter/Soot - Particulate matter at ground level is only a matter of concern very close to the fire and under the plume. The concentration of particulates in the smoke plume may not be a concern past about 500 metres. The level of respirable particulates, those which have a size less than $10 \mu$, is poorly understood. These may be carried away in the vestiges of the smoke plume. Respirable particulates have not been detected at ground or sea level.

Water Emissions - No compounds have yet been detected in the water of the test tanks or under the water at sea. The aquatic toxicity of the water under a burn is either not measurable or not extant.

Organic Compounds - No exotic or highly-toxic compounds are generated as a result of the combustion process. Organic macro-molecules are in lesser concentration in the smoke and downwind than they are in the oil itself. Volatile organic compounds are released in large concentration by fires, but in lesser concentrations than the evaporating slick if not burning.

Residue - The residue is generally lighter than water. Density appears to relate to efficiency. If a burn is highly efficient ( $>99.9 \%$ ), then the residue may be neutrally buoyant. The residue resembles high-weathered oil, measurements showed this to be about 40 to $50 \%$ weathered (\% weight loss). The residue contains a lower amount of PAHs than the starting oil, although proportionately high amounts of multi-ringed PAHs are present. Metals are concentrated in the residue.

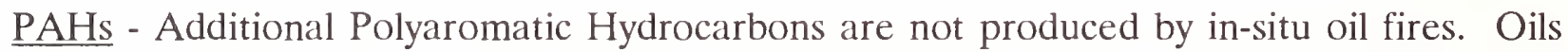
contain significant quantities of PAHs. These are largely destroyed in combustion. The $\mathrm{PAH}$ concentrations in the smoke, both in the plume and the particulate precipitation at ground level are much less than the starting oil. This also includes the concentration of multi-ringed PAHs that are often created in other combustion processes such as lowtemperature incinerators and diesel engines. This finding is very different from that noted in earlier lab experiments. It is suspected that re-precipitation of large soot particles occurs in large-scale tests which does not occur in laboratory tests. These large soot particles are conducive to the accumulation of large multi-ringed PAHs. The burn residue does, however, show a slight increase in the concentration of multi-ringed PAHs. However, when considering the mass balance of the burn, most of the five and six-ringed PAHs is destroyed by the fire.

\section{REFERENCES}

1. Fingas, M.F., Li, K., Ackerman, F., Campagna, P.R., Turpin, R.D., Getty, S.J., Soleki, M.F., Trespalacios, M.J., Paré, J., Bissonnette M.C., and Tennyson, E.J., Emissions From Mesoscale In-Situ Oil Fires: The Mobile 1991 and 1992 Tests, in: Proceedings of The Sixteenth Arctic and Marine Oil Spill Program Technical Seminar, Environment Canada, Ottawa, Ontario, pp. 749-821, 1993. 


\title{
IN SITU BURNING: LEGAL AND REGULATORY ISSUES
}

\author{
John Cunningham, Chief \\ Oil Pollution Response \& Abatement Branch \\ Emergency Response Division \\ U.S. Environmental Protection Agency \\ Washington, DC 20460 USA
}

\section{SUMMARY}

U.S. Environmental Protection Agency (EPA) regulations generally prohibit oil spills but authorize permits for intentional spills used to research response techniques such as in-situ burning. However, thousands of accidental spills occur each year, and recent experiences show that accidental spills can be burned successfully. EPA, therefore, encourages researchers to make use of accidental spills wherever possible and is developing guidance to ensure that the burning of such spills is safe and effective. The Agency may issue permits for intentional spills; in fact, EPA is updating its guidelines and regulations for this purpose. Nevertheless, permits are granted only when applicants meet strict requirements for addressing the risks of the intentional spills they propose and for balancing those risks against the benefits of the proposed research projects.

\section{INTRODUCTION}

EPA regulations under the Clean Water Act (CWA) generally prohibit the discharge of oil to navigable waters and in certain other cases (40 CFR 110.6). Nevertheless, accidental spills do happen, so technologies are needed to mitigate the damage these spills may cause. EPA supports efforts -- including research on the emerging, promising technique of in-situ burning -- that will help us better protect the environment from oil spills. In fact, EPA regulations make an exception to the oil discharge prohibition by allowing EPA to issue permits for research-related discharges of oil (40 CFR 110.9).

\section{The Goals of Environmental Protection and Research Must Be Balanced}

Research is important. We must, however, ensure that research activities (such as the intentional discharge of oil) do not threaten the very environment we seek to protect. The goal of improving oil spill response technology must be balanced with the original, fundamental goal of protecting the environment.

For in-situ burning, a good way to balance these goals is to carry out research on accidental spills (spills of opportunity) wherever possible. Such research should be the primary source of data concerning in-situ burning. Permits for intentional spills should be granted only in special cases where a significant need exists for data unobtainable from accidental spills and where that need can be met without harming the environment. 
Research on in-situ burning must comply with other regulations besides the 40 CFR Part 110 regulations noted above. These include additional EPA regulations (such as the National Oil and Hazardous Substances Pollution Contingency Plan, or NCP), regulations of other Federal agencies (such as the worker health and safety regulations administered by the Occupational Safety and Health Administration), and regulations issued by States and localities. Because these regulations generally would apply regardless of whether accidental or intentional spills are used for research, they will not be discussed in detail in this paper.

The remainder of this paper will discuss the possibilities for in-situ burning research on accidental spills and the special requirements for intentional discharge permits.

\section{RESEARCH ON ACCIDENTAL SPILLS}

An estimated 15,000 accidental oil spills occur each year -- on average, about 40 spills every day. Few of these spills may be ideal for an in-situ burning experiment, and even where burning is feasible, it is not always the best response option. Still, with so many spills, there are bound to be many cases in which burning is at least part of the preferred response strategy. Valuable information can be -- and has been -- accumulated from burns of accidental spills.

\section{Burning Can Be Used}

Although in-situ burning of accidental spills has not been a common practice to date, Federal regulations do allow it when certain requirements are met. The NCP, the Federal government's blueprint for oil spill planning and response, does not exclude burning from the "defensive actions" that "shall begin as soon as possible to prevent, minimize, or mitigate threat(s) to public health or welfare or the environment" (40 CFR 300.310(a)).

As with any oil spill response measure, burning must be conducted under the direction of the On-Scene Coordinator (OSC) for the response, and must be consistent with plans prepared by the relevant Regional Response Team (RRT). Burning works best on freshly spilled oil, so time is of the essence in getting RRT approval for a burn. For that reason, an increasing number of RRTs, such as the Region 6 RRT, have streamlined the approval process by preauthorizing the use of in-situ burning.

Burning agents, such as gelled gasoline, may not be needed to conduct a burn, but the NCP does allow OSCs to authorize their use on a case-by-case basis if the relevant RRT members and natural resource trustees concur (40 CFR 300.910(b)). 


\section{Burning Has Been Used Successfully}

In-situ burning has already been used successfully on some accidental spills. On the second day of the response to the March 1989 Exxon Valdez spill, about 15,000 gallons of oil were burned with a high degree of oil removal. In April 1993, responders used in-situ burning to effectively remove part of a jet fuel spill from a marsh in Maine. Lessons are also being learned from intentional spills outside the U.S., such as the Newfoundland Offshore Burn Experiment conducted in August 1993.

The Valdez and the Maine marsh incidents are examples that show we can burn at least some accidental spills successfully. None of the burns conducted to date have been perfect, so there is more we need to learn. After all, the possible dangers of a burn -- excessive smoke in populated areas, or shoreline fouling by unburned oil -- are just as bad for an accidental spill as they are for an intentional spill. Nevertheless, with the solid base of knowledge we now have, we can refine our understanding of and technique for burning through the prudent use of accidental spills.

\section{Research on Accidental Spills Will Be Persuasive}

Managing a research project under the exigencies of an accidental oil spill is admittedly a challenging task. The results of such a project, however, would be far more persuasive than those of an intentional-spill project in gaining wider acceptance of the technology.

When a research project is designed around an intentional spill, the research plan is simplified and key parameters (such as weather, oil type, and response equipment) are carefully selected. Unfortunately, though, the simplicity and controls of such an experiment may cast doubt on its applicability to accidental spills, which are notoriously unpredictable and problematic. Critics might contend that such an experiment is specially designed and controlled to maximize the technology's effectiveness while minimizing its adverse environmental effects. Even the most impressive demonstration of a technology is of limited relevance if it can't be duplicated for accidental spills.

In contrast, broader use of in-situ burning on accidental spills will build a large body of empirical data that responders and planners can use to better understand the factors that determine the success or failure of a burn. After all, the ultimate test of a technology's success (including the acceptability of environmental effects such as air emissions) is whether it can be managed under the constraints and imperfect conditions of the "real-world" situations faced by responders.

\section{Response Authorities Need to Know What We Have Learned}

Although in-situ burning has been used on accidental spills and shows promise, it is used only rarely. Why? The answer is that the basic knowledge about how to conduct a burn exists, but it has not been collected, organized, and disseminated to the response authorities 
who can use it. These authorities -- RRTs and OSCs -- need both environmental and operational information about in-situ burning.

- Environmental Information: What short- and long-term hazards does burning pose for the health and safety of both the public and spill responders? What are the short- and long-term ecological hazards of in-situ burning? How can these hazards be minimized? How should the concerns of the public about the smoke plume produced by burning be addressed? How can monitoring be used to guide the burn operation? What data collection is needed to allow reliable post-burn analysis that adds to the body of knowledge on in-situ burning? What Federal, State, and local regulatory approvals need to be obtained prior to burning?

- Operational Information: Under what oil and weather conditions will in-situ burning most likely be effective? What is the correct procedure for conducting a burn, and how should that procedure be adjusted as weather or spill conditions change? When should be burning be used instead of, or in addition to, other response measures?

Recognizing the need for information about burning, some RRTs have already developed guidance for their respective Regions. For example, the Region 4 RRT has prepared a guide to the use of in-situ burning in Region 4, complete with a spill evaluation "checklist" and State-by-State approval requirements. The Region 6 RRT also has developed a checklist. The Alaska RRT has developed its own in-situ burning guidelines.

To aid and promote these RRT efforts, EPA Headquarters has been developing comprehensive national guidance for the preparation of Regional in-situ burning plans. The guidance will describe how to conduct an in-situ burn that is successful and that accomplishes research objectives. Specifically, the guidance will explain how to define the area in which burns may be feasible; evaluate the burnability of a particular spill; identify the logistical needs and mechanics of burn operations, including monitoring and post-burn analysis; discuss health and environmental precautions; and describe how to implement the plan through training efforts and communication with the public. We welcome submissions of information for possible inclusion in this document.

Because the scope of the guidance has expanded from an initial focus on safety and environmental concerns to a more comprehensive view, and because any official guidance to RRTs should come from the National Response Team (NRT), we are exploring the possibility of having the NRT complete, finalize, and distribute the document.

\section{RESEARCH ON INTENTIONAL SPILLS}

There may be cases in which oil spill response research requires the control of key spill characteristics such as location, timing, spill size, and oil type. Selection of such variables, along with careful control and monitoring of burn operations, may help us see more clearly and precisely how certain variables influence the outcome of a burn. 
EPA may issue permits to allow the intentional discharge of oil for research purposes (40 CFR 110.9). We are very careful in granting these permits because many opportunities for research on accidental spills already exist, and because intentional oil spills -- along with burning or other responses to such spills -- inevitably pose risks of additional damage (beyond the damage caused by accidental spills and related response efforts).

The risks of intentional spills impose two general requirements on applications for oil discharge permits. First, applicants must demonstrate a complete understanding of the human health and ecological risks of the intentional spill, and must propose measures that are adequate to protect against these risks. For example, an applicant for a permit to conduct research on in-situ burning must not only show a full understanding of constituents of the smoke produced by oil combustion and the hazards they pose to humans, but also must propose steps to keep the smoke sufficiently far from populated areas.

The second requirement is based on the recognition that even when steps are taken to protect against risks, the risks cannot be completely avoided. Thus, applicants must justify the risks of the spill by citing the benefits of the data sought and the need to obtain the data from an intentional spill. Are the data to be obtained the first of their kind, or have substantially similar data already been obtained? Are the data available through other, less risky methods, such as research on accidental spills, or on land-based burns in test tanks? Do the potential benefits of the project outweigh its potential risks?

\section{Permit Guidelines and Regulations Are Being Updated}

Given the dangers of intentional spills and the need for carefully developed, well-justified oil discharge permit applications, guidelines for preparing applications would be helpful. In fact, such guidelines exist, but they were published in 1971 and are now out of date. The guidelines allow only relatively small (1,000 gallons or less) research spills, and they reflect the relatively early state of environmental science and regulation that existed at the time.

EPA, therefore, is working to update the guidelines. The revised guidelines will reflect: (1) gains in understanding of human health and environmental risks; (2) the current interest in discharging larger volumes of oil (which pose substantially greater risks); (3) permitting program concepts (such as public participation) and methods that have evolved since 1971; and (4) new requirements of other EPA offices and other agencies. The Agency expects to publish the revised guidelines in the Federal Register in Fiscal Year 1994.

After it publishes the revised guidelines, EPA will work on revising the oil discharge permit regulation (40 CFR 110.9). As a part of this effort, EPA will consider expanding the permits to cover the use of oil spill response products in conjunction with intentional spills. Although burning agents and other products may be used on accidental spills, there is currently no 40 CFR 110.9 provision for their use on intentional spills. We believe, however, 
that until such a change is made, EPA could authorize the use of response products on intentional spills under other CWA regulations (specifically, those of the National Pollutant Discharge Elimination System, also known as NPDES) or EPA regulations under the Ocean Dumping Act.

\section{CONCLUSION}

EPA supports research to help realize the promising potential of in-situ burning as an oil spill response technique. At the same time, the Agency recognizes that research efforts must not compromise the paramount goal of environmental protection. Therefore, the Agency is encouraging research on accidental spills and is allowing for intentional, research-related spills only in special, justified cases. 


\title{
TEXAS MARSH BURN \\ REMOVING OIL FROM A SALT MARSH USING IN SITU BURNING
}

\author{
M. F. Gonzalez, G.A. Lugo \\ Texas General Land Office \\ Division of Oil Spill Prevention and Response \\ $1700 \mathrm{~N}$. Congress \\ Austin, Texas 78701
}

\section{PREFACE}

The grounding of the Exxon Valdez in March of 1989 and later separate incidents along the Texas coast, including the Mega Borg and the Apex barge collision in the summer of 1990, caused a rippling effect on the State Legislature to introduce S.B. 14, commonly referred to as the Oil Spill Prevention and Response Act of 1991.' This Act established the Texas General Land Office as the lead state agency for oil spill prevention and response in the coastal marine environment. Through these efforts, this agency along with other state agencies are ensuring that the Texas coast is better protected from oil spills.

\section{INTRODUCTION}

An oil spill occurred from the Exxon Pipeline Company (EPC) on the morning of January 7, 1992, during a routine pipeline transfer of South Texas Light Crude (API Gravity 36.0) from their Harbor Island facility to their facility in Vanderbilt, Texas. The Harbor Island facility, located near Ingleside, Texas, consists of several large above-ground storage tanks and a marine terminal. The interstate, below ground pipeline, suffered a rupture due to corrosion, along the seam on the underside which extended about $1.5 \mathrm{~m}(4.9 \mathrm{ft})$. The line was installed in 1966 and is $40.64 \mathrm{~cm}$ (16 in) in diameter, with a wall thickness of $5.56 \mathrm{~mm}$ (0.219 in) and rated for a maximum operating pressure of $1104 \mathrm{psig.} \mathrm{On} \mathrm{the} \mathrm{evening} \mathrm{before}$ the incident at approximately 22:45, EPC's Oil Traffic Control Center confirmed a probable leak on the pipeline in question. Earlier, the Ingleside pumps had shut down on an operational trip after switching from a very light plant distillate to a heavy crude. At the time, the recording pressure chart at Ingleside showed a momentary pressure increase to 1145 psig at the station, $3.7 \%$ above the maximum operating pressure, well within the $10 \%$ surge allowable. Apparently, at the same time, a leak occurred $22.8 \mathrm{~km}$ (14.2 mi.) away at the site at 1072 psig, again well below the 1104 psig maximum operating pressure. Even though pressures were in acceptable operating range, the date of the latest test was 26 years prior to the incident in 1966 and then had achieved a maximum test pressure of 1380 psig. ${ }^{2}$ The rupture occurred in a privately owned tidal mud flat at the mouths of Chiltipin Creek and the Aransas River near Copano Bay (figure 1) and $50 \mathrm{~km}$ (31 mi.) from the Aransas Wildlife Refuge. 
Copano Bay (figure 2) is a body of water about $13 \mathrm{~km}(8 \mathrm{mi}$.) wide and $39 \mathrm{~km}$ (24 mi.) long that flows into the Aransas Bay system and is primarily used by recreational and commercial fisherman. However, it does have oil and gas facilities and Liquid Petroleum Gas processing plants in and around the bay which pose other environmental threats.

\section{RESPONSE}

At the time of the release, it was raining, cold, and windy. The temperature was about 7 degrees centigrade ( 45 degrees Fahrenheit) with winds at 15 to 20 knots. Rainfall in recent days had been heavy leaving the ground saturated and a continued forecast of rain was predicted for the next several days.

After the problem was encountered, EPC ordered their air patrol to investigate. Hampered by fog, the patrol finally discovered the leak at 10:45 the next day. Maintenance and clean up crews were dispatched and agency notifications were made. The National Response Center ${ }^{3}$ was notified along with a host of state agencies. The Texas General Land Office ${ }^{4}$ received its first call at 1322 on January 7, 1992. The caller stated that a 750 barrel crude oil spill from a ruptured pipeline in a plowed field had occurred. When agency representatives converged at the site, EPC's Incident Commander briefed them with these additional comments: Two valves 11 miles apart had been shut in, but 16,000 barrels remained in the line and continued to pose a threat. EPC's initial response was to contain and control the movement of the oil and to commence pipeline repair operations. Containment boom had been placed in the river and sorbent boom was placed at the leading edge of the spill, which at the time was approximately $457 \mathrm{~m}$ (1500 feet) from the river. EPC had established a 24-hour operation effort. In the days following, over 130 personnel would be utilized to mitigate the situation.

\section{INCIDENT COMMAND}

After Federal and State jurisdictional issues were addressed and agreed to, an Incident Command System was initiated and with modifications, established, a Unified Command structure. EPC assumed the role as the responsible party and Incident Commander, the Environmental Protection Agency (EPA) as Federal On Scene Coordinator (FOSC) and the Texas General Land Office (Oil Spill Division) as State On Scene Coordinator (SOSC). The goal of the Unified Command was to safely remove the oil from the marsh with the least damage to the environment, prevent any oil from entering the river, and restore EPC's pipeline transfer capabilities. A command post was positioned on the surrounding farmland by EPC about a mile from the spill site, with established security radius of $3 \mathrm{~km}$ (1.9 mi.). At this command post and through this system, all decisions were made and agency concerns addressed. Agencies participating on scene included the Texas General Land Office (Coastal Division), Texas Parks and Wildlife Department, Texas Railroad Commission, Texas Water Commission and Texas Air Control Board (now comprise the Texas Natural Resource Conservation Commission), United States Coast Guard, and United States Fish and Wildlife Services. The EPA chose to handle their duties from the Region 6 
headquarters office in Dallas. They did, however, send an EPA Technical Assist Team (TAT) from Houston during the initial days of the event. Meetings were conducted twice daily to brief all representatives and interested stakeholders on all actions. Evening planning meetings with EPC and the SOSC were held to further discuss operational, regulatory and public relations matters.

\section{ASSESSMENTS}

Initial assessments were done by aerial inspection. Little was seen from the air as the oil's migration was through the dense marsh grasses rather than over it. Ground assessments were the best way to determine the extent of the damage and were restricted to response personnel. With all the rains, transportation to the site was accomplished via helicopter, sleds pulled by D-8 tractors, or All Terrain Vehicles. Ingress and egress to the site were around the marsh over neighboring farmland. Walking through the marsh on foot was extremely difficult and only contributed to the damage by trampling. To go about $1.6 \mathrm{~km}$ (1 mi.) took the better part of an hour by sled. The logistical problem of getting equipment to the site was slow and tedious. Once at the site, it was discovered that the spilled oil encompassed between 8.1 and 10.13 ha (20 and 25 acres) of sensitive marshlands. The majority of the habitat affected was principally vegetated with salt-flat grass, Virginia dropseed, sea ox-eye daisy, sea-lavender, glasswort, and saltwort. ${ }^{5}$ Wildlife was minimally affected. Two oiled gadwalls were recovered and taken to a certified rehabilitator and several sheephead minnows were discovered dead in a nearby pond. The initial reported volume of 750 barrels quickly increased to over 2900 barrels. Heavy equipment was moved in to dig up the line, cold cut it and replaced it with a 63' section of new line. A bell hole was dug around the rupture to control the trickling flow of oil.

\section{CONVENTIONAL CLEANUP}

Eventually two tankage systems with pumps were set up with a capacity of 2400 barrels. One tank system by the spill site and the other near the command post were both connected by a $3 "$ plastic line where vacuum trucks could enter and take the recovered crude back to EPC's facility. Conventional cleanup techniques at the site such as skimmers, pumps and sorbents proved to be inadequate, and some ruled out completely due to the greater potential damage to the marsh. Other alternative cleanup methods had to be considered as the oil continued to migrate closer to the river.

\section{ALTERNATIVE CLEANUP TECHNIQUES}

Alternative cleanup methods like bioremediation, flooding, peat moss application and in-situ burning were considered. Bioremediation might have been a viable action to take but was later discouraged because of extensive Regional Response Team permitting protocols. Water flooding of the marsh with low pressure, high volume pumps might have worked, but logistically would have been disastrous. Feat moss was used at the leak site to absorb the remaining free oil allowing personnel to work in the area. Tall marsh grasses prevented 
peat moss application to the oil and would have left a greater than desired total petroleum hydrocarbon content. Any oil-saturated peat moss could not have been able to be picked up. Because less manpower and equipment was needed in-situ burning seemed to be the most effective method of oil removal from the marsh.

\section{IN-SITU BURN}

Once the decision to burn was made, the Unified Command planned to expeditiously obtain a positive consensus decision from all stakeholders. The FOSC was called in Dallas and stated that the decision lay on the Texas Air Control Board (TACB). EPC formally requested permission from the $\mathrm{TACB}$ and after gaining positive response from all stakeholders. The TACB permit came back with these directives: ${ }^{6}$

1. Burn will be under the direction of the Texas General Land Office.

2. Burning only conducted to eliminate emergency conditions and threat to the wetland environment.

3. Disposal site must stay in compliance with all applicable rules and regulations of appropriate State and Federal agencies.

4. Burn must always be attended.

5. Heavy oils, asphaltic materials and vehicle tires shall not be burned.

6. Burning shall not be commenced when the surface wind speed is predicted to be less than 5 knots or greater than 20 knots during the burn.

7. Local TACB office was to be notified during any burning.

Seventy-six hours into the event, a test burn was conducted to determine the oil's ignitability. An isolated area measuring $6 \mathrm{~m}(16 \mathrm{ft})$ in diameter was chosen. A small berm was built around the area. Using diesel to ignite the oil, it slowly burned then quickly raged with crackling flames $7 \mathrm{~m}(21 \mathrm{ft})$ high. It was a successful test. Meanwhile, EPC's crews completed repairs on the line and slowly continued to pump out oil from the marsh into the tanks. The Unified Command needed to quickly prepare for the full burn.

Planning for the burn was as follows: The line had to be repaired and covered. Continued site safety had to be maintained. Heavy equipment had to be retrieved onto higher ground. Experts in fire safety, like the Texas Forest Service (TFS) and the Refinery Terminal Fire Company, Corpus Christi, were called in to conduct and manage the burn. Logistical problems continued to hamper and slow the process. The TFS called for the D-8 tractors to build fire breaks through the surrounding brush. Ignition sources were considered and it was later determined that mineral spirits would do the job.

The Texas Division of Emergency Management was contacted and with their assistance, calls were made notifying all the local fire, sheriff's and police departments of the controlled burn. Nearby residents were alerted of possible evacuation. The Department of Public Safety (DPS) maintained traffic control on the nearby county roads. The Federal Aviation Administration (FAA) was alerted of the potential smoke plume from the burning oil. 
Finally, the local news media was notified and the evening's newscast provided viewers with a public service announcement to prevent alarm from any fire and smoke seen in the night. They stated, "It was a controlled burn." A control site was prepared by the USF\&WS for later study. However the USF\&WS was told by the Unified Command that this was a response effort for the removal of spilled oil from the marsh and science might have to take a back seat. Communication to Austin Control was frequent and support for burning was continued.

Before the commencement of the burn, a final meeting was held by the Unified Command to again secure a consensus decision from all stakeholders at the scene. The decision was unanimous... burn. Recommendation from the TFS and the RTFC was to leave a contiguous layer of oil on the ground to maintain a good burn. This would allow the fire fighters to ignite the oil on the upwind side and retrieved back. Mechanical pumping of the oil was ceased and all the equipment removed. Responders and cleanup personnel were placed in safe zones. Six fire fighters positioned themselves and at 1750 on January 11, 1992, ignited the oil. One mile from the spill site at the command post, the flames were barely visible with the naked eye -- within minutes the flames towered to heights in excess

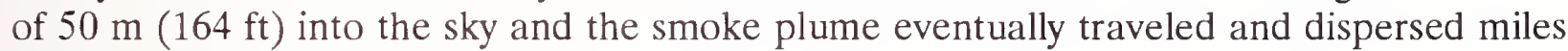
away over farmland. Through the rain and twenty-one hours later, the flames finally died.

Observers from the Unified Command, along with fire fighters, made aerial inspections of the site and visually estimated that -- 80 to 85 percent had been removed. Three small ponds remained and the order was given to continue burning. Each burned successfully for approximately 4 hours. Again, visual inspection showed similar removal percentages. The remaining residue was an asphaltic material that adhered to anything it came in contact with. That evening forceful rains fell and flooded the marsh. Drainage was directly into Chiltipin Creek and flooding had cleared by the next day. Residue was visible and EPC personnel continued to conduct smaller burns to remove as much oil as possible. Plywood planks were laid out to gain access to the remaining affected areas preventing any further damage.

\section{FINAL CLEANUP}

Oil sheen and residue remained. Sorbent sweeps were placed and slowly absorbed the final remnants of floating oil and sorbent pompoms were used to recover the residue. Twenty days from the initial discovery of the leak the site was deemed clean.

\section{CLOSING}

It is agreed that this spill damaged the environment, but as in any spill event, concessions and difficult decisions were made. Many times, it is a choice of the lesser of the evils. In this instance, the goals of the Unified Command were to minimize any further damage to the environment. The final totals of oil released from the line were 2950 barrels. Twelve hundred barrels removed from the bell hole and pumped into tankage, 1700 barrels entered the marsh, 500 barrels recovered from the marsh and pumped into tankage, 50 barrels in 
sorbents and 1150 evaporated or burned. The oil was removed, no oil entered the river and damage to the marsh was minimized by burning. The goals were achieved. Follow up inspections to the site revealed that the heartier vegetation had sprouted within two weeks of the burn. Four months later, 75 percent of the impacted area had regrown. Although the vegetation diversity had diminished, the regrowth process is crucial to the restoration of the marsh. 


\section{REFERENCES}

1 Texas Natural Resources Code, Chapter 40 (S.B. 14, 72nd Legislature)

2 Exxon Pipeline Company, Department of Transportation Accident Report

$3 \quad$ National Response Center (Case \# 101878)

$4 \quad$ Texas General Land Office (Spill \# 92-013)

$5 \quad$ Texas General Land Office (Field Investigation Report, Coastal Division)

6 Texas Air Control Board, Request to Conduct Outdoor Burning, Special Provisions. 


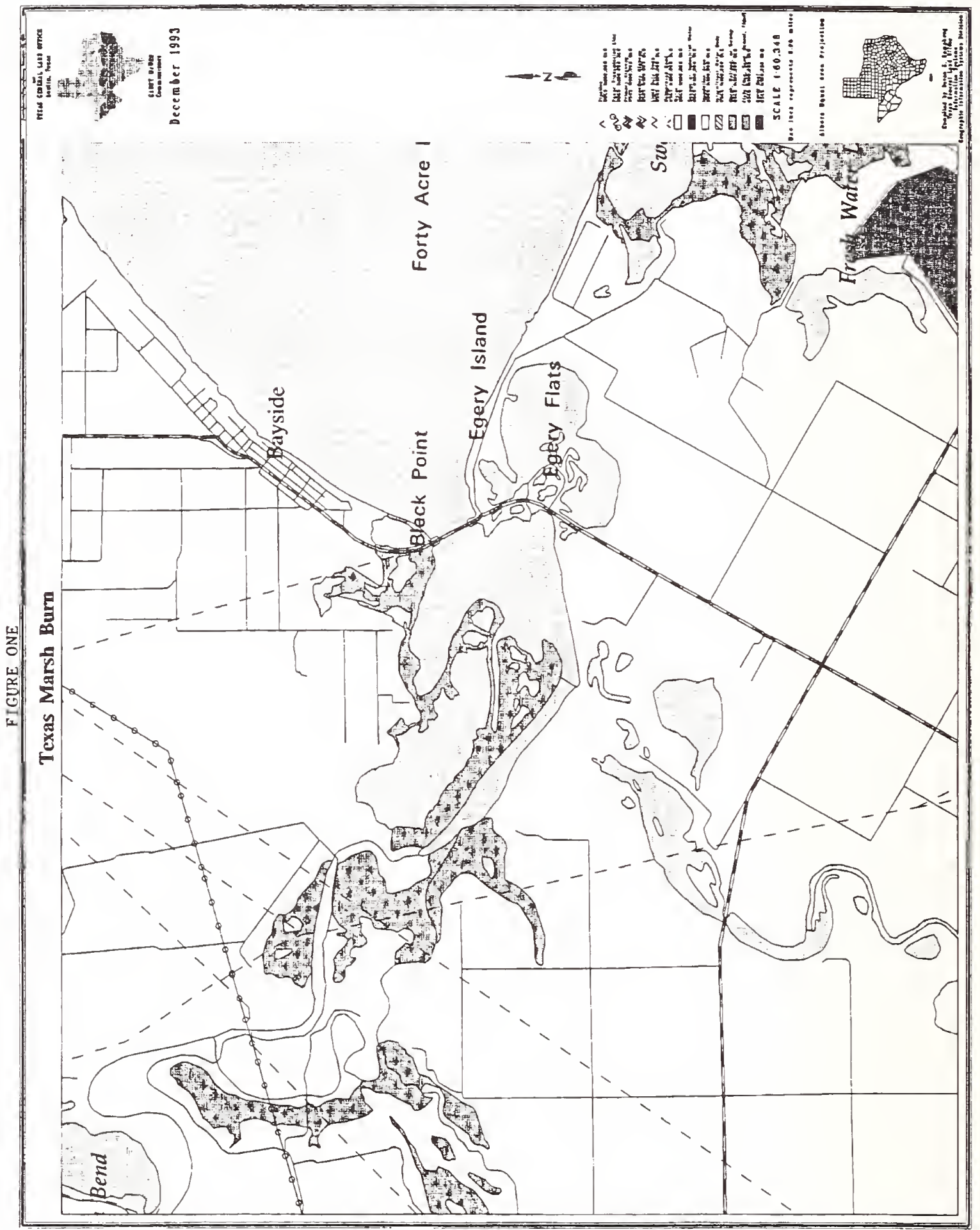




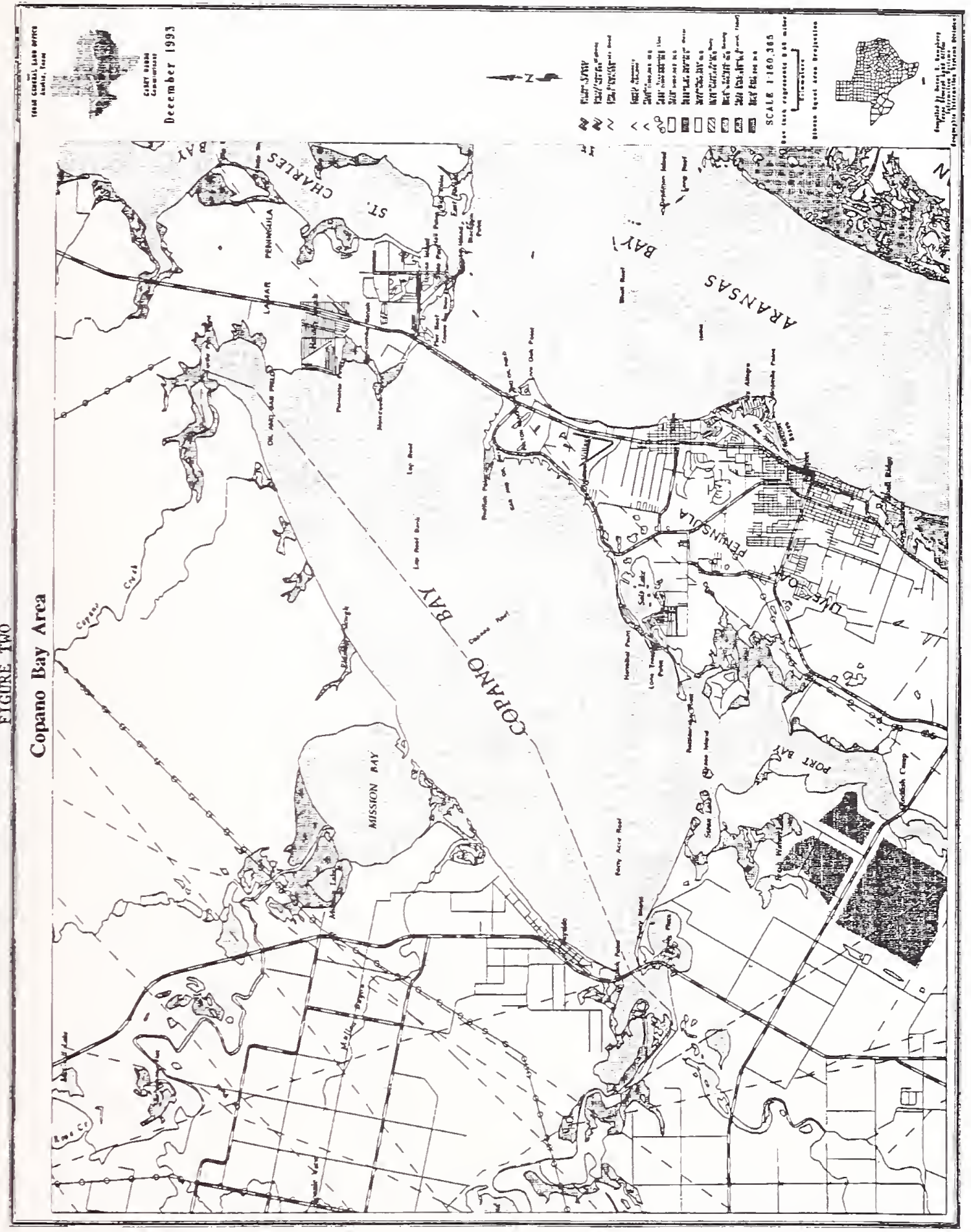





\title{
BRUNSWICK NAVAL AIR STATION JP-5 AVIATION FUEL DISCHARGE IN SITU BURN OF FUEL REMAINING IN FRESH WATER MARSH APRIL 6-8, 1993
}

\author{
Steven J. Eufemia \\ Maine Department of Environmental Protection \\ 312 Canco Rd. \\ Portland, Maine 04103
}

\section{SUMMARY}

On March 26-29, 1993 approximately 240,350 liters (63,500 gallons) of JP-5 aviation fuel was discharged from a fuel farm located at the Brunswick Naval Air Station, Brunswick, ME. The fuel entered the storm sewer system and migrated into a fresh water wetland where it was contained by ice, snow and other natural barriers. Conventional oil spill recovery technologies were employed at the outset of the clean-up efforts; however, due to limited access and the potential for physical damage to the wetland by equipment and manpower needed to complete the project, a decision was made to remove the fuel remaining within this wetland by means of in-situ burning.

A large scale burn was conducted on April 6, 1993 at which time the entire surface area of the wetland that had been oiled was allowed to burn. Two smaller burns followed on April 7 and April 8 to remove remaining pockets of oil not burned in the initial operation.

\section{INTRODUCTION}

In-situ burning can be used successfully as an oil spill clean-up technique for inland oil spills. In these applications it is particularly effective when integrated with mechanical clean-up methods. It is an attractive alternative to more conventional methods where access to the spill site is limited or where there is the potential to cause additional damages by the movement of the equipment and human resources necessary to effect mechanical oil removal.

\section{BACKGROUND}

On Monday March 29, 1993 Navy personnel discovered a discharge of JP-5 aviation fuel from a newly constructed fuel tank farm located on the Brunswick Naval Air Station. The Navy estimates that 240,350 liters (63,500 gallons) of fuel was discharged from a pipeline valve sometime between Friday, March 26, 1993 and Monday, March 29, 1993 when the discharge was discovered. Notifications were made to appropriate regulatory agencies including the United States Coast Guard Marine Safety Office, the Maine Department of Environmental Protection (M.D.E.P.), as well as local public safety agencies. A command post was established and an incident command system instituted. The Navy contracted with Clean Harbors, a pollution contractor, to provide clean-up equipment, personnel and services. The M.D.E.P. established itself as a crucial element of the incident command system and the overall response effort due to the experience that M.D.E.P. personnel were able to bring to bear to a clean-up of this nature as well as their familiarity with the pollution contractor.

Once it had been determined that a substantial portion of the fuel discharge had been contained within a freshwater wetland situated between the base and the Androscoggin River, it was evident to all parties involved in the response effort that access to this area by the oil spill recovery equipment and the manpower required to operate it would be severely limited. The main body of the wetland 
was accessible only by a residential driveway and a utility right-of-way. The right-of-way was only traversable by four wheel drive vehicle even under ideal conditions. The accessibility problem was compounded by the hilly terrain surrounding the wetland and snow cover of several feet. The depth of the water and the ice cover precluded the use of all but small unpowered watercraft.

The M.D.E.P. and others on the incident command staff were also keenly aware of the fragile ecosystems that wetlands of this type support and the potential for physical damage to the ecosystem by clean-up equipment and manpower. Also considered was additional oil contamination of the sediments on the periphery of the wetland due to foot traffic. These viewpoints were echoed by the Regional Response Team's Scientific Support Coordinator, whose input had been requested by the Federal On-Scene Coordinator consistent with the National Contingency Plan. The Maine Department of Inland Fisheries and Wildlife that is designated, along with the M.D.E.P., as the State Trustee of Natural Resources for spills into these types of environments, also was concerned that the response efforts could cause additional damage to the wetland.

In consideration of these constraints, the M.D.E.P. proposed a clean-up plan combining conventional oil spill technologies followed by in-situ burning. This plan called for augmenting the natural containment of the wetland using containment boom, sorbent boom, and underflow dams. Vacuum trucks would be staged at accessible locations to begin product removal. A residential driveway and the utility right-of-way required upgrading to facilitate the movement of the vacuum trucks in order to conduct this phase of the clean-up. Despite the road improvements, there were still areas within the wetland, where product thickness exceeded $20 \mathrm{~cm}$, that were $150-200$ meters from the closest point that recovery equipment could be staged. The pollution contractor would be instructed to limit the number of personnel entering the wetland and to restrict them to designated routes of entry and egress. The proposed plan include in-situ burning operation which would be conducted once the mechanical product removal was determined to have become impractical or inefficient due to a high percentage of water in the recovered oil/water mix.

The mechanical recovery operation began immediately; however, there was some opposition to the insitu burn phase of the clean-up by some members of the incident command structure. This opposition had basis both from a public relations standpoint, as well as the opinion that the JP-5 would not readily ignite and remain burning. Although the mechanical recovery operation progressed well, it became apparent that these mechanical means alone would not provide a satisfactory recovery of the oil in the wetland. It was agreed upon by the command structure to conduct a test burn and to endorse a large scale burn provide the test burn was successful.

In the meantime, the M.D.E.P. had been working to secure approvals to conduct the burn. These included approvals from within the M.D.E.P., from various Federal agencies and from the Fire Chiefs of both the Town of Brunswick, ME and the Brunswick Naval Air Station. Internal policy of the Me.D.E.P. requires that State Oil Spill Coordinator, as designated in State of Maine Marine Oil Spill Contingency Plan, must authorize any in-situ burn and the air quality section of the M.D.E.P. must be informed of the specifics of the burn. The Federal agencies from which approvals were sought and granted were the United States Coast Guard (OSC), the Environmental Protection Agency and the Department of the Interior. Both Fire Chiefs had been included on the incident command staff and had concurred.

Mechanical clean-up continued through April 4, 1993 at which time it was determined that the vacuum trucks were recovering as much water as fuel. The mechanical recovery was suspended at this time. 
In excess of 151,400 liters (40,000 gallons) of JP-5 had been recovered. Factored into this decision was the intent to leave a sufficient product layer atop the water to support combustion. A small test burn was successfully conducted on April 5, 1993 confirming the opinion of the M.D.E.P.that the JP-5 could be readily ignited. The appropriate meteorological conditions under which to conduct a large scale burn of the wetland were discussed and decided upon and the operation was planned for the next day on which these conditions existed.

The conditions under which the burn would be conducted would be a clear sky with no overcast and a light wind from a westerly direction. The clear conditions would facilitate smoke plume rise and atmospheric dispersion. The westerly wind would direct the plume away from the population centers. Ideal conditions existed on April 6, 1993 and a large scale burn was begun at approximately 11:30 A.M. A high voltage power line which crosses the headwaters of the wetland upstream from the burn area was not considered at risk; however, a fire break had been designed and was put in place to slow the rate of flame advance in the upstream direction. No other overhead hazards existed. The ice and snowcover served to contain the fire to the oiled portions of the wetland.

The fire was allowed to burn for approximately five hours at which time it all but extinguished itself. Smaller burns were conducted on April 7, 1993 and April 8, 1993 as additional oil was released from beneath the ice and collected in burnable quantities. The remaining product layer was virtually eliminated throughout the burn area. It was estimated by M.D.E.P. personnel that less than 1700 liters (450 gallons) remained within the wetland at the conclusion of the burns.

Pre-burn as well as post-burn samples were collected under the direction of the RRT Scientific Support Coordinator. The samples were submitted to the Institute for Environmental Studies, Louisiana State University for analysis. The analysis report concludes that the pre-burn and postburn samples were compositionally similar except for a slight increase in the concentration of combustion sourced aromatic hydrocarbons ${ }^{1}$.

\section{CONCLUSION}

In-situ burning was successfully combined with mechanical recovery techniques to remove a discharge of 240,350 liters (63,500 gallons) of JP-5 from a freshwater wetland in Brunswick, ME.

Factored into the decision to burn was the inaccessibility to the area by mechanical recovery equipment, the potential to cause additional physical damage to the wetland by response activities, the concurrence of various Federal, State and local agencies as well as the time of year. In this incident the time of year was significant both from the fact that the ice and snowcover would serve to contain the fire to the oiled areas within the wetland and and in terms of migratory wildlife which had not yet returned to the area.

Visual inspections of the wetland throughout the Spring and Summer months of 1993 indicate very little residual impact from the oil spill or the burn. The long term impacts from the spill, response effort and the in-situ burn are expected to be negligible. 


\section{REFERENCES}

1 Henry, C. B. Characterization of Weathered JP-5 Fuel Oil Before and After In-Situ Burning. Technical Report IES93-06. Institute for Environmental Studies, Louisiana State University, Baton Rouge, Louisiana (1993). 


\title{
IN SITU BURNING: LOUISIANA OIL SPILL RESPONSE INTERESTS
}

\author{
J. Heather Warner Finley \\ Louisiana Oil Spill Coordinator's Office \\ Office of the Governor \\ P O Box 94004 \\ Batcn Rouge, Louisiana 70804-9004
}

\section{SUMMARY}

Oil spills are of particular concern to the state of Louisiana. Approximately 150 million barrels of oil and 130 million cubic feet of natural gas are produced in the state annually. In addition, approximately 20 percent of the nation's imported oil passes through the Louisiana Offshore Oil Port facility annually. Louisiana's coastal area contains more than 2.5 million acres of salt and brackish marshes, and more than 1.6 million acres of fresh marshes. These wetlands, in addition to providing important wildlife habitat and water quality services, are an integral part of the life cycle of 90 percent of the commercially important species in the Gulf of Mexico. The economic activity generated by wildlife and fishery resources in the state of Louisiana exceeds 2 billion dollars annually.

The Louisiana Oil Spill Coordinator's Office (LOSCO) was created in 1991 by the Oil Spill Prevention and Response Act. In creating the office, the Legislature found that"the release of oil into the environment presents a real and substantial threat to the public health and welfare, to the environment, the wildlife and aquatic life, and to the economy of the state" (LA R.S. 2453 A). The Louisiana oil spill coordinator is charged with developing a statewide oil spill prevention and response plan that includes, among other things, the "use of both proven and innovative prevention and response methods and technologies" (LA R.S. 2460 A.9).

LOSCO recognizes the need for a variety of alternative clean-up options in order to best protect Louisiana's fragile coastal resources. The office is interested in promoting research into in-situ burn technology. Currently, LOSCO's Oil Spill Research and Development Program is considering funding for several studies on the effects of burning hydrocarbons in coastal marshes. We hope that through the concerted efforts of various agencies, both state and federal, the needed research will be carried out, and our collective oil spill response and prevention efforts will be strengthened. 



\section{ABOUT THE AUTHORS AND PANEL CHAIRS}

John M. Cunningham is Chief, Oil Pollution Response and Abatement Branch (OPRAB) in EPA's Emergency Response Division. OPRAB leads EPA efforts to implement the requirements of the Oil Pollution Act of 1990 (OPA). OPRAB administers the schedule of dispersants and other chemicals, required by Section 311 of the Clean Water Act, which lists products that may be used to respond to oil spills in navigable waters. OPRAB also administers the Oil Pollution Prevention regulation (40 CFR Part 112), also known as the Spill Prevention, Control and Countermeasures (SPCC) regulation, which implements EPA oil spill prevention program for fixed, onshore facilities. Before joining the Emergency Response Division, John was with the Superfund remedial program, with a private consulting firm working on projects on waste water discharge issues and with ERPA's Office of Water developing regulations for industrial waste water discharge control. He holds a Bachelor of Science in chemical engineering from the University of Texas. He has a Master of Chemical Engineering and a Juris Doctor from the Catholic University of America.

Elmer P. Danenberger is Chief of Mineral Management Service's (MMS) Engineering and Technology Division with responsibilities for safety and pollution-prevention research, engineering support, and offshore operating regulations. Bud has been employed as an engineering in the Department of the Interior's offshore oil and gas program since 1971. He has served as District Supervisor for the Minerals Management Service (MMS) field offices in Santa Maria, California, and Hyannis, Massachusetts; as a staff engineer in the Gulf of Mexico regional headquarters office of the U. S. Geological Survey. He received a B.S. degree in petroleum and natural gas engineering and a masters degree in environmental pollution control, both from the Pennsylvania State University.

Steven J. Eufemia is a Unit Supervisor in the Maine Department of Environmental Protection (Me. D.E.P.) Southern Maine Regional Office. He is an Oil and Hazardous Materials Specialist III within the Me. D.E.P.'s Bureau of Hazardous Materials and Solid Waste Control, Division of Response Services. The responsibilities of the Division include responding to discharges of oil and hazardous materials which occur within the State of Maine and providing technical assistance as well as regulatory oversight. Steve worked as a commercial fisherman before joining Me.D.E.P. He has a B.S. degree in Natural Resource Management from the University of Maine, Orono.

David D. Evans is Acting Chief, Fire Safety Engineering Division at the National Institute of Standards and Technology (NIST). Formerly he was Group Leader of the Large Fire Research Group; this group is concerned with measurement and prediction of effects of industrial fires. Dave has been Principal Investigator on two major research projects conducted at NIST on behalf of MMS. In one, the capabilities of new technology water spray injection systems for reduction of fire effects and extinguishment of gas-well blowout fires were determined. In the other, a multi-disciplined team was assembled to develop new measurement and predictive methods to characterize the burning, combustion product emission, and smoke particulate transport from large crude oil spill fires. Though this project NIST has developed unique long range smoke plume dispersion calculations and field instrumentation to characterize emission from large fires. Dave initially worked in the area of building fire protection systems at NIST. In this work he designed an apparatus to measure the time response characteristics of fire sprinkler hardware in order to obtain input data for predictive methods. He received his $\mathrm{PhD}$ in Mechanical Engineering from Harvard University. 
Merv F. Fingas is Chief of the Emergencies Sciences Division, Environment Canada. The division is responsible for performing research on oil and chemical spill behavior and control. Current responsibilities include the management and performance of research related to the following areas: study of in situ countermeasures such as oil burning; fate, behavior and modelling of oil and chemical spills generally; development of analytical and remote sensing techniques; preparation of spill manuals, information compilations and overview reports; testing and development of chemical spill treating agents. Merv has spent the last 19 years in spill research and has over 200 papers and publications in the field. He has three masters degrees: chemistry, business, mathematics. He is currently completing his doctorate in environmental sciences.

J. Heather Warner Finley is a Natural Resource Specialist at the Oil Spill Coordinator's Office, Office of the Governor, State of Louisiana, working on oil spill contingency planning and resource protection projects. Previously Heather worked in the field of petroleum exploration and production. She has a B.S. and M.S. in Biology from the University of Southwestern Louisiana and a B.S. in Geology from Michigan State University.

Thomas M. Gernhofer is the Associate Director for Offshore Minerals Management, MMS, and served as Acting Deputy Director, MMS, for the first half of 1993. Previously Tom became the Assistant Director for Administration in the newly created bureau, MMS. He then served as the Assistant Director for Administration until he was named Acting Deputy Director, MMS, and then appointed the Associate Director for Management and Budget, MMS, responsible for all administrative, budgetary, and appeals activities. He graduated from the University of Virginia.

Manuel F. Gonzalez is the Director of Field Operations, Oil Spill Prevention and Response Division of the Texas General Land Office. Manny manages three coastal regional field offices from Austin. As needed, acts as the State On-Scene Coordinator for medium to major spill events. He is a member of the Governor's Environmental Task Force. He graduated from Texas A\&I University.

David M. Kennedy is the Chief of the Hazardous Materials Response and Assessment Division within the National Ocean Service of the National Oceanic and Atmospheric Administration(NOAA) in Seattle, Washington. He currently directs a multi-disciplinary program that works to reduce risks to coastal and marine resources from oil and hazardous material releases through emergency response to oil and chemical spills in the Nation's coastal zone, developing and applying scientific protocols to research spill prevention, contingency planning, operational forecasting and working to protect and restore trust resources affected by hazardous waste sites in coastal and marine habitats. Previously David managed the Scientific Support Coordination and previously was the Scientific Support Coordinator, acting as a liaison between the scientific community and the U.S. Coast Guard during spills to identify problem areas, research ideas, resolve issues, and generally ensure that cleanup proceeds as rapidly as is effective and environmentally beneficial. During this time he coordinated the Federal scientific response to spills in Alaska, Washington, Oregon, Hawaii, and Oceania, California, and the Gulf of Mexico. Previously David was Director of the Spilled Oil Research Team at the University of Alaska Geophysical Institute. He received the NOAA Administrator's Gold Medal for performance in the Exxon Valdez oil spill. 
Bruce McKenzie is the Manager of Planning and Development with Alaska Clean Seas, an Alaskan based oil spill response cooperative. In this position he is responsible for training, research and development and planning. Bruce has been a strong and active proponent of burning; his efforts have focused on having in situ combustion recognized as a viable spill response tool and broadening the window in which it can be effectively used. Bruce has been involved in the detailed project planning for two offshore, full-scale burn tests, participated in the planning of the 1993 Newfoundland burn and funding of an active burrı research program conducted in Norway. Previously Bruce was in the oil spill business, primarily in the Arctic and has worked for both government and the oil industry. He has a degree in Geography and graduate studies from the University of Victoria, British Columbia.

Jean E. Snider is responsible for program development and interagency liaison for the Hazardous Materials Response and Assessment (HAZMAT) Division, National Oceanic and Atmospheric Administration (NOAA). The HAZMAT Division provides technical assistance to the US Coast Guard during spills of oil and hazardous materials through its Scientific Support Coordinators; provides technical assistance to the Environmental Protection Agency (EPA) for the cleanup of Superfund sites through its Coastal Resource Coordinators. Jean has worked for NOAA in both headquarters and field assignments, as well as spending several years on Capitol Hill. All of her years with NOAA have been spent in the areas of marine pollution and the effects of other man-related impacts on the marine environment. She was involved with the scientific response to the Argo Merchant and this incident provided the idea for NOAA's Scientific Support Coordinator program. When she joined the HAZMAT Division, Jean established a Washington, DC office to better support the Division's numerous interagency programs. Jean represents the Department of Commerce on the National Response Team, the interagency committee overseeing all aspects of the Nation's response to oil and hazardous materials spills and chairs its subcommittee on Research and Development. She spent several months in Alaska during 1989 working on the Exxon Valdez spill, and revisited the area briefly in subsequent summers. She has a decorate in Oceanography from Texas A \& M University and a B.A. from Earlham College, Richmond, IN.

Peter A. Tebeau is a maine environmental consultant specializing in marine environmental protection technology and policy. Previously Peter was with the U.S. Coast guard in the areas of marine science and marine environmental protection, particularly in technology development and assessment of oil and hazardous chemical spill response. His operational experience includes a seagoing tour of duty on the icebreaker CGC GLACIER, where he coordinated the logistics for oceanographic research in the Arctic and Antarctica. This was followed by a tour as staff officer at Seventh Coast Guard District, Marine Environmental Protection Branch, where he was the environmental impact assessment coordinator for Coast Guard projects and worked with the enforcement of oil pollution and ocean dumping regulations in the Seventh District. He played a significant role in revitalizing the Coast Guard's marine environmental protection research and development effort following the Exxon Valdez oil spill. He has a B.S. in Engineering from the Coast Guard Academy, a B.S. in Environmental Engineering from Florida International University, and an M.S. in Physical Oceanography from the University of Miami. He is currently completing the Master of Marine Affairs program at the University of Rhode Island. 
Edward J. Tennyson is the Program Manager for Oil Spill Response Research within the Technology Assessment and Research Branch, MMS. He is credited with being the chief architect of the MMS research program to increase response capabilities for marine oil spills. This program has made significant contributions to nonconventional response strategies including in situ burning, chemical treating agents and increased understanding of the fate of spilled oil in the marine environment. He recently received the Meritorious Service Award from the Department of the Interior for his efforts. He holds a patent for original research and is widely published. Previously Ed was an officer in the U. S. Coast Guard. He has an M.S. degree in Marine Biology and has completed additional graduate studies in Oceanography. 


\section{ACKNOWLEDGMENT}

No workshop is the effort of any one person. Ed Tennyson, John Gregory and Joe Mullin (MMS Herndon Headquarters Office) assisted in developing the agenda and identifying speakers and participants. Jean Snider (NOAA) and Bruce McKenzie (ACS) did an outstanding job in keeping the panel members focussed on the purpose of the Workshop. They kept the panel members focused on the topic and did an excellent summary. The Keynote Speaker, Speakers and Panel Chairs provided the input for the Proceedings. Last, but not least, special thanks to Betty Thames (NIST) for providing excellent secretarial and receptionist support throughout the workshop and to Wanda Duffin (NIST) for the digitization of several manuscripts and figures. 



\section{LIST OF ATTENDEES}

David Atkinson

U.S. Coast Guard

2100 2nd St., SW

Room 6205

Washington, DC 20593

USA

202/267-0888

FAX 202/267-4758

Don Aurand

MSRC

1350 I St., NW

Suite 300

Washington, DC 20005

USA

202/408-5733

FAX 202/371-0401

Nir Barnea

NOAA/HAZMAT

7600 Sand Point Way

Seattle, WA 98115

USA

206/526-6317

J. Bruce Bartz

Clift Berry, Inc.

P.O. Box 13079

Port Everglades Station

Fort Lauderdale, FL 33316

USA

305/763-5455

FAX 305/763-8375

Linda Bernhardt

WA Dept. of Ecology

300 Desmond Dr.

P.O. Box 47600

Olympia, WA $98504-7600$

USA

206/407-6963

FAX 206/407-6903

Ian Buist

S.L. Ross Environmental

200-717 Belfast Rd.

Ottawa, Ontario, K1G OZ4

CANADA

613/232-1564

FAX 613/232-6660
Philip Campagna

U.S. EPA/ERT

2890 Woodbridge Ave.

MS 101, Bldg. 18

Edison, NJ 08837

USA

908/321-6689

Matthew O. Carr

EPA

222 W. 7th Ave.

Ste. 19

Anchorage, AK 99513

USA

907/271-5083

FAX 907/271-3424

Andrie Chen

Exxon Production Research

P.O. Box 2189

Houston, TX 77252-2189

USA

713/965-4166

Warren E. Colburn

USCG, R\&D Center

1082 Shennecossett Rd.

Room 237

Groton, CT 06340-6096

USA

203/441-2608

FAX 203/441-2792

John Cunningham

EPA

401 M St., SW

Washington, DC 20460

USA

703/603-8707

FAX 703/603-9116

Elmer (Bud) Danenberger

Minerals Mgmt. Service

381 Elden Street

Herndon, VA 22070-4817

USA

703/787-1596

FAX 703/787-1115
Linda DuCharme

Exxon Company USA

1555 Poydras Street

Room 465

New Orleans, LA 70112

USA

504/561-4390

Terry L. Edwards

FL Dept. of Environ. Prot.

P.O. Box 21564

Ft. Lauderdale, FL 33335

USA

305/467-5970

FAX 305/467-5975

Lee Ellwein

U.S. Coast Guard

2100 2nd Street, SW

Room 2110

Washington, DC 20593-0001

USA

202/267-6882

FAX 202/267-4677

Steven J. Eufemia

ME Dept. of Environ. Prot.

312 Canco Rd.

Portland, ME 04103-4278

USA

207/822-6340

FAX 207/822-6303

David D. Evans

NIST

Bldg. 224, Room B250

Gaithersburg, MD 20899-0001

USA

301/975-6862

Joseph Falk

TCOM L.P.

7115 Thomas Edison Dr.

Columbia, MD 21046

USA

410/312-2405

FAX 410/312-2437 
Merv F. Fingas

Environment Canada

3439 River Rd.

Ottawa, Ontario, K1A OH3

USA

9-613-998-9622

FAX 9-613-991-9485

Robert Forrest

U.S. EPA

1445 Ross Ave.

MC 6E-EP

Dallas, TX 75202

USA

214/655-2269

FAX 214/655-7447

Julian Foster

EPA

1445 Ross Ave.

MC 6E-EP

Dallas, TX 75202

USA

214/655-6494

FAX 214/655-7447

John Fraser

Oil Spill Response Plann.

23 Asbury Drive

Houston, TX 77024

USA

713/780-9224

FAX 713/789-1347

Paul Frederick

Exxon Company, U.S.A.

1555 Poydras Street

Room 547

New Orleans, LA 70112

USA

504/561-3450

FAX 504/561-3061

David Fritz

Amoco Oil Company

P.O. Box 3011

$\mathrm{MC} \mathrm{H}-9$

Naperville, IL 60566

USA

708/420-4985
Thomas Gernhofer

Minerals Mgmt. Service

1849 C St., NW

Washington, DC 20240

202/208-3500

Manuel (Manny) Gonzalez

Texas General Land Office 1700 N. Congress Ave.

Room 740

Austin, TX 78701-1495

USA

512/475-1505

FAX 512/475-1560

Edwin Kent Gray

$\mathrm{HHS} / \mathrm{CDC}$

MC F38

Atlanta, GA 30333

USA

404/488-7100

FAX 404/488-7107

Chantal Guenette

SINTEF Applied Chemistry

$\mathrm{N}-7034$

Trondheim,

NORWAY

47-73-59-5172

FAX 47-73-59-6363

Joseph Hennessey

Minerals Mgmt. Service

1201 Elmwood Park Blvd.

MS 5231

New Orleans, LA 70123

USA

Robert Hiltabrand

U.S. Coast Guard

2 Whalehead Rd.

Gales Ferry, CT 06340

USA

203/441-2701

J. Heather Warner Finley

Louisiana Oil Spill

Coordinator's Office

Office of the Govenor

P.O. Box 94004

Baton Rouge, LA 70804-9004
Gregory Hogue

Dept. of the Interior

75 Spring St., SW

MC 306

Atlanta, GA 30303

USA

404/331-4524

FAX 404/331-1736

Shane Ishiki

U.S. Coast Guard

Commandant G-MEP-2

2100 Second St., SW

Washington, DC 20593

USA

N. Ake Jacobson

EPA

21295 Rumford Dr.

H-8-5

Cupertino, CA 95014

USA

415/744-2203

FAX 415/744-1796

Karyn Jaskoviak

Amoco Oil Company

200 E. Randolph Dr.

MC 1103

Chicago, IL 60601

USA

312/856-5265

FAX 312/616-0529

Nora Jason

NIST

Bldg. 224, Room B250

Gaithersburg, MD 20899-0001

USA

301/975-6862

FAX 301/975-4052

Jerry Jeschke

Minerals Mgmt. Service

949 East 36th Street

MS 8200

Anchorage, AK 99508

USA 
Jimmy Jones

Ergon Nonwovens, Inc.

P.O. Box 1639

Jackson, MI 39215-1639

USA

601/933-3206

FAX 601/933-3361

Brian Kelly

Unocal

376 S. Valencia Ave.

Brea, CA 92621

USA

714/577-1653

FAX 714/577-1610

John Kern

LA Dept. of Environ. Qlty.

2290 Bluebonnet Rd.

P.O. Box 82215

Baton Rouge, LA 70887-2215

USA

504/765-0867

FAX 504/765-0866

Scott Knutson

U.S. Coast Guard

915 Second Ave.

Room 3510

Seattle, WA 98174

USA

206/220-7210

FAX 206/220-7225

Robert LaBelle

Minerals Mgmt. Service

381 Elden St.

MS 4360

Herndon, VA 22070-4817

USA

703/782-1728

FAX 703/787-1010

Richard Lazes

Oil Stop, Inc.

804 First Ave.

Harvey, LA 70058

USA

304/347-8888

FAX 304/347-9999
Bruce McKenzie

Alaska Clean Seas

P.O. Box 196010

Suite 200

Anchorage, AK 99519-6010

USA

907/345-3142

FAX 907/345-2435

Timothy McKinna

Texas General Land Office

1700 North Congress Ave.

MC 740

Austin, TX 78750

USA

512/463-5195

FAX 512/475-1560

Kenneth McSperitt

Phillips Petroleum Co.

13 Phillips Bldg.

Bartlesville, OK 74004

USA

918/661-1630

FAX 918/661-5664

W. F. "Bill" Merlin

Marine Spill Response Corps.

901 Lakeshore Drive

Suite 900

Lake Charles, LA 70605

USA

318/437-9602

FAX 318/437-9678

Amy Merten

PCCI/SUPSALV-Navy

1201 E. Abingdon Dr.

Ste. 201

22314

USA

703/684-2060

FAX 703/684-5343

Peter Milne

Univ. of Miami

4600 Rickenbacker

RSMA-MAC

Miami, FL 33149

USA

305/361-4786

FAX 305/361-4786
David Mogan

U.S. Coast Guard

909 SE, 1st Ave.

Room 908, Brickell Fed. Bldg.

Miami, FL 33131

USA

305/536-5651

Joseph V. Mullin

Minerals Mgmt. Service

381 Elden Street

MS 4700

Herndon, VA 22070-4817

USA

703/787-1564

FAX 703/787-1575

Donald Noviello

U.S. Coast Guard

915 Second Ave.

Room 3506

Seattle, WA 98174

USA

206/220-7210

FAX 206/220-7225

Craig Ogawa

Minerals Mgmt. Service

770 Paseo Camarillo

MS 7100

Camarillo, CA 93010

USA

James Pearce

American Marine, Inc.

401 Shearer Blvd.

Cocoa, FL 32922

USA

407/636-5783

FAX 407/636-5787

Jim Pennington

EPA

2600 Blair Stone Rd.

Tallahassee, FL 32359-2400

USA

904/488-1344

FAX 904/922-2390 
Terri Porche

LA Applied Oil Spill R\&D

E302 Howe-Russell Geoscience

Baton Rouge, LA 70803

USA

504/388-3477

FAX 504/388-5328

Benn Potier

LA Dept. of Environ. Qlty.

P.O. Box 82135

Baton Rouge, LA 70884-2135

USA

504/765-0108

FAX 504/265-0222

Scott Robertson

ARCO

515 South Flower St.

AP-4159

Los Angeles, CA 90091

USA

213/486-8523

FAX 213/486-2021

Ed Schrader

Millsaps College

1701 North State St.

Jackson, MS 39210

USA

601/974-1342

FAX 601/974-1345

Paul Schuler

Clean Caribbean Cooperative

2381 Stirling Rd.

Ft. Lauderdale, FL 33312

USA

305/983-9880

FAX 305/987-3001

Gary Shigenaka

NOAA/Hazmat

7600 Sand Point Way, NW

Bin $\mathrm{C} 15700$

Seattle, WA 98115

USA

206/526-6402
Robert Simmons

Exxon Company, U.S.A.

1555 Poydras Street

Room 545

New Orleans, LA 70112

USA

504/561-4938

FAX 504/561-3061

James L. Simmons

MSRC

1350 I Street, NW

Ste. 300

Washington, DC 20005

USA

202/408-7490

FAX 202/371-0401

Shawn Smith

U.S. Coast Gaurd R\&D

1082 Shennecossett Rd.

ESB

Groton, CT 06340

USA

203/441-2812

Jean Snider

NOAA

2100 2nd Street, SW

Washington, DC 20850

USA

202/267-0418

Bea Stong

Aramco Services Co.

9009 West Loop South

MS 1090

Houston, TX 77096

USA

713/432-5031

FAX 713/432-5747

Per Sveum

SINTEF Applied Chemistry

N-7034

Trondheim,

NORWAY

47-73-59-2830

FAX 47-73-59-6363
Peter Tebeau

Marine Environmental

Consultant

158 Wyassup Rd.

North Stonington, CT 96359

USA

203/535-4171

FAX 203/535-4171

Edward J. Tennyson

Minerals Mgmt. Service

381 Elden Street

Herndon, VA 22070-4817

USA

703/787-1564

FAX 703/787-1575

Andrew Tirpak

Texas A\&M University

P.O. Box 1675

Galveston, TX 77553-1675

USA

409/740-4490

Christian Toelle

Chemische Betriebe

Thiesstr. 617

Pluto

D-44649 Herne,

GERMANY

4912325/980-284

FAX 4912325/980-289

W. Douglas Walton NIST

Bldg. 224, Room B250

Gaithersburg, MD 20899-0001

USA

301/975-6862

Mike White

U.S. Coast Guard

501 Magazine Street

Room 1341

New Orleans, LA 70130-3396

USA

504/589-6901

FAX 504/589-4999 
David Williams

Conoco, Inc.

2210 Old Spanish Trail

Westlake, LA 70669

USA

$318 / 497-4916$

Henry Woodcock

DOL-OSHA

200 Constitution Ave., NW

Room N-3653

Washington, DC 20210

USA

202/219-7065 

NST-114

F.EV. 6-93)

IDMAN 4.09
U.S. DEPARTMENT OF COMMERCE

NATIONAL INSTITUTE OF STANDARDS AND TECHNOLOGY

\section{MANUSCRIPT REVIEW AND APPROVAL}

STRUCTIONS: ATTACH ORIGINAL OF THIS FORM TO ONE (1) COPY OF MANUSCRIPT AND SEND TO IE SECRETARY, APPROPRIATE EDITORIAL REVIEW BOARD.

TLE AND SUBTITLE (CITE IN FULL)

In Situ Burning Oil Spill Workshop, Orlando, Florida, January 26-28, 1994 , Proceedings

JNTRACT OR GRANT NUMBER

TYPE OF REPORT AND/OR PERIOD COVERED

JTHOR(S) (LAST NAME, FIRST INITIAL SECOND INITIAL)

Jason, Nora H., Editor

\$BORATORY AND DIVISION NAMES (FIRST HIST AUTHOR ONLY

Building and Fire Research Laboratory, Fire Safety Engineering Division

ONSORING ORGANIZATION NAME AND COMPLETE ADDRESS (STREET, CITY, STATE, ZIP)

Minerals Management Service, U.S. Department of Interior, Herndon, VA 22070

\section{ROPOSED FOR NIST PUBUCATION}

JOURNAL OF RESEARCH (NIST JRES)

J. PHYS. \& CHEM. REF. DATA (JPCRD)

HANDBOOK (NIST HB)

SPECIAL PUBUCATION (NIST SP)

TECHNICAL NOTE (NIST TN)

TOPOSED FOR NON-NIST PUBUCATION (CITE FULLV)

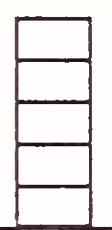

MONOGRAPH (NIST MN)

NATL STD. REF. DATA SERIES (NIST NSRDS)

FEDERAL INF. PROCESS. STDS. (NIST FIPS)

UST OF PUBUCATIONS (NIST LP)

NIST INTERAGENCY/INTERNAL REPORT (NISTIR)
(ERB USE ONLY)

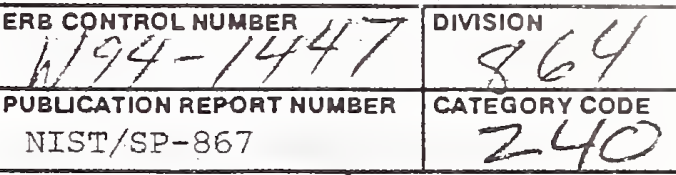

PUBUCATION DATE

August 1994

101

PERFORMINO ORGANIZATION (CHECK $(X)$ ONE BOX)

NIST/GAITHERSBURO

NIST/BOULDER

JILA/BOULDER

\section{u}

UPPLEMENTARY NOTES

U.S. $\square$ FOREION

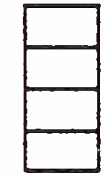

LETTER CIRCULAR

BUILOINO SCIENCE SERIES

PRODUCT STANDARDS

OTHER

PUBLSHING MEDIUM

BSTRACT (A 2000-CHARACTER OR LESS FACTUAL SUMMARY OF MOST SIGNIFICANT INFORMATION. IF DOCUMENT INCLUDES A SIGNIFICANT BIBLOGRAPHY

R LTERATURE SURVEY, CITE IT HERE. SPELL OUT ACRONYMS ON FIRST REFERENCE.) (CONTINUE ON SEPARATE PAGE, IF NECESSARY.)

The goal of the workshop was: To present the state of knowledge to the user community, representaives from local, state, and federal agencies, oil industry, manufacturers, and researchers; to reach consensus on the present status of decision making to allow the use of in situ burning and to prioritize research and information needs to support decisions on the use of in situ burning of spilled oil. To facilitate the discussions, preprints of technical papers were distributed at registration. Participants were divided into two breakout panels: Environmental and human health; Operational implications. The panels examined the information presented, determined a consensus, and developed a list of priority needs. The results of the workshop will be used by MMS to refine future research efforts to address the most important issues developed by the participants.

EY WORDS (MAXIMUM OF 9; 28 CHARACTERS AND SPACES EACH; SEPARATE WITH SEMICOLONS; ALPHABETIC ORDER; CAPITAUZE ONLY PROPER NAMES) Fire research; oil spills; in situ burning; environmental effects; operational hazards; human beings 



\section{Periodical}

Journal of Research of the National Institute of Standards and Technology-Reports NIST research and development in those disciplines of the physical and engineering sciences in which the Institute is active. These include physics, chemistry, engineering, mathematics, and computer sciences. Papers cover a broad range of subjects, with major emphasis on measurement methodology and the basic technology underlying standardization. Also included from time to time are survey articles on topics closely related to the Institute's technical and scientific programs. Issued six times a year.

\section{Nonperiodicals}

Monographs-Major contributions to the technical literature on various subjects related to the Institute's scientific and technical activities.

Handbooks-Recommended codes of engineering and industrial practice (including safety codes) developed in cooperation with interested industries, professional organizations, and regulatory bodies.

Special Publications - Include proceedings of conferences sponsored by NIST, NIST annual reports, and other special publications appropriate to this grouping such as wall charts, pocket cards, and bibliographies.

Applied Mathematics Series - Mathematical tables, manuals, and studies of special interest to physicists, engineers, chemists, biologists, mathematicians, computer programmers, and others engaged in scientific and technical work.

National Standard Reference Data Series - Provides quantitative data on the physical and chemical properties of materials, compiled from the world's literature and critically evaluated. Developed under a worldwide program coordinated by NIST under the authority of the National Standard Data Act (Public Law 90-396). NOTE: The Journal of Physical and Chemical Reference Data (JPCRD) is published bimonthly for NIST by the American Chemical Society (ACS) and the American Institute of Physics (AIP). Subscriptions, reprints, and supplements are available from ACS, 1155 Sixteenth St., NW, Washington, DC 20056.

Building Science Series-Disseminates technical information developed at the Institute on building materials, components, systems, and whole structures. The series presents research results, test methods, and performance criteria related to the structural and environmental functions and the durability and safety characteristics of building elements and systems.

Technical Notes-Studies or reports which are complete in themselves but restrictive in their treatment of a subject. Analogous to monographs but not so comprehensive in scope or definitive in treatment of the subject area. Often serve as a vehicle for final reports of work performed at NIST under the sponsorship of other government agencies.

Voluntary Product Standards - Developed under procedures published by the Department of Commerce in Part 10, Title 15, of the Code of Federal Regulations. The standards establish nationally recognized requirements for products, and provide all concerned interests with a basis for common understanding of the characteristics of the products. NIST administers this program in support of the efforts of private-sector standardizing organizations.

Consumer Information Series - Practical information, based on NIST research and experience, covering areas of interest to the consumer. Easily understandable language and illustrations provide useful background knowledge for shopping in today's technological marketplace.

Order the above NIST publications from: Superintendent of Documents, Government Printing Office, Washington, DC 20402 .

Order the following NIST publications-FIPS and NISTIRs-from the National Technical Information Service, Springfield, VA 22161.

Federal Information Processing Standards Publications (FIPS PUB) - Publications in this series collectively constitute the Federal Information Processing Standards Register. The Register serves as the official source of information in the Federal Government regarding standards issued by NIST pursuant to the Federal Property and Administrative Services Act of 1949 as amended, Public Law 89-306 (79 Stat. 1127), and as implemented by Executive Order 11717 (38 FR 12315, dated May 11,1973) and Part 6 of Title 15 CFR (Code of Federal Regulations).

NIST Interagency Reports (NISTIR) - A special series of interim or final reports on work performed by NIST for outside sponsors (both government and non-government). In general, initial distribution is handled by the sponsor; public distribution is by the National Technical Information Service, Springfield, VA 22161, in paper copy or microfiche form. 


\section{U.S. Department of Commerce}

National Institute of Standards and Technology

Gaithersburg, MD 20899-0001

Official Business

Penalty for Private Use $\$ 300$ 